\title{
CHARACTERIZING TERRITORIALITY AND THE MECHANISMS THAT MEDIATE IT IN FEMALE ANOLIS GUNDLACHI LIZARDS
}

\begin{tabular}{c} 
A Dissertation \\
presented to \\
the Faculty of the Graduate School \\
at the University of Missouri-Columbia \\
In Partial Fulfillment \\
of the Requirements for the Degree \\
Doctor of Philosophy \\
\hline ELLEE G. COOK \\
JuLY 2019 \\
Manuel Leal, Dissertation Supervisor \\
July
\end{tabular}


The undersigned, appointed by the dean of the Graduate School, have examined the dissertation entitled

\title{
CHARACTERIZING TERRITORIALITY AND THE MECHANISMS THAT MEDIATE IT IN FEMALE ANOLIS GUNDLACHI LIZARDS
}

\author{
Presented by Ellee G. Cook, \\ a candidate for the degree of \\ Doctor of Philosophy,
} and hereby certify that, in their opinion, it is worthy of acceptance.

Professor Manuel Leal

Professor Reginald Cocroft

Professor Kevin Middleton

Professor Johannes Schul 


\section{ACKNOWLEDGEMENTS}

Countless people have contributed to this dissertation and to the successful culmination of my graduate work at the University of Missouri. I have had the tremendous good fortune to have an incredible support system, both in terms of my academic and scientific development, and the emotional support that is critical for success in this field. I have learned more from Manuel Leal than from any other teacher or mentor I have had the fortune to work with. His mentorship challenged me to develop as a critical thinker, and has instilled in me a confidence in facing new challenges. I will be forever grateful for his perpetual willingness to talk and laugh, his tremendous investment in me as a student and scientist, and in always encouraging me to pursue lines of inquiry of interest to me in science and beyond. The other members of my committee have also invested substantially in my success, and I thank Rex Cocroft, Kevin Middleton, and Johannes Schul for taking the time to teach me, talk with me, and make this dissertation what it is.

The Division of Biological Sciences has been a hub of support. No day was complete without my visiting with Nila Emirich and Rebecca Ballew, and I would not have survived this process nearly as gracefully without the support of Melody Kroll, Alan Marshall, Nick Valentine, and all the other staff that make this place great. I also thank Lori Eggert and Candi Galen for their mentorship in teaching, and thank Barb Sonderman and Richard Daniel for always being ready to meet to have executive discussions about our classes. And last but certainly not least, my fellow graduate students and lab mates. I can't possibly mention all of the individuals I've spoken to about science, life, and lifeafter-graduate-school, but I thank you all! In particular, I thank Jake Burkhart, Ronnie 
Lacombe, Arianne Messerman, Erin Sellner, and Levi Storks for always being my people both in science and beyond.

This work would not have been possible without the help of field assistants who went above and beyond what I asked of them. Deborah Lopez-Nieves, Karen Patterson, Jessica Pita-Aquino, and Phil Pearson, your thoughtfulness and hard work made these projects better and I am so grateful for the adventures we had. Furthermore, my collaborators Miguel Acevedo, Matthew B. Lovern, David Clark so graciously agreed to collaborate with us, and I thank them for the tools that made these projects what they are. Finally, none of this would have been possible without the support of my family. Doug and Paula Cook have been my cheerleaders for the last six years, never once doubting my ability to succeed. I am forever grateful to them for reminding me that I can do anything I set out to do. 


\section{TABLE OF CONTENTS}

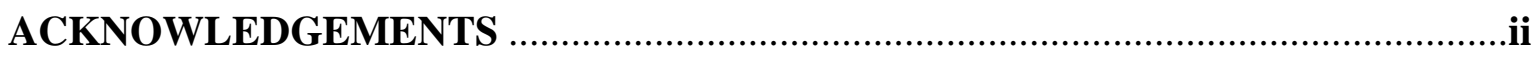

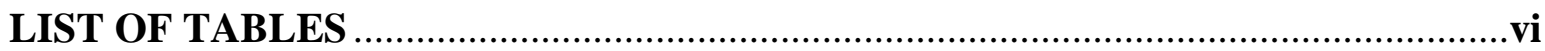

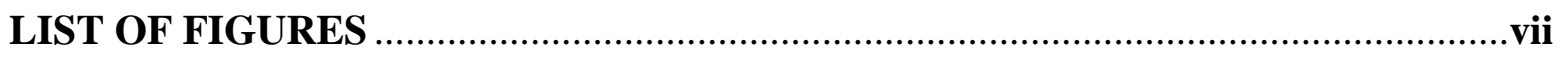

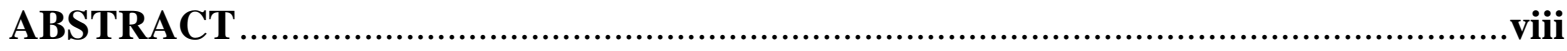

\section{CHAPTER $1 \cdot$ INTRODUCTION}

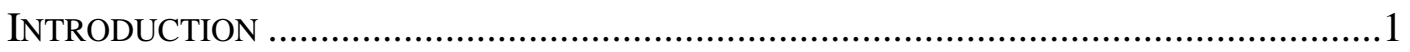

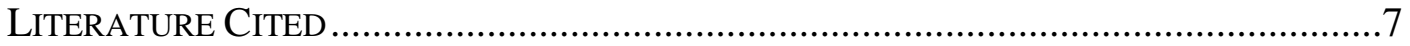

CHAPTER 2 - TERRITORIALITY: A SURVEY OF THE PROGRESSION FROM OBSERVATION TO EXPERIMENTATION TO UNDERSTAND THE EVOLUTION, FUNCTION, AND REGULATION OF TERRITORIAL BEHAVIOR

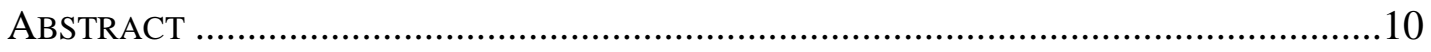

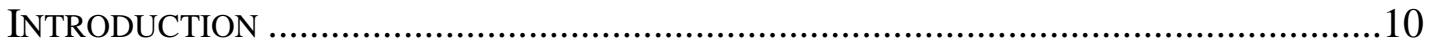

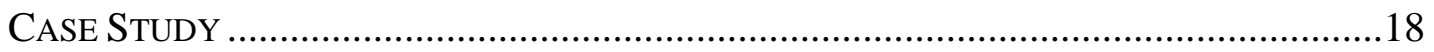

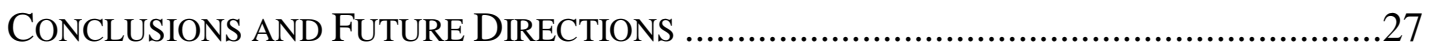

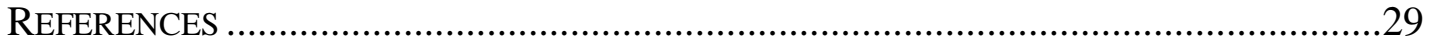

CHAPTER 3 - SIMILAR BEHAVIOR, SHARED MECHANISM? EVALUATING THE INLFUENCE OF BODY CONDITION ON TERRITORIAL BEHAVIOR IN FEMALE ANOLIS GUNDLACHI LIZARDS

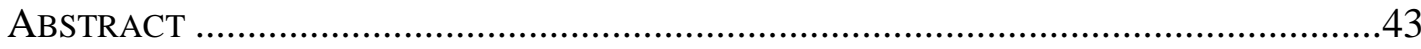

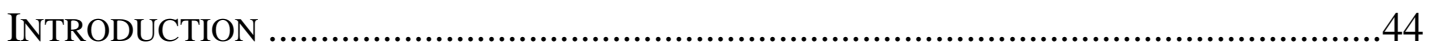

MATERIALS AND METHODS ……………………………....................................49

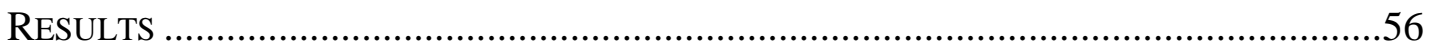

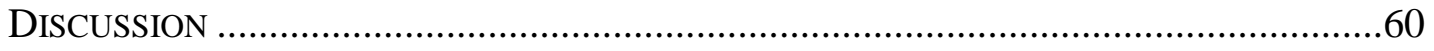

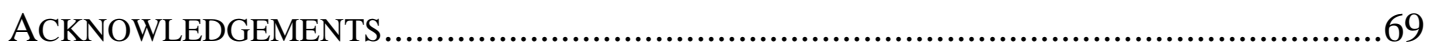


REFERENCES

\section{CHAPTER 4 - EVALUATING THE POTENTIAL FOR TESTOSTERONE TO MEDIATE AGGRESSIVE BEHAVIOR IN WILD FEMALE ANOLIS GUNDLACHI LIZARDS}

ABSTRACT

INTRODUCTION

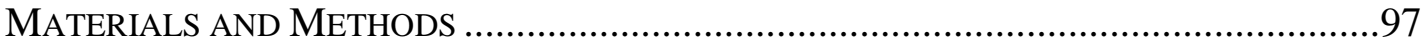

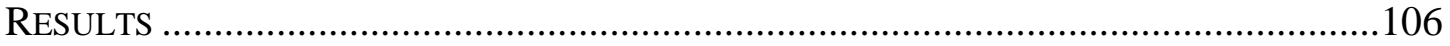

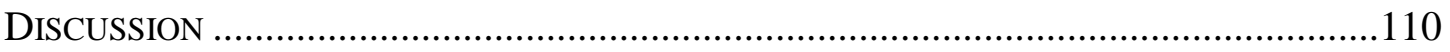

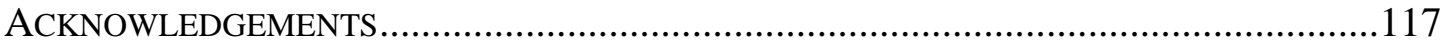

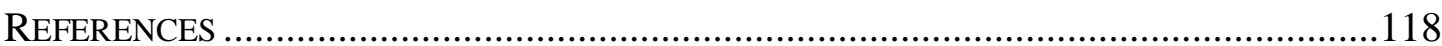

CHAPTER 5: TESTOSTERONE AND PARASITE LOAD: AN INVESTIGATION OF THE IMMUNOCOMPETENCE HYPOTHESIS IN WILD ANOLIS GUNDLACHI LIZARDS

ABSTRACT

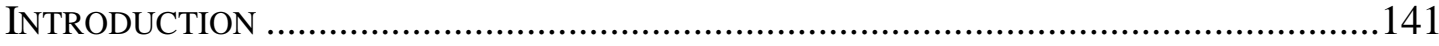

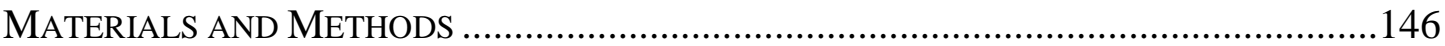

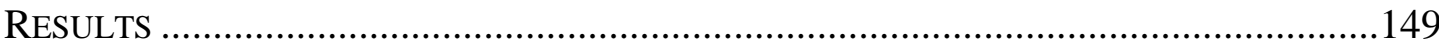

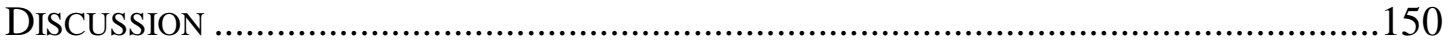

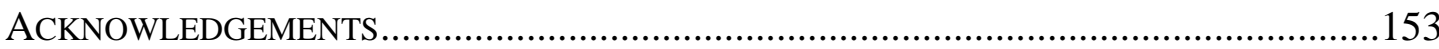

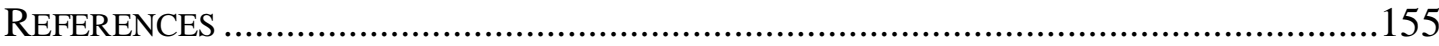

CHAPTER 6 • CONCLUSIONS

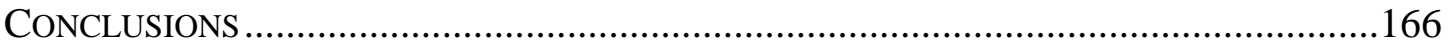

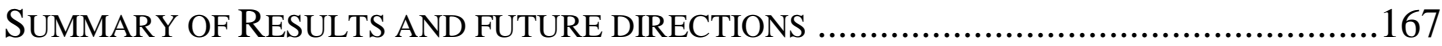

VITA 


\section{LIST OF TABLES}

\section{CHAPTER 2.}

Table 1. Results of literature search for lizard territoriality

\section{CHAPTER 3.}

Table 1. Descriptions of observed territorial behaviors .......................................80

Table 2. Results of t-tests comparing variables across sampling years ....................81

\section{CHAPTER 4.}

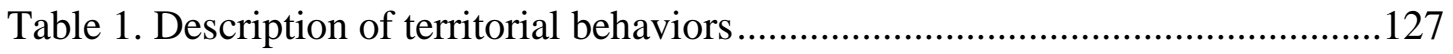

Table 2. Description of aggressive behaviors observed.......................................128

Table 3. Model comparison for probability of undetectable concentrations of testosterone in males and females....

Table 4. Model comparison for probability of undetectable concentrations across staged intrusion treatments 


\section{LIST OF FIGURES}

\section{CHAPTER 3.}

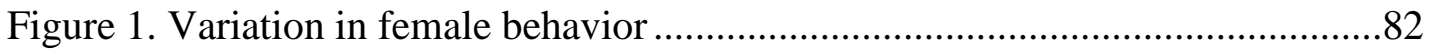

Figure 2. Spatial distribution of males and females.............................................83

Figure 3. Relationship between the number of locations used by an individual and

(a) home range size and (b) territory size and locations

Figure 4. Relationship between the body condition of lizards and (a) home range size and (b) territory size.

\section{CHAPTER 4.}

Figure 1. Comparison of corticosterone and testosterone concentrations to plasma volume.

Figure 2. Baseline concentrations of testosterone in males and females

Figure 3. Baseline concentrations of corticosterone in males and females

Figure 4: Aggression scores across staged intrusion treatments

Figure 5. Aggression scores of females in treatment facing conspecific. .136

Figure 6. Aggression scores and testosterone in females

Figure 7. Comparison of corticosterone across all females .138

Figure 8. Comparison of testosterone across all females

Figure 9. Relationship between concentrations of corticosterone and testosterone in all females

\section{CHAPTER 5.}

Figure 1. Infected and uninfected erythrocytes stained with Giemsa .161

Figure 2. Relationship between testosterone concentration and probability of parasitism in Anolis gundlachi.

Figure 3: Relationship between corticosterone concentration and probability of parasitism in Anolis gundlachi. 


\title{
Characterizing territoriality and the mechanisms that mediate it in female Anolis gundlachi lizards
}

\begin{abstract}
Territoriality is a suite of behaviors through which animals secure access to particular areas or resources. It is prevalent across animal groups and has the potential to exert substantial influence on fitness by mediating how individuals are distributed across the landscape, which individuals interact socially, and those that have access to resources. Territoriality has been the subject of extensive research on animal behavior over the last century and has influenced our understanding of other aspects of species ecology, such as mating systems. However, a substantial portion of research on territoriality has focused primarily on males, despite the fact that females of many species are also observed to exhibit territoriality. This is particularly true of studies investigating the mechanisms that modulate territoriality, such as circulating hormones and morphological characteristics including body condition. As such, two important questions remain open for many territorial taxa—within territorial species, do both sexes use similar repertoires of territorial behavior, and if so, are these behaviors mediated by the same mechanisms in both females?
\end{abstract}

The aim of this dissertation has been to pursue these two questions in the lizard Anolis gundlachi. Anolis have figured prominently in territorial research over the last century but are plagued with the same pitfall of lack of studies of females, which is a common problem across many groups, as is observed in other species. Integrating field studies and laboratory techniques, I characterized the behavior and space use of freeliving female $A$. gundlachi in Puerto Rico to assess whether females exhibit similar behavioral patterns as males. As part of this research, I assessed the potential for 
individual variation in body condition to mediate differences in territory size. I also characterized the testosterone and corticosterone profiles of free-living male and female A. gundlachi, and staged territorial intrusions among females to evaluate the potential for these hormones to mediate differences in territorial behavior across the sexes and among females. Finally, I evaluated the potential for a tradeoff between testosterone, corticosterone, and parasite load by measuring parasite loads of Plasmodium sp. in the same free-living population.

Together, the results presented in this dissertation demonstrate that female $A$. gundlachi exhibit territorial behaviors that highly resemble those observed in male $A$. gundlachi and other species of Anolis. However, two mechanisms commonly implicated in the control of territoriality in males - metrics of body size and circulating hormones concentrations — did not explain similar patterns in females. In addition, we found no evidence of a tradeoff between hormone concentration and parasite load. Taken together, these results demonstrate that different mechanisms may influence similar behaviors exhibited by males and females of the same species. In combination with a growing body of work investigating the evolution of territorial and other aggressive behaviors in females, our findings demonstrate the need for more direct studies of females to more clearly understand why these behaviors have arisen in both sexes and to identify the mechanisms that mediate them in females. 


\section{CHAPTER 1}

\section{Introduction}

Historically, many areas of animal behavior research have been heavily biased toward the study of males (Clutton-Brock 2009, Rosvall 2013, Stockley and Campbell 2013). More specifically, outside the context of courtship, reproduction, and parental care, a substantial portion of empirical studies has been focused on males. One potential reason to explain this bias is that, in many species, males are much more conspicuous on the landscape than females are. Males are typically the ones sporting flashy ornaments and weapons (Emlen 2008, Berglund 2013) and also readily engage in particularly visible behaviors such as courtship and agonistic interactions (Nelson 2005). Observations that males exhibit these behaviors more frequently led to the over arching hypothesis that males are the primary agents of sexual selection, either because of male-male competition over resources or because of female preference for particular males based on traits that, in turn, improve the fitness of their male offspring (Batemen 1948, Emlen and Oring 1977, Andersson and Iwasa 1996). As such, a large body of work has focused on how behavior influences male reproductive success, and thus our understanding of animal behavior and its impact on species' ecology and evolution has been based largely on studies that have mainly focused on males.

More recently, a growing body of contemporary literature is addressing this bias.

There are many accounts of females of a variety of species engaging in behaviors such as territoriality and aggression, which are behaviors that have long been associated with mediating intraspecific variation in male reproductive success (Clutton Brock 2007 \& 2009). Until recently, however, these accounts have remained largely sequestered as 
anecdotes to patterns being studied in males. Furthermore, these behaviors have often been considered merely the byproducts of the evolution of the behavior in males. Evidence from a variety of taxa suggests that female reproductive success can be much more variable than previously presumed, drawing attention to the possibility that variation in female behavior, morphology, and physiology may influence female reproductive success just as it does in males (reviewed in Drea 2005). For example, research in birds has demonstrated that females of socially monogamous, territorial birds produce offspring sired by multiple males. This finding challenges the long-standing hypothesis that males maintain exclusive access to their mates by being territorial and has inspired an exciting new line of inquiry evaluating why extra-pair paternity is so prevalent and considering how female traits also influence the life history of these species (reviewed in Griffith et al. 2002, Westneat and Stewart 2003). The time is ripe to expand research programs in other species to include direct study of females, which may yield similar shifts to our understanding of other aspects of animal behavior.

The aim of this dissertation was to shed some light on the behavior of female Anolis lizards and, particularly, their territorial behavior and the mechanisms that mediate it. Specifically, we aimed to identify and characterize the aggressive and territorial behavior of female Anolis gundlachi lizards. Furthermore, we explored the potential for mechanisms known to mediate these behaviors in males to explain similar behavior patterns in females. Anolis have served as an important model system for understanding the evolution of behavior, and have figured prominently in animal behavior research over the last century (reviewed in Losos 2009). They have been the subject of a large body of empirical and theoretical work investigating widespread behaviors such as territoriality, 
and rank among the best-studied territorial systems outside birds and fish. However, many aspects of female behavior remain understudied.

Within Anolis, the function of territoriality has been functionally defined as the mechanism through which males increase reproductive success. In most Anolis species, males establish and defend territories throughout the summer breeding season that encompass one or more females. Males use highly stereotyped suites of aggressive behaviors to defend their territories and differ in their abilities to secure territories and maintain them over time (Jenssen 1977, Carpenter 1978). Furthermore, male territories can differ substantially in size and shape, and these differences have been associated with differences in reproductive success (Trivers 1976, Tokarz 1985 \& 1987). In particular, it has been shown that large territories encompass more females and that large males tend to defend larger territories than small males. Several different traits have been shown to influence variation in male territoriality, including intraspecific variation in body size, circulating androgen concentrations, and propensity to engage in aggressive interactions (Schoener and Schoener 1982, Jenssen and Nunez 1998, Jenssen et al. 2005). The longstanding assumption in Anolis has been that males of superior competitive ability secure territories that contain many females, and increase their reproductive success by actively defending these territories - and thus the females contained within them - against conspecifics.

Research on Anolis territoriality has faced the pitfall of heavily biased study of males, as is true of many other territorial taxa. Relatively few studies have focused on the spatial and social dynamics among females beyond their interactions with males and residence within male territories (Andrews 1971, Stamps 1973, Jenssen and Nunez 1998). 
Interestingly, just as has been observed in birds, evidence from several different Anolis species demonstrates that females produce offspring sired by multiple offspring, and the time has come to reconsider the notion that male territoriality dictates reproductive success in both males and females (Calsbeek et al. 2007, Kamath and Losos 2017, Bush and Simberloff 2018, Stamps 2018).

We focused on the behavior of female A. gundlachi, a species in which male territoriality is relatively well studied but for which there is limited data about female behavior, territorial or otherwise (Rand 1964, Rodríguez-Robles et al. 2005). We characterized the space use and social behavior of females in order to demonstrate whether males and females exhibit similar patterns of territoriality and intrasexual aggression and assessed the potential for traits known to modulate male behavior to modulate similar behaviors in females. We mapped the home ranges and territories of adult males and females to assess potential intersexual differences in space use observed the behavior of females to demonstrate that females exhibit a repertoire of aggressive and other behaviors comparable to those observed in males. Second, we experimentally induced territorial interactions in females to evaluate whether females 1) occupy exclusive space and, if they do, 2) behave aggressively toward conspecific intruders in a similar fashion as males. Third, we evaluated the potential for two traits known to modulate territoriality and aggression male Anolis—body size and circulating concentrations of testosterone and corticosterone - to modulate similar behavior in females. Finally, we investigated the potential for circulating hormone concentrations to mediate infection by a malarial parasite in male and female A. gundlachi, which is, to our 
knowledge, the first evaluation of a potential trade-off between hormones and parasite load in Anolis.

Together, our findings demonstrate that female A. gundlachi exhibit territorial dynamics of their own and corroborate previous studies documenting territorial behavior in other Anolis species. We observe that they occupy areas of exclusive space that do not overlap with other females and that they will behave aggressively toward conspecifics in those areas, theoretically to reinforce territory boundaries. Thus, what we observe on the landscape in this species is not determined solely by the behavior of males, as has been historically presumed. Rather, female $A$. gundlachi are actively partitioning space and determining their own distribution through the use of the same social behaviors as males. If males intentionally establish territories around females rather than other resources, female territoriality may actually be directly driving male territoriality. If this is the case, the description of female anoles as relatively passive players in the social-spatial dynamics of Anolis lizards is likely incomplete. This provides impetus for further study of territoriality and aggression in female Anolis, and other species. Furthermore, we observe that body condition and circulating testosterone concentrations appear to exert different influences on female space use and behavior than has been documented in males of other Anolis species. Thus, important work remains to be completed in evaluating the potential for shared mechanisms to mediate behavior across the sexes, or in identifying how different suites of traits mediate behavior in males and females.

We have long appreciated that territoriality can exert substantial influence on species' life histories (e.g., Noble 1939, Burt 1943, Carpenter 1958), and this is highly apparent in anoles. Male territorial behavior has served as the basis from which we 
understand Anolis mating systems, and territoriality has been repeatedly hypothesized to be the mechanism through which males increase their fitness (Trivers 1976, Jenssen et al. 2001, Kamath and Losos 2017). Male-male competition associated with territoriality has shaped our understanding of Anolis social behavior, as well as the evolution of that behavior. In combination with recent work with other Anolis species, our findings demonstrate that our understanding of the behavioral ecology of Anolis has been limited by a historical bias toward the study of males. Supplementing existing work with more data on females will not only expand our knowledge of the ecology of these model species in animal behavior research, but also has the potential to shift long-standing hypotheses to explain animal behavior that have largely excluded females (Stockley and Bro-Jørgensen 2011, Clutton-Brock and Huchard 2013, Rosvall 2013). 


\section{References}

Andersson, M., \& Iwasa, Y. (1996). Sexual selection. Trends in Ecology \& Evolution, $11(2), 53-58$.

Andrews, R. M. (1971). Structural habitat and time budget of a tropical Anolis lizard. Ecology, 52(2), 262-270.

Bateman, A. J. (1948). Intra-sexual selection in Drosophila. Heredity, 2(3), 349-368.

Berglund, A. (2013). Why are sexually selected weapons almost absent in females? Current Zoology, 59(4), 564-568.

Burt, W. H. (1943). Territoriality and home range concepts as applied to mammals. Journal of Mammalogy, 24(3), 346-352.

Bush, J. M., \& Simberloff, D. (2018). A case for anole territoriality. Behavioral Ecology and Sociobiology, 72(7), 111.

Calsbeek, R., Bonneaud, C., Prabhu, S., Manoukis, N., \& Smith, T. B. (2007). Multiple paternity and sperm storage lead to increased genetic diversity in Anolis lizards. Evolutionary Ecology Research, 9(3), 495-503.

Carpenter, C. R. (1958). Territoriality: a review of concepts and problems. Behavior and Evolution, 224.

Carpenter, C. C. (1978). Ritualistic social behavior in lizards. In: Behavior and Neurology of Lizards (Ed. by N. Greenberg \& P. D. MacLean), pp. 253-267. Maryland: National Institute of Mental Health.

Clutton-Brock, T. (2007). Sexual selection in males and females. Science, 318(5858), 1882-1885.

Clutton-Brock, T. (2009). Sexual selection in females. Animal behaviour, 77(1), 3-11.

Clutton-Brock, T. H., \& Huchard, E. (2013). Social competition and selection in males and females. Philosophical Transactions of the Royal Society B: Biological Sciences, 368(1631), 20130074.

Drea, C. M. (2005). Bateman revisited: The reproductive tactics of female primates. Integrative and Comparative Biology, 45(5), 915-923.

Emlen, D. J. (2008). The evolution of animal weapons. Annual Review of Ecology, Evolution, and Systematics, 39. 
Emlen, S. T., \& Oring, L. W. (1977). Ecology, sexual selection, and the evolution of mating systems. Science, 197(4300), 215-223.

Griffith, S. C., Owens, I. P., \& Thuman, K. A. (2002). Extra pair paternity in birds: a review of interspecific variation and adaptive function. Molecular Ecology, 11(11), 2195-2212.

Jenssen, T. A. (1977). Evolution of anoline lizard display behavior. American Zoologist, 17(1), 203-215.

Jenssen, T. A., \& Nunez, S. C. (1998). Spatial and breeding relationships of the lizard, Anolis carolinensis: evidence of intrasexual selection. Behaviour, 981-1003.

Jenssen, T. A., Lovern, M. B., \& Congdon, J. D. (2001). Field-testing the protandrybased mating system for the lizard, Anolis carolinesis: does the model organism have the right model?. Behavioral Ecology and Sociobiology, 50(2), 162-172.

Jenssen, T. A., Decourcy, K. R., \& Congdon, J. D. (2005). Assessment in contests of male lizards (Anolis carolinensis): how should smaller males respond when size matters?. Animal Behaviour, 69(6), 1325-1336.

Kamath, A., \& Losos, J. (2017). The erratic and contingent progression of research on territoriality: a case study. Behavioral Ecology and Sociobiology, 71(6), 89.

Losos, J. B. (2009). Lizards in an Evolutionary Tree: Ecology and Adaptive Radiation of Anoles. Berkeley, California: University of California Press.

Nelson, R. J. (Ed.). (2005). Biology of Aggression. London: Oxford University Press.

Noble, G. K. (1939). The role of dominance in the social life of birds. The Auk, 263-273.

Rand, A. S. (1964). Ecological distribution in anoline lizards of Puerto Rico. Ecology, 45(4), 745-752.

Rodríguez-Robles, J. A., Leal, M., \& Losos, J. B. (2005). Habitat selection by the Puerto Rican yellow-chinned anole, Anolis gundlachi. Canadian Journal of Zoology, 83(7), 983-988.

Rosvall, K. A. (2013). Proximate perspectives on the evolution of female aggression: good for the gander, good for the goose?. Philosophical Transactions of the Royal Society B: Biological Sciences, 368(1631), 20130083.

Schoener, T. W., \& Schoener, A. (1982). Intraspecific variation in home-range size in some Anolis lizards. Ecology, 63(3), 809-823. 
Stamps, J. A. (1973). Displays and social organization in female Anolis aeneus. Copeia, 264-272.

Stamps, J. A. (2018). Polygynandrous anoles and the myth of the passive female. Behavioral Ecology and Sociobiology, 72(7), 107.

Stockley, P., \& Bro-Jørgensen, J. (2011). Female competition and its evolutionary consequences in mammals. Biological Reviews, 86(2), 341-366.

Stockley, P., \& Campbell, A. (2013). Female competition and aggression: interdisciplinary perspectives. Philosophical Transactions of the Royal Society B: Biological Sciences. 368, 20130073.

Trivers, R. L. (1976). Sexual selection and resource-accruing abilities in Anolis garmani. Evolution, 30(2), 253-269.

Tokarz, R. R. (1985). Body size as a factor determining dominance in staged agonistic encounters between male brown anoles (Anolis sagrei). Animal Behaviour, 33(3), 746-753.

Tokarz, R. R. (1987). Effects of corticosterone treatment on male aggressive behavior in a lizard (Anolis sagrei). Hormones and Behavior, 21(3), 358-370.

Westneat, D. F., \& Stewart, I. R. (2003). Extra-pair paternity in birds: causes, correlates, and conflict. Annual Review of Ecology, Evolution, and Systematics, 34(1), 365396. 


\title{
CHAPTER 2
}

\section{Territoriality: A survey of the progression from observation to experimentation to understand the evolution, function, and regulation of territorial behavior}

\begin{abstract}
Territoriality has figured prominently in research since the first accounts of animal behavior by humans, if not in name at least in nature. It is prevalent across animal taxa, with examples in amphibians, birds, fish, insects, mammals, and reptiles.

Researchers working with these taxa have sought to characterize territorial behavior, such that mechanisms that mediate the evolution of and variation within the diversity of territorial systems might be elucidated. To date, life history traits such as mating system and foraging mode have been used to predict the evolution of different territorial systems, and a variety of behavioral, morphological, and physiological traits have been implicated in regulating intraspecific-variation in territorial behavior. Here, we discuss the history of research on territoriality, and continue this discussion with an argument for why lizards represent an important taxonomic group in which to investigate outstanding questions in territoriality. Finally, we highlight avenues for future research on territoriality in lizards and other taxonomic groups.
\end{abstract}

\section{Introduction}

Human beings have been documenting patterns of animal behavior since we began keeping records. For example, 20,000-year-old cave paintings include depictions of humans in pursuit of game animals, suggesting that they may have been following the seasonal movements of herds on the landscape (Valladas et al. 2001). Knowledge of animal movements may have improved the efficacy of hunting and thus provided 
practical benefits to humans, and we have been recording animal behavior ever since. However, it would be several thousand years before records indicate any more detailed study of behavior beyond the scope of pure observations. Around the time that Charles Darwin published his foundational works proposing a mechanism through which individual variation arises in animal behavior and other traits (1859), more empirical studies of animal behavior began emerging rapidly. From then on, research on animal behavior accumulated and diversified, as increasing numbers of studies on a variety of animal groups documented patterns and attempted to experimentally elucidate the mechanisms that mediate these patterns.

The $20^{\text {th }}$ century saw another major revolution in animal behavior research with the work of Ernst Mayr, Nikko Tinbergen, and the frameworks they developed to investigate behavior at different scales. Mayr (1961) differentiated between proximate and ultimate questions, classifying inquiries into the two categories on the grounds that some evaluated mechanisms currently at work (i.e., proximate) and others evaluated those that shaped traits over evolutionary time (i.e., ultimate). Tinbergen (1963) expanded upon Mayr's (1961) framework, classifying questions of animal behavior into four categories. Proximate questions considered behaviors at present, and targeted the mechanisms that regulate behavior ('causation') or how behavior changes across an animal's lifetime ('ontogeny'). Ultimate questions focused at the evolutionary scale, and evaluated the effects of behavior on reproductive success ('survival value') or described how and why behavior evolved over time ('evolution'). Using these frameworks, researchers compiled comprehensive descriptions of behavior that in turn informed our understanding of species' life histories. One prominent example of this is apparent in the 
literature evaluating the evolution of promiscuity and the varied mating systems of birds (reviewed in Orians 1969, Trivers 1972, Gladstone 1979). At the ultimate level, for example, researchers found that promiscuity likely improved male reproductive success and thus identified an impetus for the evolution of promiscuity among birds. At the proximate level, factors such as population density and resource availability were associated with variation in the size and quality of breeding territories, demonstrating that current extrinsic conditions impact mating systems in real time. As demonstrated by this example, researchers using these research frameworks came to describe behavior at different scales, and gradually compiled complex pictures of behaviors and the mechanisms that influence them at present and throughout evolutionary history.

Ultimately, these comprehensive research approaches led to the development of overarching hypotheses to explain important concepts in animal behavior such as foraging theory, communication, mating systems, and spatial behavior (reviewed in Emlen and Orgin 1977, Pyke 1984, Bradbury and Vehrencamp 2011). These hypotheses have served as the basis for much of the animal behavior research over the last several decades and have been used to develop models to explain a variety of behaviors at the scale of Tinbergen's four questions. In some cases, however, the assumptions of these models have become canon and are taken as fact without direct tests to assess whether they apply in every circumstance. In birds, for example, modern genetic tools are revealing that extra-pair copulations are prevalent, and it is common for females to produce clutches sired by multiple males even within species presumed to be both socially and sexually monogamous based on behavioral observations (Petrie et al. 1998, Griffith et al. 2002). This calls into question the long-standing hypothesis that males 
benefit from promiscuity but females do not, an assumption that has served as the primary basis for our understanding of mate choice and the associated evolution of life history traits like mating systems (Clutton-Brock 2007, Stockley and Bro-Jorgensen 2011, Stockley and Campbell 2013). Thus, the models we derive from a particular suite of observations can break down as new tools and lines of inquiry reveal observations that the models cannot account for, which warrants revisiting these models to incorporate contemporary information.

Another behavior for which older models are failing to explain recently identified patterns is territoriality. Territoriality, or the behavioral defense of a particular area or resource, has figured prominently in animal behavior research over the last several decades (reviewed in Brown 1964, Stamps 1994, Adams 2001). Early studies documented territoriality across a diversity of taxonomic groups (e.g., Nice 1941, Burt 1943, Test 1948). In these studies, researchers found that individuals could be observed in the same location over time, and that they exhibited aggressive behavior towards conspecifics that entered that space. Birds were an important focus of much of this early work (reviewed in Nice 1941), but territoriality has ultimately been described in every animal group, including examples in amphibians, fish, insects, mammals, reptiles, and others (e.g., Evans 1938, Noble and Curtis 1939, Burt 1943, Test 1948, Kormondy 1961). Studies that followed began to move beyond observation and evaluated the function and advantages of territorial behavior. Territories seemed to confer access to resources such as food and shelter, and thus it was hypothesized that defense of territories might exert substantial influence on fitness (reviewed in Verner 1977, Kaufmann 1983). 
At this time, experiments also began to evaluate the influence territorial behavior on factors associated with reproductive success, such as the number of mates that individuals have access to by being territorial. The results of this work sparked inquiries about the associated between territoriality and species' mating systems, one of the first life history traits hypothesized to be inexorably tied to territorial behavior. For example, work synthesizing foundational studies of territoriality of birds and mammals for the first half of the $20^{\text {th }}$ century hypothesized that territorial polygyny or polyandry (e.g., mating systems in which individuals of one sex defend territories and mate with multiple individuals of the other sex) are associated with species exhibiting a specific suite of traits and occurring in habitats with particular attributes. For example, territoriality is commonly observed in species that occur in habitats with economically defendable resources that enable individuals to behaviorally carve habitats into areas in which they secure access to resources (reviewed in Brown 1964). Furthermore, territorial species also exhibit variable aggressive behavior, such that they aggressive toward conspecifics but also exhibit seasonal shifts in behavior that coincide with the times of year where territoriality is advantageous (e.g., the breeding season (Orians 1969, Emlen and Oring 1977). As such, researchers came to view territoriality as a life history trait with substantial influence on other aspects of species' life history, which in turn inspired a series of studies evaluating how territoriality directly mediates reproductive success. For example, it is common to observe that individuals defend territories that differ substantially in size, shape, and location, all of which may influence the amount or quality of resources the territory provides access to (e.g., Odum and Kuenzler 1955, Alcock 1979, Ewald et al. 1980). Two non-mutually exclusive hypotheses emerged from 
this observation to explain how such variation in territoriality might contribute to individual differences in reproductive success. First, for a hypothetical species in which males are territorial and females are not, females may choose to reside in male territories that are particularly rich in resources, and thus the male's reproductive success increases because of her preference for his territory. Second, for the same hypothetical species, certain individuals may be able to carve out large territories that encompass many potential mates relative to conspecifics, thereby increasing their reproductive success by sequestering access to these mates. Observations such as the finding that larger territories provide access to more potential mates lend support to the latter hypothesis (Balmford et al. 1992, Rothmair 1994), and inspired yet another new wave of territorial research searching for mechanisms to explain the observed variation in territoriality.

At the proximate scale, a variety of different behavioral, morphological, and physiological traits have been implicated in the regulation of territoriality and to explain how and why it varies among individuals. The list of traits continues to grow-winner effects, residency status, body size, weapon size, and circulating androgen concentrations, among others, have all been repeatedly correlated with individual variation in aspects territorial behavior, and thus reproductive success (reviewed in Maher and Lott 2000, Kelly 2007, Arnott and Elwood 2009). At the ultimate scale, phylogenetic studies have evaluated interspecific differences in territoriality, and led to hypotheses to explain patterns of territoriality across taxonomic groups. For example, territory size is correlated with body size at the species level (reviewed in Adams 2001). For instance, work with territorial carnivores demonstrates that larger species tend to have larger territories on average relative to smaller species (e.g., Lindstedt et al. 1986, 
Jetz et al. 2004). Furthermore, carnivores tend to have larger territories than similarly sized herbivores, suggesting that diet and foraging habits also mediate the evolution of different territorial systems across taxa (e.g., Harestad and Bunnel 1979, Mcloughlin and Ferguson 2000). Together, these studies began to bring the subject of territoriality full circle by elucidating both proximate and ultimate mechanisms that influence territorial behavior.

By following the four-question approach proposed by Tinbergen (1963), the field of territoriality research has continued to advance. Early descriptions of territoriality for species in different taxonomic groups have served as the basis from which we have described many other aspects of species' ecology, particularly for those that exhibit territorial polygyny or polyandry (e.g., Verner and Engelsen 1970, Manzur and Fuentes 1979). From this foundation, we have developed overarching models to explain how territorial behavior influences the distribution of populations across landscapes, determines why certain individuals interact and have access to resources, and serves as a mechanism through which reproductive success varies among conspecifics (e.g., Fretwell 1969, Holm 1973, Verner 1977, MacLean and Seastedt 1979). However, for many taxonomic groups that have served as model organisms for the study of territoriality, the early work that characterized territorial behavior focused disproportionately on the behavior of a single sex - males. Although several of these studies noted that females also exhibit territorial behavior, many descriptions of female territoriality, and female behavior in general, were primarily anecdotal and rarely extended beyond females' residence within male territories and interactions with territorial males (e.g., Pitelka 1942, Burt 1943, Jenssen et al. 1995). 
Even as empirical work investigating the causes and consequences of male territoriality continued to accumulate, few studies evaluated whether these same causes and consequences were at work in territorial females despite observations of territoriality and other aggressive behaviors in females of many species (Clutton-Brock $2007 \& 2009$, Clutton-Brock and Hechard 2013). As a result, hypotheses regarding the evolution, fitness benefits, and mechanistic control of territoriality remain largely untested in females of many territorial species. While it is possible that the same hypotheses may apply to female behavior, there are also important reasons to consider that many will fail to do so and warrant direct tests in females. For example, many of the traits that hypothesized to modulate male territoriality are either absent in females (e.g., weapons and ornaments), or differ substantially between the sexes (e.g., circulating androgens or extent of morphological asymmetry among conspecifics, reviewed in Arnott and Elwood 2009). Observations that female reproductive success varies much more than historically presumed suggests that competitive interactions such as territorial disputes among females may have important implications for female fitness and provides an impetus for identifying traits to explain variation in reproductive success among females (reviewed in Stockley and Bro-Jorgensen 2011, Clutton-Brock et al. 2013, Rosvall 2013).

Thus, the time is ripe to assess female-female competition and to evaluate the potential influence of territoriality on female fitness. A growing body of work is challenging the long-standing assumption that variation in reproductive success is limited in females outside the context of polyandry and is highlighting that female-female aggression plays a significant role in species' ecology (as reviewed in Stokley and BroJorgensen 2011, Clutton-Brock et al. 2013, Rosvall 2013). Moving forward, both 
observational and manipulative studies are needed to characterize female behavior and evaluate the mechanisms that mediate it, and field studies are particularly necessary to describe these patterns under natural conditions. One group of organisms that offers plentiful opportunities in which to do so is lizards (Kamath and Losos 2017, Bush and Simberloff 2018, Stamps 2018).

\section{A Case for Lizard Territoriality as a Model System}

Lizards have been the frequent subjects of territorial research, particularly over the last century. Several species have served as model organisms for the study of territorial systems and behavior, including some particularly well-studied examples in the genera Sceloporus (e.g., S. jarrovi, S. undulatus) and Anolis (e.g., A. carolinensis, A. sagrei). This large body of research has contributed significantly to the development of theoretical models to explain different aspects of territoriality, such as the association between body size and territory size (Schoner and Schoener 1982), the influence of

environment on evolution of various territorial systems (Stamps 1994, Martins 1994), and the endocrine regulation of aggressive and territorial behavior (Hirschenhauser and Oliveira 2006). In the following sections, I will present a historical perspective of the major themes and findings of studies evaluating territoriality in lizards and describe how the field has progressed through time. I will conclude with a perspective on the future directions of these studies, particularly as it relates to our relatively poor understanding of the mechanisms mediating territoriality in female lizards.

As is true of territorial research in general, our understanding of lizard territoriality first came from descriptive studies. Researchers working with a variety of species observed individuals exhibiting site-fidelity, occupying exclusive space, and 
using highly stereotyped signaling displays and fighting behaviors towards conspecifics who entered those areas (e.g., Evans 1938, Stebbins 1944, Goin and Goin 1951, Carpenter 1978). This evidence was used to support the hypothesis that lizards defended territories using behaviors similar to those observed in birds and mammals (e.g., Burt 1943, Brown 1964). As the number of studies of territoriality increased, one of the first observations that attracted a significant amount of research was variation in territory size, both across and within species. As research continued, several general patterns began to emerge. First, the different territorial systems used by lizards seem to be associated with foraging mode (e.g., Pianka 1966, Moermond 1979). Active foragers like the Racerunners (genus Cnemidophorus) that move almost constantly in search of prey generally lack territorial behavior, although they may frequent a particular area (e.g., undefended home range) and exhibit aggression towards conspecifics that they come into contact with (Carpenter 1960, Eifler 1996). Herbivorous species that occur at high density also seem to exhibit less territorial behavior, such as Marine and Green Iguanas which may seasonally defend breeding territories but would quickly deplete their food supply if they defended permanent feeing territories (Amblyrhynchus cristatus and Iguana iguana, Trillmich and Trillmich 1984, Alberts and Werner 1993). In contrast, territoriality is common among sit-and-wait foragers, which would benefit from territoriality by demarcating an exclusive and semi-permanent area in which they await the occurrence of prey. Second, habitat also seems to have impacted the evolution of lizard territoriality, as species that use different microhabitats can exhibit substantial differences in territorial behavior. For example, closely related species of Anolis lizards on the Greater Antilles exhibit differences in territory size and behavior that are 
consistent across ecomorphs on different islands rather than genetic relatedness (Johnson and Wade 2010, Johnson et al. 2010). This indicates that the particular attributes of the microhabitats these ecomorphs use likely had direct consequences to the evolution of ecomorph-specific territorial behavior. Finally, differences in territoriality are also frequently observed among nocturnal and diurnal lizard species. In diurnal species like those the Anolis and Sceloporus genera, it is typical to observe a single male monopolizing access to multiple females and that males occur relatively far apart from one another as a result. In contrast, individuals of nocturnal species such as the Western Banded gecko (Coleonyx verigatus) exhibit territorial behavior but also occur much more gregariously than Anolis lizards, perhaps due to limitations to signaling distance in the dark (e.g., Greenberg 1943). Thus, several different life history and habitat characteristics likely interact to influence the evolution and maintenance of the different territorial systems observed in lizards.

In addition to these broader phylogenetic and species-level studies, a large body of work has also considered intraspecific variation in territoriality. For example, in many species, it is common to observe substantial variation in territory size among conspecifics — a few individuals defend large territories, while others occupy small ones (e.g., Ruby and Dunham 1987, Schoener and Schoener 1982). In some cases, certain individuals even seem to forgo territoriality entirely. So-called "floaters" of lizard species in several different genera do not defend territories (Winker 1998) but travel through others' territories in search of food and potential mates (e.g., Anolis aneus: Stamps and Eason 1989; Eluamprus heatolei: Stapley and Keogh 2004; Platysaurus broadleyi: Whiting et al. 2006). In some species the floater phenotype has reached an extreme with 
some males exhibiting morphological and behavioral traits that closely mimic females, enabling these males to sneak copulations in the territories of other males by being disguised as females (Whiting et al. 2009). Thus, many studies have considered the mechanisms through which these different territorial phenotypes arise, as well as the traits that explain variation among individuals of the same territorial phenotype.

Several factors associated with territoriality in other animals were also hypothesized to influence lizard territoriality. For example, food abundance, population density, and defensibility of resources were all hypothesized to be determinants of variation in territory size (Brown 1964, Adams 2001). Food abundance was negatively correlated with territory size in several species. For example, male and female Sceloporus jarrovi expanded their territories when food was experimentally increased (e.g., Simon 1975), and male and female Dipososaurus dorsalis increased their territory sizes following a storm that substantially decreased food availability (Krekorian 1976). Thus, individuals seem to alter their territories as a direct consequence of shifts in resource availability, suggesting that variation in territory size is likely linked to energetics (e.g., Schoener 1983). Population density has also been negatively associated with territory size. For example, individuals of Sceloporus merriami from populations with high density defended significantly smaller territories than individuals from less dense populations (Ruby and Dunham 1987), and territory size was negatively associated with population density in four species of Anolis lizards (Schoener and Schoener 1982). Thus, as population density increases, individuals are inevitably forced to carve out smaller habitats. 
Taken together, these findings suggest that both food and population density may significantly influence territory size. However, continued study of lizard territoriality also identified cases in which these and other extrinsic factors did not predict territory size. For example, territory size still varies substantially among males of the same Anolis species in the Caribbean, even though they occur in habitats with relatively homogenous resource distributions (Schoener and Schoener 1982, Johnson 2007). Thus, researchers began investigating the potential influence of intrinsic factors on territoriality, focusing on a variety of behavioral, morphological, and physiological traits.

Body size has been repeatedly associated with territory size in lizards (e.g., Simon 1975, Jenssen and Nunez 1998, Perry and Garland 2002), such that territory size is often positively correlated with body size. This pattern is also observed in other taxa, and several non-exclusive hypotheses may explain why such an association exists. Two hypotheses that have been widely tested are 1) that territory size and body size are correlated due to energetic demands of territory holders, and 2) that large individuals have large territories due to increased competitive advantage conferred by body size. With regard to the energetics hypothesis, large individuals may require large territories to satisfy their energetic needs (Serrano-Meneses et al. 2006, Grant and Diaconescu 2016). Thus, the positive correlation observed between body size and variation in territory size at both intra- and interspecific levels may be due to energetic requirements. Empirical investigations that include manipulations of food abundance or distribution in combination with differences in body size may reveal an influence of the interaction between body size and resource needs on territory size (reviewed in Jetz et al. 2004). Alternatively, the association between large body size and large territory size may be due 
to asymmetries in competitive ability conferred by body size. Large body size has been associated with success in agonistic interactions in a variety of taxa (reviewed in Arnott and Elwood 2009). If large body size confers competitive advantage in territorial disputes, larger individuals may have better success in establishing and maintaining territories over time relative to smaller conspecifics. Increased contest success has been observed in larger individuals of several lizard species (e.g., Zucker and Murray 1996, Jenssen et al. 2005, Sacchi et al. 2009) and lends support to this hypothesis.

Traits other than body size may also influence competitive availability (reviewed in Maher and Lott 2000). Asymmetries in characteristics such as colorful ornaments or weaponry have also been associated with variation in competitive ability. For example, components of ultraviolet signals were associated with intraspecific differences in fighting ability among male Augrabies flat lizards (Platysaurus broadleyi), and dewlap (i.e., throat fan) size was associated with bite force of males in two Anolis species (A. grahami and A. lineatopus), a trait that may mediate fighting ability in territorial contests (Vanhooydonck et al. 2005, Whiting et al. 2006). Such traits may convey information about an individual that is associated with its competitive ability if only particularly healthy or strong individuals sport these bright colors or large dewlaps, for example. Thus, these traits may play an indirect role in territorial contests and thus be associated with variation in territory size or other territorial behavior (Arnott and Elwood 2009).

The role of hormones in mediating territorial behavior in lizards has also been frequently investigated. Numerous studies have evaluated the potential for circulating concentrations of androgens such as testosterone to mediate aggressive behavior and demonstrated the potential for these hormones to explain territorial behavior and its 
variation across populations. Testosterone has been associated with dominance and other aggressive behaviors such as territoriality in multiple lizard genera, including several examples in Anolis (A. sagrei, Tokarz 1995; A. carolinensis, Greenberg and Crews 1990) and Sceloporus (S. jarrovi, Moore and Marler 1987, S. undulatus, Hews et al. 2012). Other hormones have also been implicated in the regulation of these behaviors. For example, male side-blotched lizards (Uta stansburiana) with experimentally elevated corticosterone defended smaller territories than males with saline implants (DeNardo and Sinervo 1994a), and experimentally blocking the production of corticosterone temporarily increased aggressive responses of male green anoles (A. carolinensis, Yang and Wilczynski 2003). However, there also cases in which these patterns are not as clear. For instance, there are several examples of well-studied taxa in which testosterone did not explain aggressive behaviors (e.g, Sceloporus jarrovi, Moore 1987, Anolis cybotes, Husak and Lovern 2014) and cases in which testosterone impacted behavior in some conditions but not others (e.g., S. jarrovi, Moore and Marler 1987). Furthermore, there is also evidence that multiple hormones and the interactions between them can impact aggressive behavior in lizards to influence territoriality (e.g., Uta stansburiana, DeNardo and Sinervo 1994b; Amblyrhynchus cristatus, Rubenstein and Wikelski 2005). Taken together, these results suggest that hormones like testosterone and corticosterone have the potential to influence territorial behavior in both males and females, but further study is need to elucidate the generality of their effects within and across species.

Thus far, the vast majority of the work presented here has focused on male behavior. As is true in several other groups, lizard territoriality remains best understood from the perspective of males. In general, the territorial behavior of females remains 
remarkably understudied in many species, even within those groups that have served as model organisms in decades of research on lizard territoriality. Interestingly, this gap is especially apparent within the more recent empirical work investigating the mechanisms that mediate territorial behavior. Early descriptive studies of lizard territoriality did often include observations of female behavior and in some cases, revealed evidence for territoriality. Literature investigating the behavior of Anolis lizards is demonstrative of this pattern, as anecdotal observations of female behavior pepper several studies initially describing the behavioral ecology of Anolis lizards, for example (e.g., Evans 1936, Andrews 1971, Yedlin and Ferguson 1973), and although limited, direct studies of female spatial patterns provided evidence for territoriality in at least some species (e.g., Stamps 1973). However, manipulative studies aimed at elucidating the control of female territoriality remain limited, particularly those conducted under natural conditions. Researchers have successfully elicited male-like aggression in female Anolis by using testosterone implants but have not yet established the natural levels of aggression or testosterone that female Anolis exhibit (Mason and Adkins 1976, Greenberg and Crews 1990).

Thus far, female territoriality has arguably been the most thoroughly studied in the genus Sceloporus relative to other lizard species. For example, a series of studies with Sceloporus jarrovi beginning in the 1970s provided evidence for aggression and territorial behavior in both males and females of this species, and began evaluating potential mechanisms to explain territorial behavior in both sexes (e.g., Simon 1975, Ruby 1978, Moore 1986). Unlike Anolis, in which the limited manipulations of hormones and other traits associated with territoriality have been conducted primarily in the lab, 
much of this work with Sceloporus was conducted under natural conditions. Without data on the natural behavior and circulating hormone concentrations of free-living females over the course of their breeding seasons like what is known for Sceloporus, it is impossible to know whether the conditions simulated under laboratory conditions mimic biologically relevant conditions for wild females of other species. Extended field studies of females will help to ameliorate this limitation.

Fortunately, a growing number of studies in recent years with in a larger diversity of lizard species is revealing new perspectives on the form, function, and significance of female territorial behavior in lizards. Females in a variety of species throughout the squamate phylogeny have been observed to occupy exclusive space and to exhibit aggressive behavior toward conspecific intruders (Table 1). Building from these data, researchers hypothesize that territory defense and aggression may widespread and benefit females in different ways, such as providing access to food, mates, and a defensible space in which to protect young (e.g., Stamps 1977, Sinn et al. 2008). Physiological mechanisms such as hormone regulation have been implicated in the control of female aggression and territoriality, and studies have investigated the potential role of corticosterone, estradiol, progesterone, and testosterone in mediating these behaviors (Woodley and Moore 1999a, 1999b; Rubenstein and Wikelski 2006). In addition to providing novel insights into female territoriality, more detailed attention to female behavior in general is causing researchers to rethink long held assumptions about the ecology of some species. Genetic evidence in Anolis lizards, for example, indicates that females produce young sired by multiple males beyond the male in whose territory they reside (Calsbeek et al. 2007). This suggests that females can exert influence on male 
reproductive success, are not solely passive players contained within male territories as part of territorial polygyny.

\section{Conclusions and Future Directions}

In summary, lizards represent an excellent group in which to pursue exciting future directions in research on female territoriality. For many species, descriptive work is needed to establish whether females exhibit territoriality, and if so, to characterize their behavior. Although laboratory studies can be informative, field-based studies over extended periods of time will be especially important for understanding female behavior and the mechanisms that regulate it within natural conditions. For example, with regard to the potential influence of hormones on female territoriality, we currently lack data on the baseline concentration of testosterone and other hormones for free-living Anolis lizards and species of many other taxonomic groups. For example, we have data on the baseline circulating concentrations of free-living males in several species, but almost none in females (e.g., Tokarz et al. 1998, Husak and Lovern 2014). Thus, although malelike aggressive and courtship behavior can be induced in female anoles by supplementing testosterone (Crews and Adkins 1976), it is not possible to know whether the experimental concentrations are at all close to natural conditions because we do not know either the baseline concentrations nor the capacity for variation within wild females. Without these data, it is difficult to assess whether conditions in laboratory studies or field-based studies using hormone-implants are representative of natural conditions that individuals may reasonably experience in the wild. Furthermore, hormone profiles often fluctuate over time, such as differences across seasons and stages of development. Thus, 
it is critical to evaluate the extent and nature of these fluctuations over time to understand how shifts in hormone profiles may impact individual variation in behavior.

Among the species in which territoriality has been described, empirical work investigating the function of female territoriality and the mechanisms that mediate it is lagging in comparison to similar work with males. As a result, we lack the data needed to appropriately assess whether the same mechanisms that influence territorial behavior in males also do so in females. Thus, hypotheses that have been used to explain patterns of territoriality in males are ripe to be tested in females. Again, fieldwork is will be paramount to this endeavor, in combination with laboratory studies of territoriality and traits that modulate it.

In conclusion, although these questions have been framed within the context of lizard territoriality, they are also likely to be widely applicable in other species in which territoriality remains primarily understood from the perspective of a single sex. 


\section{References}

Adams, E. S. (2001). Approaches to the study of territory size and shape. Annual Review of Ecology and Systematics, 32(1), 277-303.

Alberts, A. C., \& Werner, D. I. (1993). Chemical recognition of unfamiliar conspecifics by green iguanas: functional significance of different signal components. Animal Behaviour, 46(1), 197-199.

Alcock, J. (1979). The Behavioural Consequences of Size Variation Among Males of the Territorial Wasp Hemipepsis ust ulata (Hymenoptera: Pompilidae). Behaviour, 71(3-4), 322-335.

Andrews, R. M. (1971). Structural habitat and time budget of a tropical Anolis lizard. Ecology, 52(2), 262-270.

Arnott, G., \& Elwood, R. W. (2009). Assessment of fighting ability in animal contests. Animal Behaviour, 77(5), 991-1004.

Auffenberg, W. (1979). Intersexual differences in behavior of captive Varanus bengalensis (Reptilia, Lacertilia, Varanidae). Journal of Herpetology, 313-315.

Balmford, A., Rosser, A. M., \& Albon, S. D. (1992). Correlates of female choice in resource-defending antelope. Behavioral Ecology and Sociobiology, 31(2), 107114.

Beck, D. D. (2004). Venomous lizards of the desert. Natural History, 113(6), 32-37.

Bezy, R. L., Gorman, G. C., Adest, G. A., \& Kim, Y. J. (1980). Divergence in the island night lizard Xantusia riversiana (Sauria: Xantusiidae).

Bombi, P., \& Vignoli, L. (2004). Distribution, ecology and conservation of Archaeolacerta bedriagae in Sardinia (Reptilia, Lacertidae). Bollettino di Zoologia, 71(S2), 135-144.

Bradbury, J. W. and S. L. Vehrencamp. Principles of Animal Communication ( $2^{\text {nd }}$ ed.). Sunderland, MA, US: Sinauer Associates.

Brown, J. L. (1964). The evolution of diversity in avian territorial systems. The Wilson Bulletin, 160-169.

Burt, W. H. (1943). Territoriality and home range concepts as applied to mammals. Journal of Mammalogy, 24(3), 346-352.

Bush, J. M., \& Simberloff, D. (2018). A case for anole territoriality. Behavioral Ecology and Sociobiology, 72(7), 111. 
Calsbeek, R., Bonneaud, C., Prabhu, S., Manoukis, N., \& Smith, T. B. (2007). Multiple paternity and sperm storage lead to increased genetic diversity in Anolis lizards. Evolutionary Ecology Research, 9(3), 495-503.

Carpenter, C. C., \& Grubits III, G. (1960). Dominance Shifts in the Tree Lizard (Urosaurus ornatus: Iguanidae). The Southwestern Naturalist, 123-128.

Carpenter, C. C. (1978). Ritualistic social behavior in lizards. In: Behavior and Neurology of Lizards (Ed. by N. Greenberg \& P. D. MacLean), pp. 253-267. Maryland: National Institute of Mental Health.

Clutton-Brock, T. (2007). Sexual selection in males and females. Science, 318(5858), 1882-1885.

Clutton-Brock, T. (2009). Sexual selection in females. Animal Behaviour, 77(1), 3-11.

Clutton-Brock, T. H., \& Huchard, E. (2013). Social competition and selection in males and females. Philosophical Transactions of the Royal Society B: Biological Sciences, 368(1631), 20130074.

DeNardo, D. F., \& Sinervo, B. (1994). Effects of corticosterone on activity and homerange size of free-ranging male lizards. Hormones and Behavior, 28(1), 53-65.

Eifler, D. A. (1996). Experimental manipulation of spacing patterns in the widely foraging lizard Cnemidophorus uniparens. Herpetologica, 477-486.

Evans, L. T. (1938). Cuban field studies on territoriality of the lizard Anolis sagrei. Journal of Comparative Psychology, 25(1), 97.

Ewald, P. W., Hunt Jr, G. L., \& Warner, M. (1980). Territory size in Western Gulls: importance of intrusion pressure, defense investments, and vegetation structure. Ecology, 61(1), 80-87.

Darwin, Charles, 1809-1882. (1859). On the origin of species by means of natural selection, or preservation of favoured races in the struggle for life. London :John Murray.

Decourcy, K. R., \& Jenssen, T. A. (1994). Structure and use of male territorial headbob signals by the lizard Anolis carolinensis. Animal Behaviour, 47(2), 251-262.

DeNardo, D. F., \& Sinervo, B. (1994a). Effects of corticosterone on activity and homerange size of free-ranging male lizards. Hormones and Behavior, 28(1), 53-65.

DeNardo, D. F., \& Sinervo, B. (1994b). Effects of steroid hormone interaction on activity and home-range size of male lizards. Hormones and Behavior, 28(3), 273-287. 
Deslippe, R. J., M'Closkey, R. T., Dajczak, S. P., \& Szpak, C. P. (1990). A quantitative study of the social behavior of tree lizards, Urosaurus ornatus. Journal of Herpetology, 337-341.

Emlen, S. T., \& Oring, L. W. (1977). Ecology, sexual selection, and the evolution of mating systems. Science, 197(4300), 215-223.

Evans, L. T. (1936). Territorial behavior of normal and castrated females of Anolis carolinensis. The Pedagogical Seminary and Journal of Genetic Psychology, 49(1), 49-60.

Evans, L. T. (1938). Cuban field studies on territoriality of the lizard Anolis sagrei. Journal of Comparative Psychology, 25(1), 97.

Ewald, P. W., Hunt Jr, G. L., \& Warner, M. (1980). Territory size in Western Gulls: importance of intrusion pressure, defense investments, and vegetation structure. Ecology, 61(1), 80-87.

Ferguson, G. W. (1966). Releasers of courtship and territorial behaviour in the side blotched lizard Uta stansburiana. Animal Behaviour, 14(1), 89-92.

Fleishman, L. J. (1988). The social behavior of Anolis auratus, a grass anole from Panama. Journal of Herpetology, 13-23.

Formanowicz Jr, D. R., Brodie Jr, E. D., \& Campbell, J. A. (1990). Intraspecific aggression in Abronia vasconcelosii (Sauria, Anguidae), a tropical, arboreal lizard. Biotropica, 391-396.

Fretwell, S. D. (1969). On territorial behavior and other factors influencing habitat distribution in birds. Acta biotheoretica, 19(1), 45-52.

Gladstone, D. E. (1979). Promiscuity in monogamous colonial birds. The American Naturalist, 114(4), 545-557.

Goin, O. B., \& Goin, C. J. (1951). Notes on the natural history of the lizard Eumeces laticeps, in northern Florida. Quarterly Journal of the Florida Academy of Sciences, 14(1), 29-33.

Greenberg, B. (1943). Social behavior of the western banded gecko, Coleonyx variegatus Baird. Physiological Zoology, 16(1), 110-122.

Grant, J. W., \& Diaconescu, M. I. (2016). The allometry of ephemeral territory size: insights into interspecific patterns of space use. Animal Behaviour, 111, 79-83. 
Greenberg, N., \& Crews, D. (1990). Endocrine and behavioral responses to aggression and social dominance in the green anole lizard, Anolis carolinensis. General and Comparative Endocrinology, 77(2), 246-255.

Griffith, S. C., Owens, I. P., \& Thuman, K. A. (2002). Extra pair paternity in birds: a review of interspecific variation and adaptive function. Molecular Ecology, 11(11), 2195-2212.

Guarino, F. (2002). Spatial ecology of a large carnivorous lizard, Varanus varius (Squamata: Varanidae). Journal of Zoology, 258(4), 449-457.

Harestad, A. S., \& Bunnel, F. L. (1979). Home Range and Body Weight-A Reevaluation. Ecology, 60(2), 389-402.

Haenel, G. J., Smith, L. C., \& John-Alder, H. B. (2003). Home-range analysis in Sceloporus undulatus (eastern fence lizard). I. Spacing patterns and the context of territorial behavior. Copeia, 2003(1), 99-112.

Hews, D. K., Hara, E., \& Anderson, M. C. (2012). Sex and species differences in plasma testosterone and in counts of androgen receptor-positive cells in key brain regions of Sceloporus lizard species that differ in aggression. General and Comparative Endocrinology, 176(3), 493-499.

Hess, N. E., \& Losos, J. B. (1991). Interspecific aggression between Anolis cristatellus and A. gundlachi: comparison of sympatric and allopatric populations. Journal of Herpetology, 25(2), 256-259.

Hirschenhauser, K., \& Oliveira, R. F. (2006). Social modulation of androgens in male vertebrates: meta-analyses of the challenge hypothesis. Animal Behaviour, 71(2), 265-277.

Holm, C. H. (1973). Breeding sex ratios, territoriality, and reproductive success in the Red-winged Blackbird (Agelaius phoeniceus). Ecology, 54(2), 356-365.

Husak, J. F., \& Lovern, M. B. (2014). Variation in steroid hormone levels among Caribbean Anolis lizards: Endocrine system convergence?. Hormones and Behavior, 65(4), 408-415.

Jennings, T. A. \& Thompson, G. C. (1999) Territorial behavior in the Australian scincid lizard Ctenotus fallens. Herpetologica, 55, 352-361.

Jenssen, T. A., Greenberg, N., \& Hovde, K. A. (1995). Behavioral profile of free-ranging male lizards, Anolis carolinensis, across breeding and post-breeding seasons. Herpetological Monographs, 41-62. 
Jenssen, T. A., \& Nunez, S. C. (1998). Spatial and breeding relationships of the lizard, Anolis carolinensis: evidence of intrasexual selection. Behaviour, 981-1003.

Jenssen, T. A., Decourcy, K. R., \& Congdon, J. D. (2005). Assessment in contests of male lizards (Anolis carolinensis): how should smaller males respond when size matters?. Animal Behaviour, 69(6), 1325-1336.

Jetz, W., Carbone, C., Fulford, J., \& Brown, J. H. (2004). The scaling of animal space use. Science, 306(5694), 266-268.

Johnson, M. A. (2007). Behavioral ecology of Caribbean Anolis lizards: a comparative approach. Doctoral Dissertation, Washington University in St. Louis, MO, US (Vol. 68, No. 09).

Johnson, M. A., Revell, L. J., \& Losos, J. B. (2010). Behavioral convergence and adaptive radiation: effects of habitat use on territorial behavior in Anolis lizards. Evolution: International Journal of Organic Evolution, 64(4), 1151-1159.

Johnson, M. A., \& Wade, J. (2010). Behavioural display systems across nine Anolis lizard species: sexual dimorphisms in structure and function. Proceedings of the Royal Society B: Biological Sciences, 277(1688), 1711-1719.

Kamath, A., \& Losos, J. (2017). The erratic and contingent progression of research on territoriality: a case study. Behavioral Ecology and Sociobiology, 71(6), 89.

Kaufmann, J. H. (1983). On the definitions and functions of dominance and territoriality. Biological Reviews, 58(1), 1-20.

Kelly, C. D. (2006). Fighting for harems: assessment strategies during male-male contests in the sexually dimorphic Wellington tree weta. Animal Behaviour, 72(3), 727-736.

Khannoon, E. R., El-Gendy, A., \& Hardege, J. D. (2011). Scent marking pheromones in lizards: cholesterol and long chain alcohols elicit avoidance and aggression in male Acanthodactylus boskianus (Squamata: Lacertidae). Chemoecology, 21(3), 143-149.

Kormondy, E. J. (1961). Territoriality and dispersal in dragonflies (Odonata). Journal of the New York Entomological Society, 69(1), 42-52.

Krekorian, C. N. (1976). Home range size and overlap and their relationship to food abundance in the desert iguana, Dipsosaurus dorsalis. Herpetologica, 405-412.

Lapini, L., Dall'Asta, A., Luiselli, L., \& Nardi, P. (2004). Lacerto horvathi in Italy: a review with new data on distribution, spacing strategy and territoriality (Reptilia, Lacertidae). Bollettino di Zoologia, 71(S2), 145-151. 
Lindstedt, S. L., Miller, B. J., \& Buskirk, S. W. (1986). Home range, time, and body size in mammals. Ecology, 67(2), 413-418.

MacLean Jr, S. F., \& Seastedt, T. R. (1979). Avian territoriality: sufficient resources or interference competition. The American Naturalist, 114(2), 308-312.

Maher, C. R., \& Lott, D. F. (2000). A review of ecological determinants of territoriality within vertebrate species. The American Midland Naturalist, 143(1), 1-30.

Manzur, M. I., \& Fuentes, E. R. (1979). Polygyny and agonistic behavior in the treedwelling lizard Liolaemus tenuis (Iguanidae). Behavioral Ecology and Sociobiology, 6(1), 23-28.

Martins, E. P. (1994). Structural complexity in a lizard communication system: the Sceloporus graciosus" push-up" display. Copeia, 944-955.

Mason, P., \& Adkins, E. K. (1976). Hormones and social behavior in the lizard, Anolis carolinensis. Hormones and behavior, 7(1), 75-86.

Mayr, E. (1961). Cause and effect in biology. Science, 134(3489), 1501-1506.

McLoughlin, P. D., \& Ferguson, S. H. (2000). A hierarchical pattern of limiting factors helps explain variation in home range size. Ecoscience, 7(2), 123-130.

Moermond, T. C. (1979). Habitat constraints on the behavior, morphology, and community structure of Anolis lizards. Ecology, 60(1), 152-164.

Moore, M. C. (1986). Elevated testosterone levels during nonbreeding-season territoriality in a fall-breeding lizard, Sceloporus jarrovi. Journal of Comparative Physiology A, 158(2), 159-163.

Moore, M. C. (1987). Circulating steroid hormones during rapid aggressive responses of territorial male mountain spiny lizards, Sceloporus jarrovi. Hormones and Behavior, 21(4), 511-521.

Moore, M. C., \& Marler, C. A. (1987). Effects of testosterone manipulations on nonbreeding season territorial aggression in free-living male lizards, Sceloporus jarrovi. General and Comparative Endocrinology, 65(2), 225-232.

Nice, M. M. (1941). The role of territory in bird life. American Midland Naturalist, 441487.

Noble, G. K., \& Curtis, B. (1939). The social behavior of the jewel fish, Hemichromis bimaculatus Gill. Bulletin of the American Museum of Natural History; 76, 146. 
Odum, E. P., \& Kuenzler, E. J. (1955). Measurement of territory and home range size in birds. The Auk, 72(2), 128-137.

Orians, G. H. (1969). On the evolution of mating systems in birds and mammals. The American Naturalist, 103(934), 589-603.

Pérez-Buitrago, N., Sabat, A. M., \& McMillan, W. O. (2010). Spatial Ecology of the Endangered Mona Island Iguana Cyclura cornuta stejnegeri: Does Territorial Behavior Regulate Density?. Herpetological Monographs, 86-110.

Perry, G., \& Garland, T. (2002). Lizard home ranges revisited: effects of sex, body size, diet, habitat, and phylogeny. Ecology, 83(7), 1870-1885.

Petrie, M., \& Kempenaers, B. (1998). Extra-pair paternity in birds: explaining variation between species and populations. Trends in Ecology \& Evolution, 13(2), 52-58.

Pianka, E. R. (1966). Convexity, desert lizards, and spatial heterogeneity. Ecology, 47(6), 1055-1059.

Pietruszka, R. D. (1988). Observations on sexual dimorphism and social structure in the lizard Angolosaurus skoogi (Cordylidae) of the northern Namib Desert dunes. African Zoology, 23(1), 47-51.

Pitelka, F. A. (1942). Territoriality and related problems in North American hummingbirds. The Condor, 44(5), 189-204.

Pyke, G. H. (1984). Optimal foraging theory: a critical review. Annual Review of Ecology and Systematics, 15(1), 523-575.

Qiu, X., Fu, J., \& Qi Y. Xia Qiu, Jinzhong Fu and Yin Qi. Tail Waving Speed Affects Territorial Response in the Toad-headed Agama Phrynocephalus vlangalii. Asian Herpetological Research, 2018, 9 (3): 182-187.

Roithmair, M. E. (1994). Male territoriality and female mate selection in the dart-poison frog Epipedobates trivittatus (Dendrobatidae, Anura). Copeia, 107-115.

Rostker, M. A. (1983). Experimental Study of Collared Lizards: Effects of Habitat and Male Quality on Fitness (Doctoral dissertation, Oklahoma State University).

Rosvall, K. A. (2013). Proximate perspectives on the evolution of female aggression: good for the gander, good for the goose?. Philosophical Transactions of the Royal Society B: Biological Sciences, 368(1631), 20130083.

Rubenstein, D. R., \& Wikelski, M. (2005). Steroid hormones and aggression in female Galapagos marine iguanas. Hormones and behavior, 48(3), 329-341. 
Ruby, D. E. (1978). Seasonal changes in the territorial behavior of the iguanid lizard Sceloporus jarrovi. Copeia, 430-438.

Ruby, D. E., \& Dunham, A. E. (1987). Variation in home range size along an elevational gradient in the iguanid lizard Sceloporus merriami. Oecologia, 71(3), 473-480.

Sacchi, R., Pupin, F., Gentilli, A., Rubolini, D., Scali, S., Fasola, M., \& Galeotti, P. (2009). Male-male combats in a polymorphic lizard: residency and size, but not color, affect fighting rules and contest outcome. Aggressive Behavior: Official Journal of the International Society for Research on Aggression, 35(3), 274283.

Schell, P. T., Powell, R., Parmerlee, J. S., Lathrop, A., \& Smith, D. D. (1993). Notes on the natural history of Ameiva chrysolaema (Sauria: Teiidae) from Barahona, Dominican Republic. Copeia, 1993(3), 859-862.

Schoener, T. W. (1983). Simple models of optimal feeding-territory size: a reconciliation. The American Naturalist, 121(5), 608-629.

Schoener, T. W., \& Schoener, A. (1982). Intraspecific variation in home-range size in some Anolis lizards. Ecology, 63(3), 809-823.

Serrano-Meneses, M. A., \& Székely, T. (2006). Sexual size dimorphism in seabirds: sexual selection, fecundity selection and differential niche-utilisation. Oikos, $113(3), 385-394$.

Simon, C. A. (1975). The influence of food abundance on territory size in the iguanid lizard Sceloporus jarrovi. Ecology, 56(4), 993-998.

Sinn, D. L., While, G. M., \& Wapstra, E. (2008). Maternal care in a social lizard: links between female aggression and offspring fitness. Animal Behaviour, 76(4), 1249-1257.

Sloan, C. L., \& Baird, T. A. (1999). Is heightened post-ovipositional aggression in female collared lizards (Crotaphytus collaris) nest defense?. Herpetologica, 516-522.

Stamps, J. A. (1973). Displays and social organization in female Anolis aeneus. Copeia, 264-272.

Stamps, J. A. (1977). Rainfall, moisture and dry season growth rates in Anolis aeneus. Copeia, 415-419.

Stamps, J. A. (1994). Territorial behavior: testing the assumptions. Advances in the Study of Behavior, 23(173), 232. 
Stamps, J. A. (2018). Polygynandrous anoles and the myth of the passive female. Behavioral Ecology and Sociobiology, 72(7), 107.

Stamps, J. A., \& Tanaka, S. (1981). The relationship between food and social behavior in juvenile lizards (Anolis aeneus). Copeia, 422-434.

Stamps, J. A., \& Eason, P. K. (1989). Relationships between spacing behavior and growth rates: a field study of lizard feeding territories. Behavioral Ecology and Sociobiology, 25(2), 99-107.

Stapley, J., \& Keogh, J. S. (2004). Exploratory and antipredator behaviours differ between territorial and nonterritorial male lizards. Animal Behaviour, 68(4), 841-846.

Stebbins, R. C. (1948). Additional observations on home ranges and longevity in the lizard Sceloporus graciosus. Copeia, 1948(1), 20-22.

Stockley, P., \& Bro-Jørgensen, J. (2011). Female competition and its evolutionary consequences in mammals. Biological Reviews, 86(2), 341-366.

Stockley, P., \& Campbell, A. (2013). Female competition and aggression: interdisciplinary perspectives. Philosophical Transactions of the Royal Society B: Biological Sciences. 368, 20130073.

Summers, C. H., \& Andrews, T. J. (1996). Aggression, and the acquisition and function of social dominance in female Anolis carolinensis. Behaviour, 133(15-16), 1265-1279.

Test, F. H. (1954). Social aggressiveness in an amphibian. Science, 120(3108), 140-141.

Tinbergen, N. (1963). On aims and methods of ethology. Zeitschrift für Tierpsychologie, 20(4), 410-433.

Tinkle, D. W., McGregor, D., \& Dana, S. (1962). Home range ecology of Uta stansburiana stejnegeri. Ecology, 43(2), 223-229.

Tokarz, R. R. (1995). Importance of androgens in male territorial acquisition in the lizard Anolis sagrei: an experimental test. Animal Behaviour, 49(3), 661-669.

Tokarz, R. R., McMann, S., Seitz, L., \& John-Alder, H. (1998). Plasma corticosterone and testosterone levels during the annual reproductive cycle of male brown anoles (Anolis sagrei). Physiological Zoology, 71(2), 139-146.

Trillmich, F., \& Trillmich, K. G. (1984). The mating systems of pinnipeds and marine iguanas: convergent evolution of polygyny. Biological Journal of the Linnean Society, 21(1-2), 209-216. 
Trivers, R. L. (1976). Parental investment and sexual selection. B. Cambell (Ed.). Sexual Selection and the Descent of Man, 1871-1971:136-179. Chicago: Aldine.

Valladas, H., Clottes, J., Geneste, J. M., Garcia, M. A., Arnold, M., Cachier, H., \& Tisnérat-Laborde, N. (2001). Palaeolithic paintings: evolution of prehistoric cave art. Nature, 413(6855), 479.

Vanhooydonck, B., Herrel, A., Van Damme, R., Meyers, J. J., \& Irschick, D. J. (2005). The relationship between dewlap size and performance changes with age and sex in a green anole (Anolis carolinensis) lizard population. Behavioral Ecology and Sociobiology, 59(1), 157-165.

Verner, J. (1977). On the adaptive significance of territoriality. The American Naturalist, 111(980), 769-775.

Verner, J., \& Engelsen, G. H. (1970). Territories, multiple nest building, and polygyny in the Long-billed Marsh Wren. The Auk, 557-567.

Whiting, M. J., Stuart-Fox, D. M., O'Connor, D., Firth, D., Bennett, N. C., \& Blomberg, S. P. (2006). Ultraviolet signals ultra-aggression in a lizard. Animal Behaviour, 72(2), 353-363.

Whiting, M. J., Webb, J. K., \& Keogh, J. S. (2009). Flat lizard female mimics use sexual deception in visual but not chemical signals. Proceedings of the Royal Society B: Biological Sciences, 276(1662), 1585-1591.

Winker, K. (1998). The concept of floater. Ornitologia Neotropical, 9(2), 111-119.

Wirminghaus, J. O. (1990). Observations on the behaviour of the Cape girdled lizard Cordylus cordylus (Reptilia: Cordylidae). Journal of Natural History, 24(6), 1617-1627.

Woodley, S. K., \& Moore, M. C. (1999a). Female territorial aggression and steroid hormones in mountain spiny lizards. Animal Behaviour, 57(5), 1083-1089.

Woodley, S. K., \& Moore, M. C. (1999b). Ovarian hormones influence territorial aggression in free-living female mountain spiny lizards. Hormones and Behavior, 35(3), 205-214.

Wu, Y., Ramos, J. A., Qiu, X., Peters, R. A., \& Qi, Y. (2018). Female-female aggression functions in mate defence in an Asian agamid lizard. Animal behaviour, 135, 215-222. 
Yang, E. J., \& Wilczynski, W. (2003). Interaction effects of corticosterone and experience on aggressive behavior in the green anole lizard. Hormones and Behavior, 44(3), 281-292.

Yedlin, I. N., \& Ferguson, G. W. (1973). Variations in aggressiveness of free-living male and female collared lizards, Crotaphytus collaris. Herpetologica, 268-275.

Zucker, N. (1989). Dorsal darkening and territoriality in a wild population of the tree lizard, Urosaurus ornatus. Journal of Herpetology, 389-398.

Zucker, N., \& Murray, L. (1996). Determinants of dominance in the tree lizard Urosaurus ornatus: the relative importance of mass, previous experience and coloration. Ethology, 102(6), 812-825. 
Table 1: Results of a literature search assessing the prevalence of studies of territorial behavior in the different lizard families. For species for which we found evidence for territoriality in the literature, we denote at least one literature source containing data to suggest that the species is territorial. We also indicate whether the studies of the territoriality in this species were "Descriptive," or observational accounts of natural behavior with no manipulation, or "Experimental," or those in which behavior is noted as part of an experimental manipulation (e.g., staged agonistic interactions, altered distribution of individuals, supplemented feeding). Finally, we indicate whether there are data available regarding the territorial behavior of both sexes. A "+" denotes that available data support territoriality in that sex, a "-“ denotes that available data suggests that territoriality is not present, and a "?" indicates that we did not find data to suggest that the sex in question is territorial or not. Some lizard groups have been the subject of a disproportionately large amount of territorial research (e.g., the genera Anolis and Sceloporus, please see text for more information). This table reflects literature for some of the particularly well studies species of these genera, and we acknowledge that this is not an exhaustive representative of data available for these genera, in particular. (Table appears on the following two pages) 


\begin{tabular}{|c|c|c|c|c|c|c|c|}
\hline Family & Genus & Species & Descriptive & Experimental & $\begin{array}{c}\text { Male } \\
\text { Territoriality }\end{array}$ & $\begin{array}{c}\text { Female } \\
\text { Territoriality }\end{array}$ & Citation \\
\hline Agamidae & Phyrnocephalus & vlangalii & $\mathrm{X}$ & $\mathrm{X}$ & + & + & Qiu et al. 2018, Wu et al. 2018 \\
\hline Anguidae & Abronia & vasconcelossi & $\mathrm{X}$ & & + & + & Formanowicz et al. 1990 \\
\hline Cordylidae & Angolosaurus & skoogi & $\mathrm{X}$ & & + & $?$ & Pietruska 1988 \\
\hline Cordylidae & Cordylus & cordylus & $\mathrm{X}$ & & + & $?$ & Wirminghaus 1990 \\
\hline Helodermatidae & Heloderma & suspectum & $\mathrm{X}$ & & _ & - & Beck 2004 \\
\hline Iguanidae & Amblyrinchus & chistatus & $\mathrm{X}$ & & $?$ & + & Rubenstein and Wikelski 2005 \\
\hline Iguanidae & Anolis & carolinensis & $\mathrm{X}$ & $\mathrm{X}$ & + & + & $\begin{array}{l}\text { Decourcy and Jenssen 1994, } \\
\text { Andrews and Summers } 1996\end{array}$ \\
\hline Iguanidae & Anolis & gundlachi & $\mathrm{X}$ & & + & + & $\begin{array}{l}\text { Hess and Losos 1991, Cook et al. } \\
\text { In Prep }\end{array}$ \\
\hline Iguanidae & Anolis & sagrei & $\mathrm{X}$ & & + & + & $\begin{array}{c}\text { Schoener and Schoener 1982, } \\
\text { Kamath and Losos } 2017\end{array}$ \\
\hline Iguanidae & Anolis & aeneus & $\mathrm{X}$ & $\mathrm{X}$ & + & + & $\begin{array}{c}\text { Stamps 1973, Samps and Tanaka } \\
1981\end{array}$ \\
\hline Iguanidae & Anolis & auratus & $\mathrm{X}$ & $\mathrm{X}$ & + & $?$ & Fleishman 1988 \\
\hline Iguanidae & Cyclura & Cornuta & $\mathrm{X}$ & & + & $?$ & Perez-Buitrago et al. 2010 \\
\hline Iguanidae & Crotaphytus & collaris & $\mathrm{X}$ & & + & + & $\begin{array}{c}\text { Rostker 1983; Sloan and Baird } \\
1999\end{array}$ \\
\hline Lacertidae & Acanthodactylus & bosikanus & $\mathrm{X}$ & $\mathrm{X}$ & + & $?$ & Khannoon and Hardege 2011 \\
\hline Lacertidae & Archaelolacerta & bedriagae & $\mathrm{X}$ & & + & $?$ & Bombi and Vignoli 2004 \\
\hline Lacertidae & Lacerta & horvathi & $\mathrm{X}$ & & + & $?$ & Lapini et al. 2004 \\
\hline Phyrnosomatidae & Sceloporus & jarrovi & $\mathrm{X}$ & & + & + & $\begin{array}{c}\text { Ruby 1978; Woodley and Moore } \\
1999 \mathrm{a \& b}\end{array}$ \\
\hline Phyrnosomatidae & Sceloporus & undulatus & $\mathrm{X}$ & $\mathrm{X}$ & + & + & Haenel et al. 2003 \\
\hline Phyrnosomatidae & Uta & stansburiana & $\mathrm{X}$ & & + & $?$ & Tinkle et al. 1962, Ferguson 1966 \\
\hline Phrynosomatidae & Urosarus & ornatus & & $\mathrm{X}$ & + & + & Zucker 1989, Deslippe et al. 1990 \\
\hline Scincidae & Egernia & whitii & & $\mathrm{X}$ & + & + & Sinn et al. 2008 \\
\hline
\end{tabular}




\begin{tabular}{|c|c|c|c|c|c|c|c|}
\hline Scincidae & Ctenotus & inornatus & X & & $\mathbf{+}$ & $\mathbf{+}$ & Jennings and Thompson 1999 \\
\hline Scincidae & Eulamprus & heatwolei & X & & $\mathbf{+}$ & $\boldsymbol{?}$ & Stapley and Keogh 2004 \\
\hline Teiidae & Ameiva & chrysolaema & X & & - & - & Schell et al. 1993 \\
\hline Varanidae & Varanus & varius & X & & - & - & Guarino 2002 \\
\hline Varanidae & Varanus & bengalensis & X & & $\mathbf{+}$ & $\boldsymbol{?}$ & Auffenberg 1979 \\
\hline Xantusiidae & Xantusia & riversiana & X & & $\mathbf{+}$ & $\mathbf{?}$ & Bezy et al. 1980 \\
\hline
\end{tabular}




\title{
CHAPTER 3
}

\section{Similar behavior, shared mechanism? Evaluating the influence of body condition on territorial behavior in female Anolis gundlachi lizards}

Ellee G. Cook, Deborah Lopez Nieves, and Manuel Leal

\begin{abstract}
Territorial behavior is an important component of social behavior for a variety of taxa. Territoriality determines individuals' spatial distribution and access to resources, and can be exhibited by both males and females. However, much of the research evaluating the mechanisms that mediate territoriality has focused primarily on males. Therefore, it remains unclear whether the same suite of traits mediates territoriality in both sexes, including for species that have served as classical examples in territorial theory. Here, we characterized the space use of free-living adult male and female Anolis gundlachi lizards in Puerto Rico during the summer breeding seasons of 2015 and 2016 to assess whether females exhibit spacing behaviors comparable to those associated with territoriality in male Anolis lizards. We also observed the behavior of these female A. gundlachi to determine whether females exhibit aggressive behavior similar to the territorial behavior that is well described in males. Finally, we tested the hypothesis that variation in body condition explains territory size. We followed marked adult male and female $A$. gundlachi in experimental plots over the course of two to four weeks, and recorded their spatial locations to estimate home range (95\% minimum convex polygons, MCPs) and territory sizes (50\% kernel utilization distributions, KUDs) characteristic of this species. We also conducted focal observations of females to document their behavior patterns and to assess whether females exhibit similar aggressive behaviors in social contexts as observed in males. Our findings suggest that both sexes exhibit territorial space use, and
\end{abstract}


that male A. gundlachi occupy significantly larger home ranges than females [male $\log _{10}$ $\mathrm{MCP}=-0.3656$, mean female $\left.\log _{10} \mathrm{MCP}=-0.0620,95 \% \mathrm{CI}(-0.803,-0.0515)\right] . \mathrm{A}$ similar pattern was observed for territory sizes [male $\log _{10} 50 \%$ KUD $=0.824$, female $\left.\log _{10} 50 \% \mathrm{KUD}=-0.149,95 \% \mathrm{CI}(-1.259,-0.687)\right]$. Territory sizes also varied among members of the same sex (female $\log _{10} 95 \%$ MCP range: $0.0176-9.208, \log _{10} 50 \%$ KUD range: $0.0173-8.058$; male $\log _{10} 95 \%$ MCP range: $0.00878-18.02$, male $\log _{10}$ 50\% KUD range: $0.278-49.8$ ). Females with higher body condition tended to have smaller territories (50\% KUDs) than females of lower condition. However, neither female home range size (95\% MCP) nor metrics of either territory or home range size in males were associated with body condition. Many females in our study exhibited high site fidelity and behaved aggressively toward conspecifics that ventured too close. Taken together, these results indicate that female A. gundlachi exhibit territorial behavior and that territory size is associated with body condition. Future work should consider how additional aspects of behavior, morphology, and physiology may interact with or even eclipse body condition to mediate territory and home range size in male A. gundlachi, and investigate why body size or condition mediates territory size in one sex but not the other.

\section{Introduction}

Territoriality, or the defense of a particular area or resource, is an important component of the social behavior of many species. By influencing how individuals are spatially distributed, territoriality dictates which members of a population are more likely to interact (Gordon 1997). Furthermore, individual variation in the size or shape of territories that individuals defend can also have consequences for fitness, as these factors may determine the quality or quantity of resources available, as well as the potential 
mates that a territory holder can monopolize (Adams 2001, Both and Visser 2008, da Rocha et al. 2018). Such variation is common across taxa, and researchers have identified a variety of behavioral, morphological, and physiological traits that are associated with intraspecific variation in territoriality (e.g., Veiga et al. 2001, Scales et al. 2013, Taylor and Lattanzio 2016).

Historically, the study of territoriality, its evolution, and the mechanisms that mediate it has been focused primarily on males. Nevertheless, there is evidence, much of which is anecdotal, that females of many species also exhibit territorial behavior. These observations have served as the impetus for a growing number of studies evaluating the potential mechanisms mediating territoriality in females (e.g., Mathis 1990, Gill et al. 2007, Ziegelbecker et al. 2018). The overarching framework of this relatively new line of inquiry can be summarized in two non-exclusive hypotheses. First, in species where both sexes are territorial, the same traits that mediate territoriality in males may also mediate territoriality in females. Alternatively, each sex may exhibit a unique set of traits, and different traits may mediate territoriality between the sexes. Sex differences in the traits used to defend territories and mechanisms that modulate territoriality may be particularly likely for species in which traits associated with territoriality are absent or substantially different in one of the sexes, such as weapons and ornaments used in agonistic interactions. Metrics of body size including length, mass, and body condition influence individual differences in territoriality in a variety of taxa, and have the potential to impact territorial behavior similarly across the sexes (e.g., Case 1978, Mathis 1990). For example, territory size is frequently correlated with both size and condition, and it is common to observe that larger individuals defend larger territories than smaller 
conspecifics (Serrano-Meneses et al. 2007, Iossa et al. 2008, Grant and Diaconescu 2016). In both invertebrates and vertebrates, asymmetry in body size can predict the outcome of competitive contests, suggesting that body size may contribute to individuals' behavior during social interactions such as territorial disputes (e.g., Jennions and Backwell 1996, Arnott and Elwood 2009, McGinley et al. 2015). Larger individuals may thus be at an advantage in establishing and maintaining a large territory. Whether the correlations between body size and territoriality are due to energetic demands driving individuals of different sizes to pursue territories of a particular size (reviewed in Grant and Diaconescu 2016), or whether larger individuals or those with higher body condition have a competitive advantage (e.g., Vervaecke et al. 2007, Hunt et al. 2009), intraspecific variation in metrics of body size remain among the most consistent predictors of variation in territory size. This pattern is observed repeatedly across males of a variety of taxa and may also apply to territorial females, but empirical investigations of the predictors of territory size are lacking for females of many species.

Anolis lizards are an excellent group in which to investigate whether similar mechanisms mediate territorial behavior in both sexes. Species in the genus Anolis have been used extensively in the study of territoriality (reviewed in Losos 2009, Kamath and Losos 2017). Strong evidence indicates that males of most species are territorial (e.g., Rand 1964, Leal et al. 1998, Johnson et al. 2010), and, although fewer studies have considered females, anecdotal evidence suggests that females are also territorial. The paradigm of Anolis territorial behavior has traditionally fixated on males and their large territories encompassing females, while relatively little research has focused directly on the behavior and space use of females (but see Andrews 1971, Stamps 1973, Jenssen and 
Nunez 1998). In Anolis, males establish territories during the breeding season that encompass one or more females and defend these territories using ritualized display behaviors and aggressive contests (Rand 1964, Jenssen 1977a, Fleishman 1988). Males may defend territories for different lengths of time, but it is common to find the same individual in the same territory over a period of several weeks (Rand 1964, Philibosian 1975). Variation in territory size has been associated with differences in access to potential mates, suggesting that territory size may influence reproductive success (Trivers 1976, Ruby 1984). Territory size is also positively correlated with body size in males of several species (e.g., Trivers 1976, Schoener and Schoener 1982, Jenssen and Nunez 1998), and larger males are more aggressive and successful in territory defense in some species (e.g., Tokarz 1985, Jenssen et al. 2005). Although the general framework of Anolis territoriality — in which males defend territories that overlap with one or more females using highly stereotyped display and aggressive behaviors - is consistent across species, levels of aggression differ across species and the different Anolis ecomorphs (Losos 1990a). This is exemplified by observations such as particularly high territorial aggression in species classified in the trunk-ground ecomorph, which includes species that are most commonly observed on tree trunks but also visit the ground to forage and engage in social interactions (Losos 1990a, Johnson et al. 2010).

Here, we studied the space use of wild male and female Anolis gundlachi, a species endemic to Puerto Rico. Anolis gundlachi is abundant in the wet, shaded forests of Puerto Rico, and is considered a trunk-ground ecomorph (Rand 1964). Both males and females are typically observed perching on the trunks of trees within approximately one meter above the ground, but also frequent the forest floor to forage and interact with 
conspecifics (Rand 1964, Rodriguez-Robles et al. 2005). Males defend territories using highly stereotyped aggressive behaviors, including frequent displays of the dewlap (throat fan) as well as pushups and head bobs. In some cases, interactions escalate into full contact physical fights. Male territories typically overlap with areas used by one or more females over the course of the breeding season (e.g., Rand 1964, Stamps 1977b, Schoener and Schoener 1982, Johnson et al. 2010). Furthermore, male A. gundlachi exhibit high amounts of territorial aggressive behaviors relative to sympatric species, as has been observed in other species classified in the trunk-ground ecomorph (Losos 1990a, Johnson et al. 2010).

We observed free-living male and female $A$. gundlachi in their natural habitat in Puerto Rico in order to characterize their patterns of space use. In addition, we further evaluated the behavior of females to address the following two hypotheses. First, based on observations of female territorial behavior in other Anolis species, we hypothesized that female A. gundlachi also exhibit territoriality and predicted that females would behaviorally defend areas of exclusive space (e.g., Andrews 1971, Stamps 1973, Jenssen and Nunez 1998). Second, based on previous work with male Anolis, we hypothesized that home range size and territory size would be positively associated with body condition in both males and females (e.g., Trivers 1976, Tokarz 1985, Jenssen et al 2005). The term home range typically describes the total area that an individual uses for activities such as foraging or social interactions. Individuals may not actively exclude other from entering the home range. In contrast, the territory is the area that the individual actively defends against conspecifics (e.g., Burt 1943, Odum and Kuenzler 1955). In many cases, portions of the home ranges of different individuals may overlap, 
but the territories typically do not (reviewed in Powell 2000). To test these hypotheses, we mapped the space use of male and female A. gundlachi to assess their habitat use and distribution and conducted focal observations of marked, adult females to characterize their behavior.

\section{Materials and Methods}

We conducted this study in the Luquillo Tropical Forest near El Verde Field Station in Rio Grande, Puerto Rico, where individuals of A. gundlachi are abundant. Data were collected over two periods, June - July of 2015 and July - August of 2016, which coincide with the breeding season of A. gundlachi (Gorman and Licht 1974). During each of these periods, we established plots in the forest in which we mapped the space use of adult male and female $A$. gundlachi and conducted focal observations of females. In 2015, we established five $10 \mathrm{~m}$ X $10 \mathrm{~m}$ plots that were at least 100 meters apart in the forest, but ultimately collected data in only five of the plots (please see below for further details). In 2016 we used a single $20 \mathrm{~m}$ X 20m plot that did not overlap with any of the plots used in 2015. We used flag tape to mark trees near the boundaries of plots and selected and flagged trees near the center of plots to serve as spatial reference points for use in territory mapping (please see more details below). We chose one reference point for each of the plots used in 2015 and chose two for the larger plot used in 2016, located 5.4 meters apart.

At the start of the study, we spent 3-4 days in the plots attempting to capture every adult $A$. gundlachi observed in the plot. We measured each individual's mass to the nearest tenth of a gram with a Pesola scale and snout-vent length (SVL, a metric of body length) to the nearest millimeter with a handheld ruler, and determined its sex. We also 
assigned each adult a unique, temporary ID using Queen Bee Tags (Bee Works, Ontario, Canada). These tags can last up to four weeks but may fall off sooner if the lizard sheds. We placed two tags on each lizard, one affixed to each shoulder, enabling us to identify the lizard even if one tag fell off prior to the conclusion of the study. Lizards were then released at the site of capture. In 2015, we marked 65 females and 41 males across the six plots, with the following distribution across the plots - 5, 8, 18, 21, and 9 females marked, and 4, 10, 10, 12, and 5 males marked. In 2016, we marked 19 females and 15 males.

We waited 24 hours after the last lizard was marked before collecting data from a plot. Following this period in 2015, each plot was visited for half a day, approximately every other day. We visited plots for four weeks and rotated our visits such that the sequence of plots and time of day varied; morning visits ranged from 0800-1200 hours, and afternoon visits from 1200-1700 hours. In 2016, we visited the plot every day for two weeks to observe lizards between 0800-1700 hours.

Once we arrived at a plot, we spent the first hour visually searching the plot for marked lizards using binoculars from outside the boundaries (hereafter referred to as the "survey period"). When a marked lizard of either sex was observed, we recorded its identity, its approximate location in the plot, and the type of perch it used. At the conclusion of the survey period, we began an "observation period," during which we conducted 20-minute focal behavioral observations of marked female A. gundlachi. We did not conduct focal observations of male behavior in this study. We collected data on the locations of males during the survey period but did not observe their behavior apart from interactions with marked females. We recorded all movement, foraging, and social 
behaviors that females performed during our focal observations, but in particular, noted all the perches lizards visited, the number of times lizards changed perches, and any display or aggressive behaviors that lizards performed (see Table 1 for descriptions of behaviors). If any displays were performed, we visually searched for any other lizards in the area to determine whether displays were directed at another individual or performed in the absence of any apparent receiver (i.e., assertion displays, Fleishman 1988). When we observed interactions between individuals, we noted the sex and species of the nonfocal lizard and recorded the identity of the individual if it was marked.

At the conclusion of each observation period, we recorded the precise location of perches used by marked lizards during both the survey and observation periods. We waited to collect these data until after completing survey and observation periods because our methods require us to enter and move around the plot, which disrupts the natural behavior of the lizards. Spatial location data were collected for all lizards seen during the survey period. For lizards watched during the observation period, we collected location data for the perches used by the lizard at the start and end of the observation, as well as any unique perches used during the observation period (i.e., perches other than the starting perch, hereafter referred to as "unique spatial locations"). All locations were determined by measuring the distance and compass angle from North between the site where the lizard was observed perching and the reference point within the plot (Johnson et al. 2010). For each location, we recorded the distance to the reference point (m) and compass angle relative to the reference point (degrees), within 30 degrees of accuracy. For the 2016 plot with two reference points, we measured the distance from the perch location to the closest of the two reference points. 


\section{Estimating Territory Size}

For each individual with at least five unique locations (female $n=36$, male $=28$ ), we converted locations to Cartesian coordinates and estimated territory size using two methods: minimum convex polygons ("MCP") and kernel utilization distributions (“KUD”). Both were calculated in R (v 3.5.0. R Core Team 2018). We used the package 'adehabitatHR' (Calenge 2015) to calculate 95\% minimum convex polygons, $50 \%$ kernel utilization distributions, and 95\% kernel utilization distributions.

In our study, we considered the 95\% MCPs and 95\% KUDs, which delineate $95 \%$ of the area that the individual visited throughout the entire study, to represent the home range of each individual. We considered the 50\% KUDs, which delineate the area in which an individual is likely to occur in half of all observations, to represent the individuals' putative territories. The data we collected do not enable us to confirm whether individuals actively defend the putative territories calculated by the $50 \%$ KUD estimate. However, we hypothesize that individuals are likely to spend more time and thus be observed more frequently within the territory than in the rest of the home range, and thus we chose to use this metric to represent putative territory sizes (Powell 2000, Anich et al. 2009).

Methods used to calculate territory size —including MCPs and KUDs, in particular - are sensitive to the number of unique locations collected for each individual (Hemson et al. 1995, Seaman and Powell 1996, Mills et al. 2006, Row and BlouinDemers 2006). Although not unprecedented in the territoriality literature, our study relies on relatively low numbers of unique locations to calculate territory size compared to studies incorporating technologies such as GPS. This is a limitation that is typical of 
observational studies at smaller spatial scales like ours (e.g., resolution of less than a meter to a few meters) and is compounded by the ecology of our focal species. Anolis gundlachi, like many other reptiles and amphibians, are often observed using the same perching sites for long periods of time or returning repeatedly to a small collection of sites. Thus, although individuals may be seen many times and researchers may be confident that these sites lie within an individual's territory, only a few unique locations will be recorded, which may introduce error into estimates of territory size (Harris et al. 1990, Powell 2000). Despite these limitations, MCPs remain the most consistently calculated and reported metric of territory size, making them particularly useful for comparisons across taxa and studies, including those of herpetofauna (e.g., Haenel et al. 2003, Bush et al. 2016). We use 95\% MCPs to represent lizard home ranges. Kernel estimates are becoming increasingly prominent within studies of animal space use, and thus we chose to calculate KUDs in our study to make those data available for future use. We did so with the knowledge that these estimates are potentially susceptible to the aforementioned limitations, for which there is currently a lack of consensus with regard to resolving these potential limitations. In summary, we consider 50\% KUDs to represent the putative territories of lizards in our study and the 95\% MCPs to represent the home ranges of individuals.

\section{Characterizing Behavior}

We quantified the number of foraging events, perch changes, bouts of display, and interactions with other lizards that occurred in each observation. For interactions observed between two A. gundlachi, we differentiated between male-female and femalefemale interactions. For female-female interactions, we noted whether behavior 
performed by the focal female escalated from less aggressive displays to more aggressive displays (i.e., escalated aggression).

Ultimately, we report the average rate at which the different behaviors occurred across all the females we observed. We calculated these rates by first calculating the rate of each behavior by the females. For each female, we calculated the total number of times the female performed a particular behavior across all observations and divided this by the total time that the female was observed throughout the study. We then calculated the average rate across all females observed throughout both years. Such calculations decrease the possibility that one individual is overrepresented in our data.

Finally, we were interested in the females' habitat use, and in particular, whether females exhibited a preference for particular perching sites in the areas in which they were active. For each female, we calculated a score of perch preference by dividing the number of unique perches that the female was observed using over the course of the study by the total number of locations collected for that female (i.e., "unique spatial locations"). Scores approaching zero indicate use of fewer unique perches and suggest that females may prefer particular perches, while scores approaching one indicate that females were equally likely to use any perch within her area of activity, suggesting lack of preference.

\section{Calculating Body Condition}

Compared to male A. gundlachi, female A. gundlachi in our study exhibited relatively limited variation in body size (male: range of SVLs $=47-70 \mathrm{~mm}$, range of masses $=2.5-9.0 \mathrm{~g}$; female: range of SVLs $=41-48 \mathrm{~mm}$, range of masses $=1.7-3.4$

g). The methods we used to measure mass and SVL are described above, and are typical 
for studies of lizards, including Anolis. However, they inherently impose restrictions to our ability to assess small differences in size or mass, and we concluded that the measurements of mass to the nearest 0.1 gram and SVL to the nearest millimeter did not fully convey the differences in body condition we observed among females. For example, two females with an SVL of $46 \mathrm{~mm}$ differed in weight by almost a gram (2.2 $\mathrm{g}$ versus 3.1 $\mathrm{g}$ ), which is a substantial amount when considering the range of masses observed among females in our study (data presented above). Thus, although there was limited variation in SVL among females, body condition varied considerably. Body condition can reflect individual health or energy reserves, both of which may influence an individual's behavior and therefore impact territoriality (e.g., Brown 1996, Ullman-Cullere and Foltz 1999). As such, we investigated the potential for body condition to predict territory size in A. gundlachi, and used the residual values of each individual's mass regressed on its SVL to represent body condition as has been done in other studies of Anolis (e.g., Tokarz et al. 1998). Residual values were calculated separately for males and females, with data from both sampling years compiled for each sex for the regression analyses.

The raw data were not normally distributed. We applied several possible data transformations to the continuous variables in our study, and found that log-transforming the data resulted in distributions that more closely resembled normal than either the raw data or other transformations assessed. Thus, we log-transformed the data for all continuous variables in the study, and all values reported for these variables hereafter reflect data after $\log _{10}$ transformation. We used Student's t-Tests to assess whether body condition, home range sizes (95\% MCP and 95\% KUD), territory size (50\% KUD), or the number of unique spatial locations collected for both sexes differed between 2015 and 
2016. All of these variables were significantly different across sampling years for females, but none differed significantly across years for males (Table 2). Thus, we considered females from 2015 and 2016 separately for data analyses but considered all males together. We used linear regressions to determine whether the number of unique locations was predictive of territory or home range size estimates for each female in our study. We first considered data from both years together in a single analysis, and then performed separate regressions for the different sampling years.

Given the observed differences across sampling years, we investigated the potential relationship between body condition and territory size in two ways. First, we used linear regressions to evaluate the potential association between body condition and territory size in the different sampling years separately. Second, we analyzed data collected in both years in a single general linear mixed model (GLMM) using the $\mathrm{R}$ package 'glmmADMB' (Fournier et al. 2012 and Skaug et al. 2013) to assess the influence of body condition on territory size. Territory size was the response variable, body condition was included as a fixed effect, and sampling year was included as a random effect. We performed these analyses separately for 95\% MCPs, 95\% KUDs, and $50 \%$ KUDs in both males and females. Statistics were performed in R (R Core Team v3.5.0) and R Studio (RStudio), and descriptive statistics are reported as means \pm standard deviation unless otherwise specified.

\section{Results}

\section{Female Territorial Behavior}

We conducted behavioral observations of 57 female A. gundlachi $(2015 \mathrm{n}=42$, $2016 \mathrm{n}=15$ ). The number of focal observations conducted for individual females varied 
(range across both years $=1-8$ observations; 2015 mode $=1$ observation; 2016 mode $=5$ observations), as did the total amount of time each female was observed (range across both years $=18-162 \mathrm{~min} ; 2015 \operatorname{mode}=20 \mathrm{~min} ; 2016$ mode $=80 \mathrm{~min}$ ). Throughout observations, females were most often engaged in behaviors such as scanning the environment (i.e., survey posture, remaining still while facing head down on the perch, Stamps 1977a) and moving on or between perches — of the behaviors we recorded, perch changes tended to occur most frequently. Most females displayed at least once over the course of our observations $(81 \%)$, and we observed displays in different social contexts (e.g., advertisement displays, interaction displays, and displays of escalated aggression; Figure 1).

Perch preference varied among females. Three females were only observed on a single perch during the study. These females had perch preference scores ranging from $0.0833-0.167$, suggesting a high preference for a single perch. But most females utilized multiple perches over the course of the study $(n=33, \bar{x}=6.27 \pm 3.16$, range $=2-14$, mode $=2)$. Perch preference scores also varied among these females $(\overline{\mathrm{x}}=0.574 \pm 0.265$, range $=0.182-1$, mode $=1)$. Five females exhibited no preference for a single perch and

were observed on different perches every time they were spotted $($ score $=1)$, with each of these females using a different number of unique perches $(\overline{\mathrm{x}}=8.40 \pm 3.21$, range $=5-$ 13).

\section{Characterizing Space Use}

To elucidate how individual home ranges were distributed throughout the habitat, we plotted the locations used to calculate $95 \%$ MCPs as spatial coordinates on an X-Y plane (Figure 2). The amount of overlap varied among individuals, such that some 
completely overlap with another lizard's home range (see examples in Figure 2A) while others did not overlap at all during our observations (Figure 2B). Most commonly, individuals seemed to overlap with conspecifics in particular regions of the home range, while other regions did not overlap with any other individuals.

Body Condition and Territory Size

There were significant differences in female body condition between the two sampling years. Females measured in 2015 had higher average body condition than females measured in $2016(2015: \mathrm{n}=23, \overline{\mathrm{x}}=0.01820 \pm 0.038,2016: \mathrm{n}=13, \overline{\mathrm{x}}=-0.0322$ $\pm 0.0235, \mathrm{p}<0.001$, Table 2 ). Male body condition did not differ significantly between years $(2015: \mathrm{n}=19, \overline{\mathrm{x}}=0.00053 \pm 0.449,2016 \mathrm{n}=9, \overline{\mathrm{x}}=-0.00222 \pm 0.434, \mathrm{p}=0.972$ Table 2 ).

Male home ranges and territories were larger than those of females (home ranges: mean male $\log _{10} \mathrm{MCP}=-0.36555$, male $\mathrm{n}=28$, mean female $\log _{10} \mathrm{MCP}=-0.06197$, female $\mathrm{n}=36,95 \% \mathrm{CI}(-0.803,-0.0515), \mathrm{p}=0.027$; territories: mean male $\log _{10} 50 \%$ KUD $=0.824$, mean female $\log _{10} 50 \%$ KUD $=-0.149,95 \%$ CI $(-1.259,-0.687), p<$ 0.0001). Both home range and territory size also varied among members of the same sex. Females sampled in 2016 had significantly larger 95\% MCPs, 95\% KUDs, and 50\% KUDs than those sampled in 2015 (2015: 95\% MCP $\bar{x}=-0.316 \pm 0.654,95 \%$ KUD $\bar{x}=$ $0.428 \pm 0.528,50 \%$ KUD $\bar{x}=-0.333 \pm 0.524 ; 2016: 95 \%$ MCP $\bar{x}=0.388 \pm 0.452,95 \%$ KUD $\bar{x}=0.965 \pm 0.425,50 \%$ KUD $\bar{x}=0.175 \pm 0.359$, all $p<0.01$; Table 2). Thus, we considered the data for females in two ways in our analyses to evaluate the influence of year on our results: first we considered females separately by sampling year, and then we considered females pooled from both years. There were no significant differences 
between males in any of the metrics of home range or territory size, and thus males from both years are analyzed together hereafter ( $\mathrm{p}$ values for all comparisons were $>0.40$, data for all males-95\% MCP: $\overline{\mathrm{x}}=0.366-0.149 \pm 0.796 ; 95 \%$ KUD: $\overline{\mathrm{x}}=1.447 \pm 0.588 ; 50 \%$ KUD: $\overline{\mathrm{x}}=0.824 \pm 0.359 ;$ Table 2).

We hypothesized that the differences in territory size observed among lizards sampled in 2015 and 2016 were due to differences in the number of locations recorded for individuals between the two sampling years. Among females sighted more than 4 times for territory size estimates, the number of spatial locations varied (range 5-21), and the average number of locations was higher for females in 2016 than in 2015 (2015: $\overline{\mathrm{x}}=0.948 \pm 0.165,2016: \overline{\mathrm{x}}=1.31 \pm 0.127, \mathrm{p}<0.001$, Table 2). For females in both 2015 and 2016, the number of locations was positively associated with 95\% MCPs (2015: p < $\left.0.0001, \mathrm{~F}_{1,21}=26.11, \mathrm{SE}=0.5707 ; 2016: \mathrm{p}=0.03, \mathrm{~F}_{1,11}=2.9, \mathrm{SE}=0.867\right)$. The number of locations was positively associated with 95\% KUDs for females only in the 2015 sample $\left(\mathrm{p}<0.001, \mathrm{~F}_{1,21}=14.47, \mathrm{SE}=0.5557\right)$. Locations were marginally associated with 95\% KUDs for females in $2016\left(\mathrm{p}=0.06, \mathrm{~F}_{1,11}=4.16, \mathrm{SE}=0.8595\right)$, but were not significantly associated with 50\% KUDs for females in either year ( $\mathrm{p}$ values for both comparisons were $>0.10$ ). Although home range size, territory size, and body condition did not differ significantly for males across the sampling years, the number of locations was also higher for males in 2016 relative to $2015(2015: \overline{\mathrm{x}}=0.921 \pm 0.154,2016: \overline{\mathrm{x}}=$ $1.16 \pm 0.186, \mathrm{p}<0.01$, Table 2 ). The number of locations was positively associated with 95\% MCPs for males sampled in both years $\left(\mathrm{p}<0.001, \mathrm{~F}_{1,26}=26.11, \mathrm{SE}=0.6298\right)$. Locations were not significantly associated with 95\% KUDs or 50\% KUDs of males (p values for both comparisons $>0.10$ ). 
When females sampled in both years were considered together in a generalized linear mixed model with sampling year included as a random effect, body condition was significantly associated with 50\% KUDs $(\mathrm{p}=0.023, \mathrm{SE}=2.149$, Log Likelihood = 27.8127), but not with 95\% MCPs or 95\% KUDs ( $\mathrm{p}$ values for both comparisons > 0.70 ). Male body condition was not significantly associated with any of the metrics of home range or territory size ( $\mathrm{p}$ values for all comparisons $>0.10$ ).

\section{Discussion}

Territoriality occurs in birds, amphibians, reptiles, and mammals, and is closely integrated with the life-history and ecology of these organisms. By impacting how individuals are distributed across landscapes, territorial behavior also determines which individuals have access to resources, and which members of the population interact (Brown and Orians 1970, Stamps 1994). As such, detailed understanding of territorial behavior can help to explain other aspects of a species' ecology, such as population dynamics, mating systems, and intraspecific variation in fitness (Emlen and Oring 1977, Sokolovska et al. 2000, Lopez-Sepulcre and Kokko 2005).

Our findings suggest that both male and female A. gundlachi occupy exclusive space and demonstrate that females, like males, exhibit territorial behavior typical of many Anolis species (e.g., Evans 1938, Rand 1964, Philibosian 1975, Johnson et al. 2010). The majority of female A. gundlachi exhibited high fidelity to a particular area within our study site, and the sizes of home ranges and putative territories varied considerably in size and shape (Figure 2). Female home ranges sometimes overlapped with those of other females and often overlapped with the home range of at least one

male (Figure 2). Furthermore, some female A. gundlachi behaved aggressively toward 
conspecifics in similar contexts as territorial males do (Table 1, Figure 2). When considered separately across sampling years, female body condition was not positively associated with any metric of territory or home range size. However, when the random effect of sampling year was taken into effect, 50\% KUDs (i.e., putative territory sizes) were negatively associated with female body condition (Figure 4B). The 95\% MCPs (i.e., home range sizes) were not associated with body condition (Figure 4A). Male body condition was not significantly associated with territory size or either metric of home range size (Figure 4C \& D).

Aggression is an important component of territoriality, as individuals use behaviors ranging from displays to physical fights to establish and maintain territories (Bush and Simberloff 2018, Stamps 2018). Male Anolis lizards exhibit highly ritualized territorial aggression (Jenssen 1977a, Ortiz and Jenssen 1982, Fleishman 1988), and here we found that female A. gundlachi exhibit a comparable repertoire of behaviors. Eighty one percent of females displayed at least once over the course of our observations, suggesting that displays and other territorial behaviors are a frequent component of their social behavior (Figure 1). Female A. gundlachi were observed performing push-up displays when no conspecific was visible to us in the immediate vicinity, a behavior that is hypothesized to function as an advertisement of territory ownership in male Anolis (e.g., "advertisement" or "assertion" displays, Table 1; Stamps 1977a, Fleishman 1988). Sixteen females (28\%) exhibited escalated aggression during an interaction with a conspecific (Figure 1), demonstrating that females can and will behave aggressively toward conspecifics in a similar capacity as is observed in males. Similar behavior patterns have been reported for females of other anoles, suggesting that female 
territoriality may be common across the genus, as it is in males (Summers and Andrews 1996, Jenssen et al. 2000).

Although the repertoire of behaviors was consistent, females performed these behaviors at lower rates than are typically reported for males, a pattern observed in several other Anolis species (Losos 1990b, Johnson and Wade 2010). Similar sex differences in territorial behavior are also observed in other groups, such as differences among territorial male and female birds in the structure of songs or frequency of singing (Levin and Wingfield 1992, Demko and Mennill 2018). Although such observations lend support to the hypothesis that females generally engage in agonistic interactions less frequently than males, we also hypothesize that the time of year in which we conducted our study contributed to the low rates of escalated aggression we observed. The breeding season of A. gundlachi lasts several months (approximately April - September, Rand 1964). If females establish territories at the start of the breeding season as males do, it is possible that, by June or July when our study took place, females have already settled the majority of their territorial disputes. As a result, females may have very few escalated agonistic interactions with neighboring females they interact with most frequently (i.e., the dear enemy phenomenon, Qualls and Jaeger 1991, Husak and Fox 2003) and only exhibit heightened aggression in the event of encountering an unfamiliar conspecific new to the study site. If this is the case, we would expect to observe relatively little escalated aggression among females at this time of the year, as we observed in this study. Future work focused at different point in the breeding season will elucidate whether female aggression changes over time. 
High site fidelity is commonly associated with territorial behavior across a wide range of taxa (Switzer 1993). This is likely because relocating can be costly, both in terms of energetic requirements and factors such as the loss of familiarity with a particular area and conspecific neighbors (e.g., Switzer 1997, Hoffman et al. 2006, McDougall and Kramer 2007). We were able to observe most of the marked females within our plots for several weeks, and in many cases, females were observed in the same general area throughout the study period. Thus, females generally exhibited a relatively high level of site fidelity. Within these areas, females differed in their preferences for particular perches. Some were observed on the same perch throughout the study, while others used many perches. In contrast, we also observed some females with low sitefidelity - these individuals were observed only once or a handful of times. One hypothesis to explain this observation is that multiple behavioral phenotypes may be present in this population and that some females are transient and/or non-territorial. Studies in a variety of species, but primarily in fish and birds, have demonstrated the existence of multiple territorial phenotypes within populations - in particular, studies have described "floaters," or non-territorial individuals that are either supplanted from their territories by competitors, or do not engage in territoriality at all (e.g., birds: Winker 1998, Tobler and Smith 2004, Penteriani et al. 2011; fish: Iguchi and Hino 1996, Oliveira et al. 2005, Awata et al. 2012; lizards: Morrison et al. 2002). Our observation that some females are observed in many different locations or only once over the course of the study suggests that some female A. gundlachi may be floaters. Alternatively, these females may have been expelled from formerly held territories following a territorial dispute, a phenomenon that also occurs in males (Tokarz et al. 1998, Reedy 2017). Future 
studies should evaluate these possibilities, and more generally, further investigate how and when females establish territories.

We found that females with higher body condition had smaller territories than females with lower condition (Figure 4). This finding contradicts our prediction that females of higher condition would maintain larger territories than females of lower condition. More generally, this finding goes against the common trend that territory size is associated with metrics of body size in anoles (Trivers 1976, Schoener and Schoener 1982). We are proposing two non-mutually exclusive hypotheses to explain the negative association between body condition and territory size in female A. gundlachi. First, it is possible that the size of the territory an individual defends is not the only factor of value to females. A common assumption in studies of animal space use is that individuals ought to maintain the largest territory they can effectively defend, as larger territories may provide access to more resources. However, other attributes of territories, such as their location, shape, or the types of resources they contain, may also influence the value of a territory (e.g., Hixon 1980, Lanyon and Thompson 1986, Stamps 1987). Differences between the sexes in the potential benefits of territory size may be driving the sexes to pursue territories with different attributes, and thus contribute to the observation that body size is correlated with territory size in some male Anolis lizards, but not in females. For males, the primary function of territories is presumed to be securing mating opportunities — during the breeding season, males defend territories that overlap the territories of one or more females (Schoener and Schoener 1982, Jenssen et al. 1995). In this case, we would predict that males aim to defend as large a territory as possible so as to overlap with many females. In contrast, females are primarily hypothesized to defend 
territories in order to secure access to food (Stamps 1973). Although larger territories could provide more food resources, it is also possible that females seek territories that simply provide sufficient resources, rather than as large a territory as possible. Perhaps it is even preferable to have a relatively small but resource-rich territory, rather than a larger one that requires more time and energy to patrol and defend (Adams 2001). In this case, the most competitively successful females might have smaller territories than less successful females.

Our second hypothesis to explain why females with higher body condition have small territories is that predation risk constrains territory size (Eason and Stamps 1992, Candolin and Voigt 2001). Female A. gundlachi are smaller than males, and because small size tends to increase the diversity of potential predators, females may face higher risk of predation than males (Scott et al. 1976, Stamps 1977a, Lafferty and Kuris 2002, Woodward et al. 2005). If this is the case, the cost of patrolling a large territory and potentially increasing exposure to predators may be higher for females than males and thus represent an addition limitation to the size of a territory that a female can maintain. Additional work investigating the factors that determine optimal territory size in female A. gundlachi, as well as factors that explain differences in territory size among the sexes, may lend answers to these open questions.

We were surprised to find that body condition was not a significant predictor of territory size in male A. gundlachi, or home range size in either sex in this study. We predicted that territory and home range size would be positively associated with body condition based on work in other taxa supporting two non-mutually exclusive hypotheses to explain why body condition is associated with space use. The first hypothesis posits 
that the association is the result of energetics, and that individuals with high body condition have large territories or home ranges because those large areas provide access to the resources needed to maintain high body condition (McNab 1963). The second hypothesis suggests that individuals with high body condition maintain larger territories and ranges than individuals with lower condition because condition confers some competitive advantage (Arnott and Elwood 2009). If condition reflects health, energy stores, or other physiological traits that impact competitive ability and large territories are valuable, individuals with high body condition may be more likely to have large, desirable areas than individuals with lower condition (Arnott and Elwood 2009, Grant and Diaconescu 2016). However, we found no association between condition and home range size. One possible explanation for this is that individuals may defend territories that provide sufficient resources, and therefore do not need to venture much further beyond their territory boundaries into the undefended home range in search of resources. Studies of other animal groups have also identified no association between condition and home range or territory size. For example, no correlation was observed between either body condition or size and territory size in the collard lizard (Crotaphytus collaris, Lappin and Husak 2005) or a reef fish (Parma victorie, Norman and Jones 1984). Additionally, traits other than condition have also been shown to be important predictors of territoriality - a variety of behavioral (e.g., winner effects), morphological (e.g., weapons), and physiological (e.g., hormones) traits have been associated with territoriality, and may interact with or even eclipse body size or condition as determinants of territory or home range size (Tokarz 1995, Kelly 2008). Future research evaluating how males and females establish their home ranges and territories, in combination with further studies of 
territorial dynamics in female Anolis lizards, may reveal how other traits mediate behaviors associated with space use, and whether the same mechanisms mediate space use and behavior across the sexes.

Although the overall patterns remained consistent throughout our study, we did observe significant differences in our data across sampling years-female body condition, home range size, and territory size all differed between 2015 and 2016 (table 2). We suspect that the differences in body condition are the result of random variation in the females sampled across the years, rather than any biologically relevant differences between the populations sampled. Furthermore, we hypothesize that the differences in territory size are the result of slight differences in study design rather than differences in behavior or habitat across the two years. Our focus on a single plot in 2016 enabled us to observe the same individuals more frequently than in 2015 , in which we observed individuals in five different plots. We hypothesize that this difference resulted in higher numbers of unique spatial locations collected for individuals in 2016 relative to individuals from 2015, which in turn may have impacted estimates of territory size, as both of the methods we used are known to be sensitive to this factor (see additional information in methods, Figure 3 A \& B). Another factor that could potentially impact territory size is the density of individuals occurring in a particular area. Although there were differences in the number of lizards marked in each of the plots we used, those differences are unlikely to result from major differences in lizard density across our years or sites. The area of forest that we worked in is relatively uniform in habitat and prime habitat for A. gundlachi (Reagan 1992, Rodriguez-Robles et al. 2005), and we established plots at sites in which we readily observed them. Thus, although there may have been 
slight differences between the plots (including the difference in size between plots used 2015 and 2016), we hypothesize that variation in the number of lizards marked in each of the plots was due to our ability to capture and mark females during the time we set to established our plots, and the length of time that females retained their tags rather than substantial differences in lizard density. Nonetheless, it is possible that differences in density may have impacted our data collection, and another interesting route for future study would be to explore how population density impacts territorial dynamics in Anolis gunldachi.

In summary, we observed that female Anolis gundlachi lizards exhibit patterns of space use and behavior that are consistent with the territorial behavior of male Anolis lizards and, more generally, the territoriality of other groups such as fish and birds (e.g., Matsumo and Kohda 2004, Illes and Yunes-Jimenez 2008). Male A. gundlachi occupied areas of exclusive space that typically overlapped with one or more females, which is consistent with descriptions of male territoriality in other Anolis species. Interestingly, female territory size was the only metric of space use that was associated with body condition in our study. It is possible that suites of traits or attributes of the habitat other than the ones we predicted actually mediate space use in A. gundladhi. Future studies investigating how and why male and female A. gundlachi establish the territories they do, as well as the potential implications for fitness, may help to reveal the intrinsic and extrinsic factors that mediate territoriality in A. gundlachi in combination with or independent of body condition.

To conclude, further investigations of the territorial and other behaviors of female Anolis lizards may provide additional insight into interesting patterns that cannot be 
explained by the current, general understanding of territorial behavior in these species.

For example, females of many Anolis species are generally presumed to exhibit high site fidelity, but produce offspring sired by males other than the one in whose territory they reside (Tokarz et al. 1998, Calsbeek et al. 2007). This pattern is being observed in other taxa, such as the widespread finding in territorial birds that females mate multiply (Akcay and Roughgarden 2007, Griffith et al. 2008). Such observations warrant more in-depth investigations of female behavior, and may require researchers to revisit our understanding of behaviors like territoriality that remain best understood from the perspective of males. Finally, there is a growing interest in female-female competition, and the roles it may play in processes such as sexual selection (Clutton-Brock 2007, Clutton-Brock and Huchard 2013). Demonstrations that aggressive behaviors like territoriality serve adaptive functions in females, in combination with the knowledge that female reproductive success may be more variable than classically considered, have stimulated exciting work investigating female aggression and the mechanisms that mediate it (e.g., Rosvall 2013, Stockley and Campbell 2013). Such studies may help to elucidate whether shared mechanisms have driven the evolution of aggressive behaviors such as territoriality in both males and females, or whether similar behaviors are governed by distinct forces across the sexes.

\section{Acknowledgements}

We thank D. Lopez-Nieves and K. Patterson for their assistance in data collection, and the staff of El Verde Field Station for access to facilities and assistance. We thank the Departmento de Recursos Naturales y Ambientales, Puerto Rico, for permitting for this work. We thank J. Burkhart, A. Messerman, S. Michael, and L. Storks for comments on 
earlier versions of this manuscript, J. Burkhart for his assistance with $\mathrm{R}$ and data analysis, and J. Bush for providing her R code to generate polygon figures. This work was conducted in compliance with protocols approved by the ACUC of the University of Missouri. This work was supported by funding from the University of Missouri, National Science Foundation, Animal Behavior Society, and Sigma-Xi Society for Research. 


\section{References}

Akçay, E., \& Roughgarden, J. (2007). Extra-pair paternity in birds: review of the genetic benefits. Evolutionary Ecology Research, 9(5), 855.

Adams, E. S. (2001). Approaches to the study of territory size and shape. Annual Review of Ecology and Systematics, 32(1), 277-303.

Andrews, R. M. (1971). Structural habitat and time budget of a tropical Anolis lizard. Ecology, 52(2), 262-270.

Anich, N. M., Benson, T. J., \& Bednarz, J. C. (2009). Estimating territory and homerange sizes: do singing locations alone provide an accurate estimate of space use?. The Auk, 126(3), 626-634.

Arnott, G., \& Elwood, R. W. (2009). Assessment of fighting ability in animal contests. Animal Behaviour, 77(5), 991-1004.

Awata, S., Tsuruta, T., Abe, S. I., Tamaki, Y., \& Iguchi, K. I. (2012). Feeding territory and variations in behavioural modes of algae - grazing fish Plecoglossus altivelis ryukyuensis (Ryukyu-ayu) in subtropical island streams. Ecology of Freshwater Fish, 21(1), 1-11.

Both, C., \& Visser, M. E. (2003). Density dependence, territoriality, and divisibility of resources: from optimality models to population processes. The American Naturalist, 161(2), 326-336.

Brown M.E. (1996) Assessing Body Condition in Birds. In: Nolan V., Ketterson E.D. (eds) Current Ornithology, 13, 67-135. Springer, Boston, MA.

Brown, J. L., \& Orians, G. H. (1970). Spacing patterns in mobile animals. Annual Review of Ecology and Systematics, 1(1), 239-262.

Burt, W. H. (1943). Territoriality and home range concepts as applied to mammals. Journal of Mammalogy, 24(3), 346-352.

Bush, J. M., Quinn, M. M., Balreira, E. C., \& Johnson, M. A. (2016). How do lizards determine dominance? Applying ranking algorithms to animal social behaviour. Animal behaviour, 118, 65-74.

Bush, J. M., \& Simberloff, D. (2018). A case for anole territoriality. Behavioral Ecology and Sociobiology, 72(7), 111.

Calenge, C. (2006) The package adehabitat for the R software: a tool for the analysis of space and habitat use by animals. Ecological Modelling, 197, 516-519 
Calsbeek, R., Bonneaud, C., Prabhu, S., Manoukis, N., \& Smith, T. B. (2007). Multiple paternity and sperm storage lead to increased genetic diversity in Anolis lizards. Evolutionary Ecology Research, 9(3), 495-503.

Candolin, U., \& Voigt, H. R. (2001). Correlation between male size and territory quality: consequence of male competition or predation susceptibility?. Oikos, 95(2), 225-230.

Case, T. J. (1978). A general explanation for insular body size trends in terrestrial vertebrates. Ecology, 59(1), 1-18.

Clutton-Brock, T. (2007). Sexual selection in males and females. Science, 318(5858), 1882-1885.

Clutton-Brock, T. H., \& Huchard, E. (2013). Social competition and selection in males and females. Philosophical Transactions of the Royal Society B: Biological Sciences, 368(1631), 20130074.

da Rocha, S. M. C., Lima, A. P., \& Kaefer, I. L. (2018). Territory size as a main driver of male-mating success in an Amazonian nurse frog (Allobates paleovarzensis, Dendrobatoidea). Acta Ethologica, 21(1), 51-57.

Demko, A. D., \& Mennill, D. J. (2018). Nest description and nesting behavior of the Rufous-capped Warbler (Basileuterus rufifrons). Ornitología Neotropical, 29(1), 167-174.

Eason, P. K., \& Stamps, J. A. (1992). The effect of visibility on territory size and shape. Behavioral Ecology, 3(2), 166-172.

Emlen, S. T., \& Oring, L. W. (1977). Ecology, sexual selection, and the evolution of mating systems. Science, 197(4300), 215-223.

Evans, L. T. (1938). Cuban field studies on territoriality of the lizard Anolis sagrei. Journal of Comparative Psychology, 25(1), 97.

Fleishman, L. J. (1988). The social behavior of Anolis auratus, a grass anole from Panama. Journal of herpetology, 13-23.

Fournier, D. A., Skaug, H. J., Ancheta, J. , Ianelli, J. Magnusson, A., Maunder, M., Nielson, A., Siebert, J. (2012). AD Model Builder: using automatic differentiation for statistical inference of highly parameterized complex nonlinerar models. Optimal Methods Software. 27, 233-249.

Gill, S. A., Alfson, E. D., \& Hau, M. (2007). Context matters: female aggression and testosterone in a year-round territorial neotropical songbird (Thryothorus 
leucotis). Proceedings of the Royal Society B: Biological Sciences, 274(1622), 2187-2194.

Gordon, D. M. (1997). The population consequences of territorial behavior. Trends in Ecology and Evolution, 12(2), 63-66.

Gorman, G. C., \& Licht, P. (1974). Seasonality in ovarian cycles among tropical Anolis lizards. Ecology, 55(2), 360-369.

Grant, J. W., \& Diaconescu, M. I. (2016). The allometry of ephemeral territory size: insights into interspecific patterns of space use. Animal Behaviour, 111, 79-83.

Griffith, S. C., Holleley, C. E., Mariette, M. M., Pryke, S. R., \& Svedin, N. (2010). Low level of extrapair parentage in wild zebra finches. Animal Behaviour, 79(2), 261-264.

Haenel, G. J., Smith, L. C., \& John-Alder, H. B. (2003). Home-range analysis in Sceloporus undulatus (eastern fence lizard). I. Spacing patterns and the context of territorial behavior. Copeia, 2003(1), 99-112.

Harris, S., Cresswell, W. J., Forde, P. G., Trewhella, W. J., Woollard, T., \& Wray, S. (1990). Home-range analysis using radio-tracking data-a review of problems and techniques particularly as applied to the study of mammals. Mammal Review, 20(2-3), 97-123.

Hemson, G., Johnson, P., South, A., Kenward, R., Ripley, R., \& MacDonald, D. (2005). Are kernels the mustard? Data from global positioning system (GPS) collars suggests problems for kernel home-range analyses with least-squares cross validation. Journal of Animal Ecology, 74(3), 455-463.

Hixon, M. A. (1980). Food production and competitor density as the determinants of feeding territory size. The American Naturalist, 115(4), 510-530.

Hoffman, A. L., Olden, J. D., Monroe, J. B., LeRoy Poff, N., Wellnitz, T., \& Wiens, J. A. (2006). Current velocity and habitat patchiness shape stream herbivore movement. Oikos, 115(2), 358-368.

Hunt, J., Breuker, C. J., Sadowski, J. A., \& Moore, A. J. (2009). Male-male competition, female mate choice and their interaction: determining total sexual selection. Journal of Evolutionary Biology, 22(1), 13-26.

Husak, J. F., \& Fox, S. F. (2003). Spatial organization and the dear enemy phenomenon in adult female collared lizards, Crotaphytus collaris. Journal of Herpetology, 211-215. 
Iguchi, K. I., \& Hino, T. (1996). Effect of competitor abundance on feeding territoriality in a grazing fish, the ayu Plecoglossus altivelis. Ecological Research, 11(2), 165-173.

Illes, A. E., \& Yunes-Jimenez, L. (2008). A female songbird out-sings male conspecifics during simulated territorial intrusions. Proceedings of the Royal Society B: Biological Sciences, 276(1658), 981-986.

Iossa, G., Soulsbury, C. D., Baker, P. J., Edwards, K. J., \& Harris, S. (2008). Behavioral changes associated with a population density decline in the facultatively social red fox. Behavioral Ecology, 20(2), 385-395.

Jennions, M. D., \& Backwell, P. R. (1996). Residency and size affect fight duration and outcome in the fiddler crab Uca annulipes. Biological Journal of the Linnean Society, 57(4), 293- 306.

Jenssen, T. A. (1977a). Evolution of anoline lizard display behavior. American Zoologist, $17(1), 203-215$.

Jenssen, T. A. (1977b). Morphological, behavioral and electrophoretic evidence of hybridization between the lizards, Anolis grahami and Anolis lineatopus neckeri, on Jamaica. Copeia, 270-276.

Jenssen, T. A., Greenberg, N., \& Hovde, K. A. (1995). Behavioral profile of free-ranging male lizards, Anolis carolinensis, across breeding and post-breeding seasons. Herpetological Monographs, 41-62.

Jenssen, T. A., \& Nunez, S. C. (1998). Spatial and breeding relationships of the lizard, Anolis carolinensis: evidence of intrasexual selection. Behaviour, 981-1003.

Jenssen, T. A., Orrell, K. S., \& Lovern, M. B. (2000). Sexual dimorphisms in aggressive signal structure and use by a polygynous lizard, Anolis carolinensis. Copeia, $2000(1), 140-149$.

Jenssen, T. A., Decourcy, K. R., \& Congdon, J. D. (2005). Assessment in contests of male lizards (Anolis carolinensis): how should smaller males respond when size matters?. Animal Behaviour, 69(6), 1325-1336.

Johnson, M. A., \& Wade, J. (2010). Behavioural display systems across nine Anolis lizard species: sexual dimorphisms in structure and function. Proceedings of the Royal Society B: Biological Sciences, 277(1688), 1711-1719.

Johnson, M. A., Revell, L. J., \& Losos, J. B. (2010). Behavioral convergence and adaptive radiation: effects of habitat use on territorial behavior in Anolis lizards. Evolution, 64(4), 1151-1159. 
Kamath, A., \& Losos, J. (2017). The erratic and contingent progression of research on territoriality: a case study. Behavioral Ecology and Sociobiology, 71(6), 89.

Kelly, C. D. (2008). The interrelationships between resource-holding potential, resourcevalue and reproductive success in territorial males: How much variation can we explain?. Behavioral Ecology and Sociobiology, 62(6), 855-871.

Lafferty, K. D., \& Kuris, A. M. (2002). Trophic strategies, animal diversity and body size. Trends in Ecology \& Evolution, 17(11), 507-513.

Lappin, A. K., \& Husak, J. F. (2005). Weapon performance, not size, determines mating success and potential reproductive output in the collared lizard (Crotaphytus collaris). The American Naturalist, 166(3), 426-436.

Lanyon, S. M., \& Thompson, C. F. (1986). Site fidelity and habitat quality as determinants of settlement pattern in male painted buntings. The Condor, $88(2)$, 206-210.

Leal, M., Rodríguez-Robles, J. A., \& Losos, J. B. (1998). An experimental study of interspecific interactions between two Puerto Rican Anolis lizards. Oecologia, $117(1-2), 273-278$.

Levin, R. N., \& Wingfield, J. C. (1992). The hormonal control of territorial aggression in tropical birds. Ornis Scandinavica, 284-291.

López-Sepulcre, A., \& Kokko, H. (2005). Territorial defense, territory size, and population regulation. The American Naturalist, 166(3), 317-329.

Losos, J. B. (1990 a). Ecomorphology, performance capability, and scaling of West Indian Anolis lizards: an evolutionary analysis. Ecological Monographs, 60(3), 369-388.

Losos, J. B. (1990 b). The evolution of form and function: morphology and locomotor performance in West Indian Anolis lizards. Evolution, 44(5), 1189-1203.

Losos, J. B. (2009). Lizards in an Evolutionary Tree: Ecology and Adaptive Radiation of Anoles. Berkeley, California: University of California Press.

Mathis, A. (1990). Territorial salamanders assess sexual and competitive information using chemical signals. Animal Behaviour, 40(5), 953-962.

Matsumoto, K., \& Kohda, M. (2004). Territorial defense against various food competitors in the Tanganyikan benthophagous cichlid Neolamprologus tetracanthus. Ichthyological Research, 51(4), 354-359. 
McDougall, P. T., \& Kramer, D. L. (2006). Short-term behavioral consequences of territory relocation in a Caribbean damselfish, Stegastes diencaeus. Behavioral Ecology, 18(1), 53-61.

McGinley, M.J., Vinck, M., Reimer, J., Batista-Brito, R., Zagha, E., Cadwell, C.R., Tolias, A.S., Cardin, J.A. \& McCormick, D.A. (2015). Waking state: rapid variations modulate neural and behavioral responses. Neuron, 87(6), 1143-1161.

Mills, K. J., Patterson, B. R., \& Murray, D. L. (2006). Effects of variable sampling frequencies on GPS transmitter efficiency and estimated wolf home range size and movement distance. Wildlife Society Bulletin, 34(5), 1463-1469.

Morrison, S. F., Scott Keogh, J., \& Scott, I. A. W. (2002). Molecular determination of paternity in a natural population of the multiply mating polygynous lizard Eulamprus heatwolei. Molecular Ecology, 11(3), 535-545.

Norman, M. D., \& Jones, G. P. (1984). Determinants of territory size in the pomacentrid reef fish, Parma victoriae. Oecologia, 61(1), 60-69.

Odum, E. P., \& Kuenzler, E. J. (1955). Measurement of territory and home range size in birds. The Auk, 72(2), 128-137.

Oliveira, R. F., Ros, A. F., \& Gonçalves, D. M. (2005). Intra-sexual variation in male reproduction in teleost fish: a comparative approach. Hormones and Behavior, $48(4), 430-439$.

Ortiz, P. R., \& Jenssen, T. A. (1982). Interspecific aggression between lizard competitors, Anolis cooki and Anolis cristatellus. Zeitschrift für Tierpsychologie, 60(3), 227238.

Penteriani, V., Ferrer, M., \& Delgado, M. D. M. (2011). Floater strategies and dynamics in birds, and their importance in conservation biology: towards an understanding of nonbreeders in avian populations. Animal Conservation, 14(3), 233-241.

Philibosian, R. (1975). Territorial behavior and population regulation in the lizards, Anolis acutus and A. cristatellus. Copeia, 428-444.

Powell, R. A. (2000). Animal home ranges and territories and home range estimators. Research Techniques in Animal Ecology: Controversies and Consequences, 442, 65-110.

Qualls, C. P., \& Jaeger, R. G. (1991). Dear enemy recognition in Anolis carolinenis. Journal of Herpetology, 25(3), 361-363. 
R Core Team (2018). R: A language and environment for statistical computing. R Founda tion for Statistical Computing, Vienna, Austria. URL https://www.R-project.org /.

Rand, A. S. (1964). Ecological distribution in anoline lizards of Puerto Rico. Ecology, 45(4), 745-752.

Reagan, D. P. (1992). Congeneric species distribution and abundance in a threedimensional habitat: the rain forest anoles of Puerto Rico. Copeia, 392-403.

Reedy, A. M., Pope, B. D., Kiriazis, N. M., Giordano, C. L., Sams, C. L., Warner, D. A., $\&$ Cox, R. M. (2017). Female anoles display less but attack more quickly than males in response to territorial intrusions. Behavioral Ecology, 28(5), 13231328.

Rodríguez-Robles, J. A., Leal, M., \& Losos, J. B. (2005). Habitat selection by the Puerto Rican yellow-chinned anole, Anolis gundlachi. Canadian journal of zoology, 83(7), 983-988.

Rosvall, K. A. (2013). Life history trade-offs and behavioral sensitivity to testosterone: an experimental test when female aggression and maternal care co-occur. PLoS One, 8(1), e54120.

Row, J. R., \& Blouin-Demers, G. (2006). Kernels are not accurate estimators of homerange size for herpetofauna. Copeia, 2006(4), 797-802.

RStudio Team (2016). RStudio: Integrated Development for R. RStudio, Inc., Boston, M A. URL http://www.rstudio.com/.

Ruby, D. E. (1984). Male breeding success and differential access to females in Anolis carolinensis. Herpetologica, 272-280.

Scales, J., Hyman, J., \& Hughes, M. (2013). Fortune favours the aggressive: territory quality and behavioural syndromes in song sparrows, Melospiza melodia. Animal Behaviour, 85(2), 441-451.

Schoener, T. W., \& Schoener, A. (1982). Intraspecific variation in home-range size in some Anolis lizards. Ecology, 63(3), 809-823.

Scott Jr, N. J., Wilson, D. E., Jones, C., \& Andrews, R. M. (1976). The choice of perch dimensions by lizards of the genus Anolis (Reptilia, Lacertilia, Iguanidae). Journal of Herpetology, 75-84.

Seaman, D. E., \& Powell, R. A. (1996). An evaluation of the accuracy of kernel density estimators for home range analysis. Ecology, 77(7), 2075-2085. 
Serrano-Meneses, M. A., Córdoba-Aguilar, A., Méndez, V., Layen, S. J., \& Székely, T. (2007). Sexual size dimorphism in the American rubyspot: male body size predicts male competition and mating success. Animal Behaviour, 73(6), 987997.

Skaug, H., Fournier, D., Bolker, B., Magnusson, A., Nielson, A. (2016). Generalized Linear Mixed Models using “AD Model Builder.” R. Package Version 0.8.5

Smith, J. M., \& Parker, G. A. (1976). The logic of asymmetric contests. Animal behaviour, 24(1), 159-175.

Sokolovska, N., Rowe, L., \& Johansson, F. (2000). Fitness and body size in mature odonates. Ecological Entomology, 25(2), 239-248.

Stamps, J. A. (1973). Displays and social organization in female Anolis aeneus. Copeia, 264-272.

Stamps, J. A. (1977 a). The function of the survey posture in Anolis lizards. Copeia, 1977(4), 756-758.

Stamps, J. A. (1977 b). Rainfall, moisture and dry season growth rates in Anolis aeneus. Copeia, 415-419.

Stamps, J. A. (1983). Growth costs of territorial overlap: experiments with juvenile lizards (Anolis aeneus). Behavioral Ecology and Sociobiology, 15(2), 115-119.

Stamps, J. A. (1987). Conspecifics as cues to territory quality: a preference of juvenile lizards (Anolis aeneus) for previously used territories. The American Naturalist, 129(5), 629-642.

Stamps, J. A. (1994). Territorial behavior: testing the assumptions. Advances in the Study of Behavior, 23(173), 232.

Stamps, J. A. (2018). Polygynandrous anoles and the myth of the passive female. Behavioral Ecology and Sociobiology, 72(7), 107.

Stockley, P., \& Campbell, A. (2013). Female competition and aggression: interdisciplinary perspectives. Philosophical Transactions of the Royal Society B: Biological Sciences. 368, 20130073.

Summers, C. H., \& Andrews, T. J. (1996). Aggression, and the acquisition and function of social dominance in female Anolis carolinensis. Behaviour, 133(15-16), 1265-1279.

Switzer, P. V. (1993). Site fidelity in predictable and unpredictable habitats. Evolutionary Ecology, 7(6), 533-555. 
Switzer, P. V. (1997). Past reproductive success affects future habitat selection. Behavioral Ecology and Sociobiology, 40(5), 307-312.

Taylor, J. N., \& Lattanzio, M. S. (2016). Boldness, dominance, and territoriality in the color polymorphic tree lizard, Urosaurus ornatus. Ethology, 122(11), 892-901.

Tobler, M., \& Smith, H. G. (2004). Specific floater home ranges and prospective behaviour in the European starling, Sturnus vulgaris. Naturwissenschaften, 91(2), 85-89.

Tokarz, R. R. (1985). Body size as a factor determining dominance in staged agonistic encounters between male brown anoles (Anolis sagrei). Animal Behaviour, 33(3), 746-753.

Tokarz, R. R. (1995). Importance of androgens in male territorial acquisition in the lizard Anolis sagrei: an experimental test. Animal Behaviour, 49(3), 661-669.

Tokarz, R. R., McMann, S., Seitz, L., \& John-Alder, H. (1998). Plasma corticosterone and testosterone levels during the annual reproductive cycle of male brown anoles (Anolis sagrei). Physiological Zoology, 71(2), 139-146.

Trivers, R. L. (1976). Sexual selection and resource-accruing abilities in Anolis garmani. Evolution, 30(2), 253-269.

Ullman-Culleré, M. H., \& Foltz, C. J. (1999). Body condition scoring: a rapid and accurate method for assessing health status in mice. Comparative Medicine, 49(3), 319-323.

Veiga, J. P., Moreno, J., Cordero, P. J., and Mínguez, E. (2001). Territory size and polygyny in the spotless starling: resource-holding potential or social inertia?. Canadian Journal of Zoology, 79(11), 1951-1956.

Vervaecke, H., Stevens, J. M., Vandemoortele, H., Sigurjónsdóttir, H., \& De Vries, H. (2007). Aggression and dominance in matched groups of subadult Icelandic horses (Equus caballus). Journal of Ethology, 25(3), 239-248.

Winker, K. (1998). The concept of floater. Ornitologia Neotropical, 9(2), 111-119.

Woodward, G., Ebenman, B., Emmerson, M., Montoya, J. M., Olesen, J. M., Valido, A., \& Warren, P. H. (2005). Body size in ecological networks. Trends in ecology \& evolution, 20(7), 402-409.

Ziegelbecker, A., Richter, F., \& Sefc, K. M. (2018). Colour pattern predicts outcome of female contest competition in a sexually monomorphic fish. Biology letters, 14(11), 20180480. 
Table 1: Descriptions of territorial behaviors exhibited by female Anolis gundlachi during focal observations. The names and descriptions of these behaviors are consistent with behavioral indices used in other studies of Anolis behavior (e.g., Flieshman 1988).

\begin{tabular}{|l|l|}
\hline \multicolumn{1}{|c|}{ Behavior } & \multicolumn{1}{c|}{ Description } \\
\hline Perch Change & $\begin{array}{l}\text { Any movement by focal lizard from one perch to another (e.g., } \\
\text { jump from tree trunk to ground) }\end{array}$ \\
\hline Foraging Event & Any consumption of prey by focal lizard \\
\hline Display & $\begin{array}{l}\text { Performance of head-bobs, pushups, dewlap extensions, and/or } \\
\text { use of display modifiers, such as dorso-ventral flattening by } \\
\text { focal lizard }\end{array}$ \\
\hline Advertisement Display & $\begin{array}{l}\text { Displays performed by focal lizard in the absence of any } \\
\text { observed conspecific }\end{array}$ \\
\hline Interaction Display & $\begin{array}{l}\text { Displays performed during an interaction, when the other lizard } \\
\text { was within one meter of the focal lizard }\end{array}$ \\
\hline Escalated Aggression & $\begin{array}{l}\text { Interactions in which the focal lizard proceeded to posturing } \\
\text { (e.g, open mouth, assuming a lateral position toward non-focal } \\
\text { lizard) chasing, lunging at, or biting the non-focal lizard }\end{array}$ \\
\hline
\end{tabular}


Table 2: Results of t-tests examining potential differences in measured variables across sampling years for both male and female Anolis gundlachi. The data have been log transformed. Locations represent the number of observations of a lizard used to calculate territory (50\% kernel utilization distributions, "KUDs") and home range sizes (95\% KUDs and 95\% minimum convex polygons, "MCPs"). Body condition is represented by the residuals of $\log _{10}$ mass regressed on $\log _{10}$ snout-vent length, with males and females analyzed separately due to the substantial sexual dimorphism in body condition.

Significance values were assigned as follows: $\mathrm{p}>0.05=\mathrm{NS}, \mathrm{p}<0.05=*, \mathrm{p}<0.01=* *$, $\mathrm{p}<0.001=* * *, \mathrm{p}<0.0001=* * * *$.

\begin{tabular}{ccccc} 
& Variable & $\begin{array}{c}2015 \text { Mean } \pm \\
\text { Standard Deviation }\end{array}$ & $\begin{array}{c}\text { 2016 Mean } \pm \\
\text { Standard Deviation }\end{array}$ & Significance \\
\cline { 2 - 5 } Females & Spatial & $0.948 \pm 0.165$ & $1.31 \pm 0.127$ & $* * *$ \\
$2015 \mathrm{n}=23$ & Locations & & & \\
$2016 \mathrm{n}=13$ & $95 \%$ MCP $\left(\mathrm{m}^{2}\right)$ & $-0.316 \pm 0.654$ & $0.388 \pm 0.654$ & $* * *$ \\
& 50\% KUD $\left(\mathrm{m}^{2}\right)$ & $0.428 \pm 0.528$ & $0.965 \pm 0.528$ & $* *$ \\
& Body Condition & $0.0182 \pm 0.038$ & $-0.0322 \pm 0.0235$ & $* * * *$ \\
\cline { 2 - 5 } Males & Spatial & $0.921 \pm 0.154$ & $1.16 \pm 0.186$ & $* *$ \\
$2015 \mathrm{n}=19$ & Locations & & & \\
$2016 \mathrm{n}=9$ & $95 \%$ MCP $\left(\mathrm{m}^{2}\right)$ & $0.344 \pm 0.706$ & $0.411 \pm 1.01$ & $\mathrm{NS}$ \\
& 50\% KUD $\left(\mathrm{m}^{2}\right)$ & $1.50 \pm 0.600$ & $1.33 \pm 0.576$ & $\mathrm{NS}$ \\
& Body Condition & $0.00053 \pm 0.437$ & $-0.00112 \pm 0.041$ & $\mathrm{NS}$
\end{tabular}


Figure 1: Schematic representing the variation in behaviors performed by female Anolis gundlachi during focal observations of marked individuals in the wild. Descriptions of the categorized behaviors are presented in table 1.

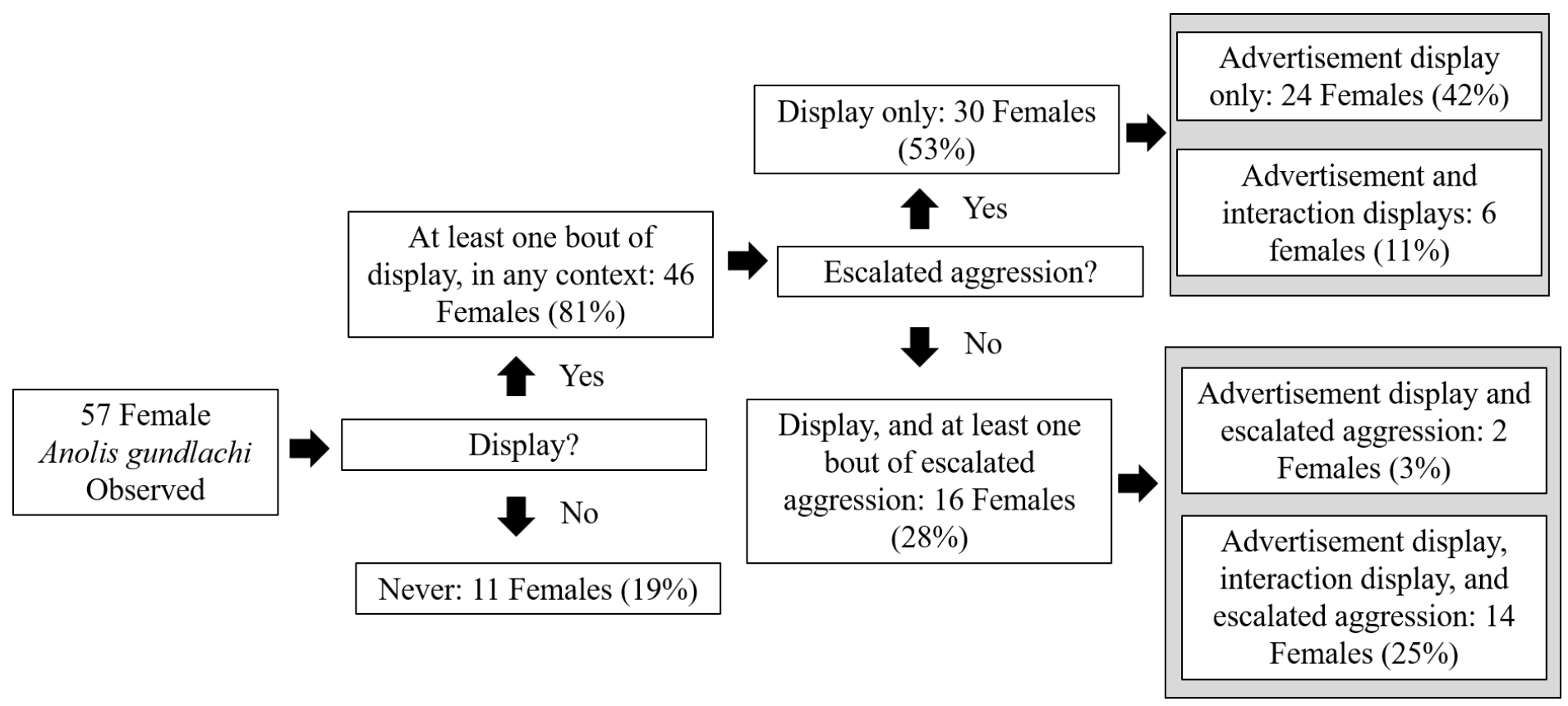


Figure 2: Spatial distribution of male and female Anolis gundlahci within our study plots. Polygons represent the home ranges of individuals calculated as $\log _{10} 95 \%$ minimum convex polygons $\left(\mathrm{m}^{2}\right)$. Polygons outlined in black represent male home ranges, and polygons in color represent female home ranges. Plots are provided for the five study plots included in the 2015 year of data collection (panels B - F), and the single plot examined in 2016 (panel A). (Figure appears on the following page) 

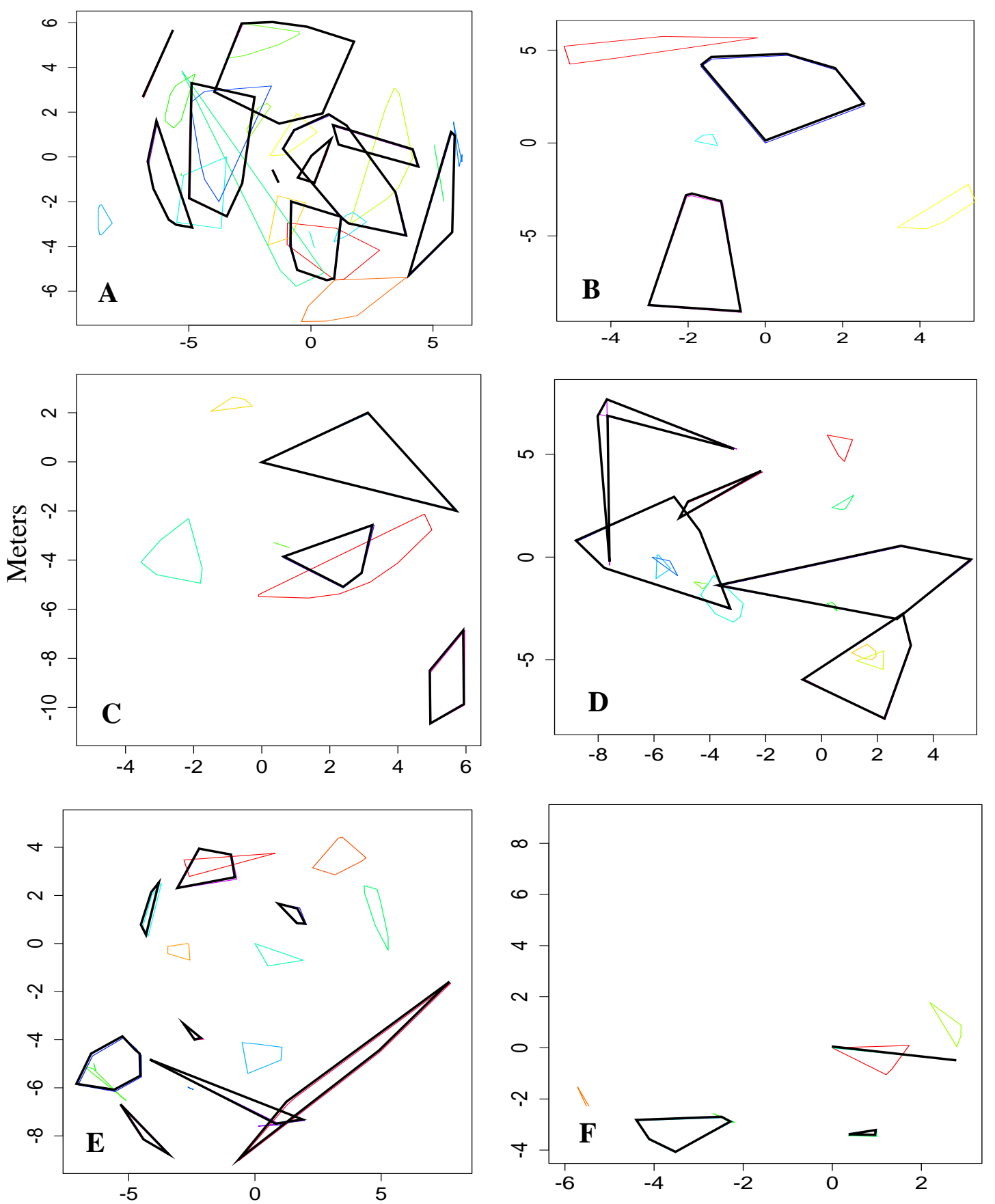

Meters 
Figure 3: Results of linear regressions evaluating the relationship between home range and territory size and the number of sightings used to calculate home range $(95 \%$ minimum convex polygons, "MCPs," in $\mathrm{m}^{2, ")}$ and territory sizes (50\% kernel utilization distributions, "KUDs," $\mathrm{m}^{2}$ ) of Anolis gundlachi. Data for females (plots A and B) and males (plots C and D) are depicted in two different panels. Females sampled in 2015 and 2016 were analyzed separately, and lizards sampled in 2015 are represented by open squares, and those in 2016 are represented by filled circles. Males from both years were considered together. Shaded areas indicate standard error. All data were log transformed. (Figure appears on the following 2 pages) 

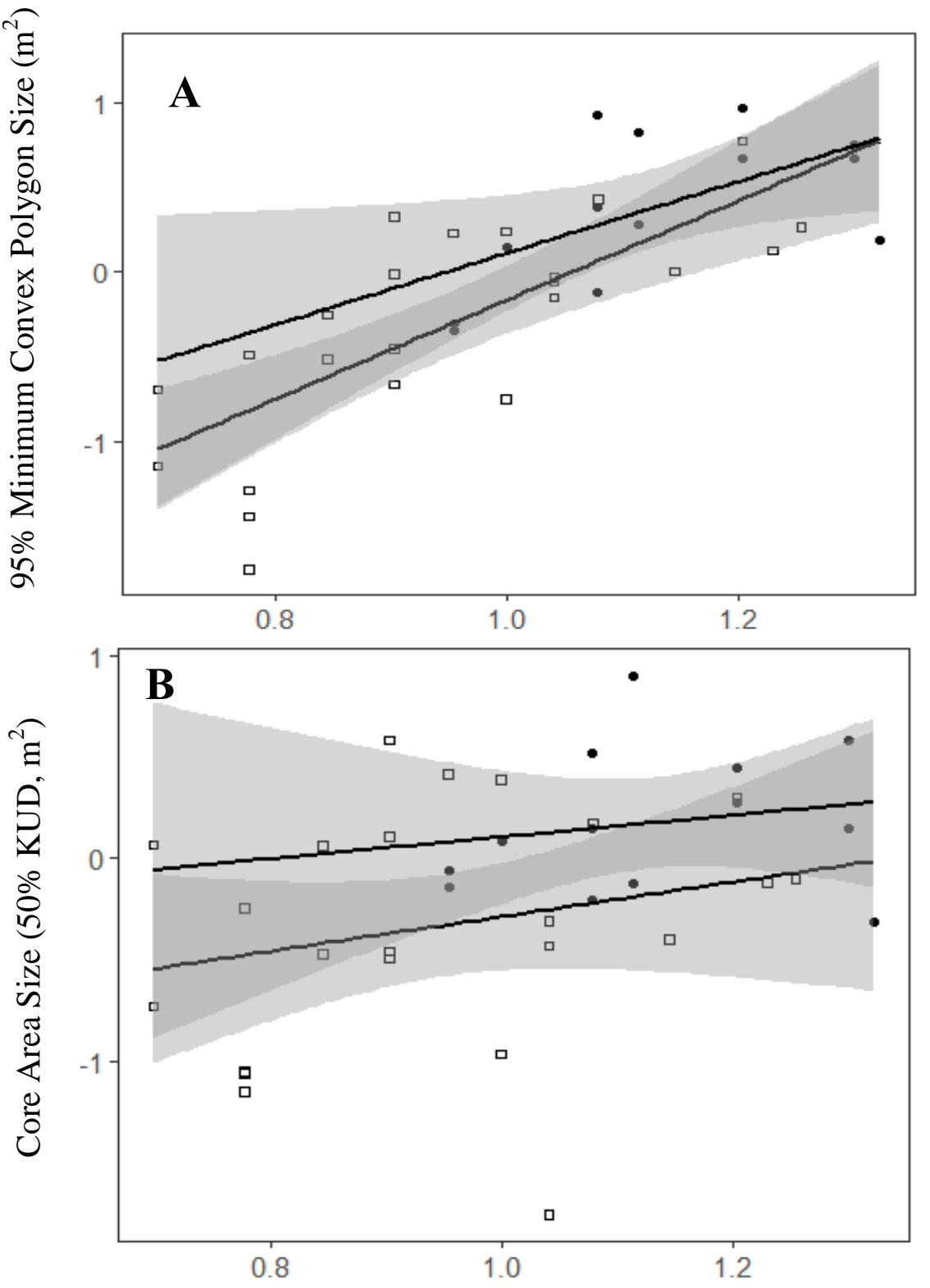

Number of Sightings 

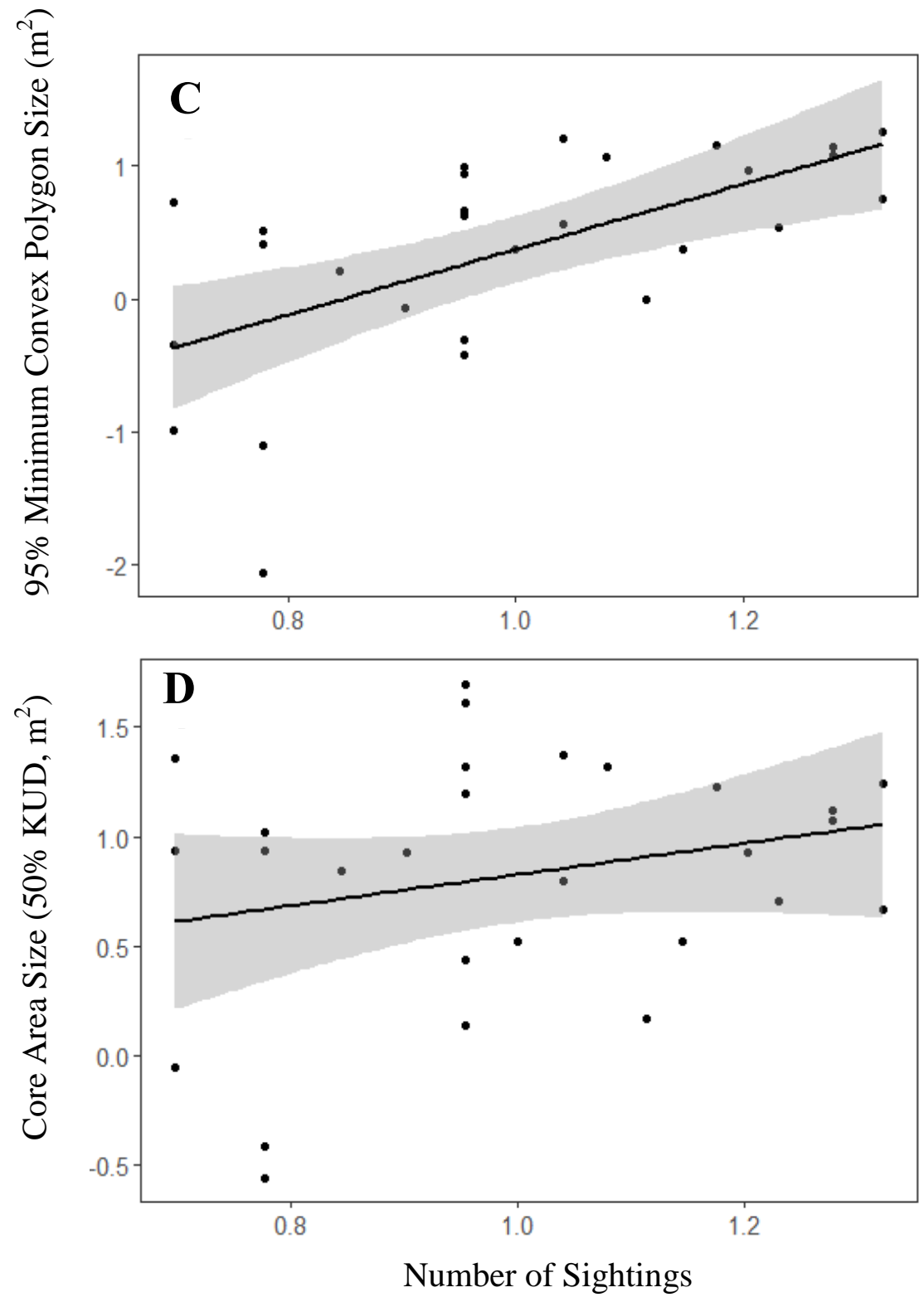
Figure 4: Results of linear regressions evaluating the relationship between body condition and home range size (95\% minimum convex polygons, "MCPs," in $\left.\mathrm{m}^{2}\right)$ and territory size (50\% kernel utilization distributions, "KUDs," in $\left.\mathrm{m}^{2}\right)$ of Anolis gundlachi. Data for females (plots A and B) and males (plots C and D) are depicted in two different panels. Shaded areas indicate standard error. All data were log transformed. (Figure appears on the following two pages). 

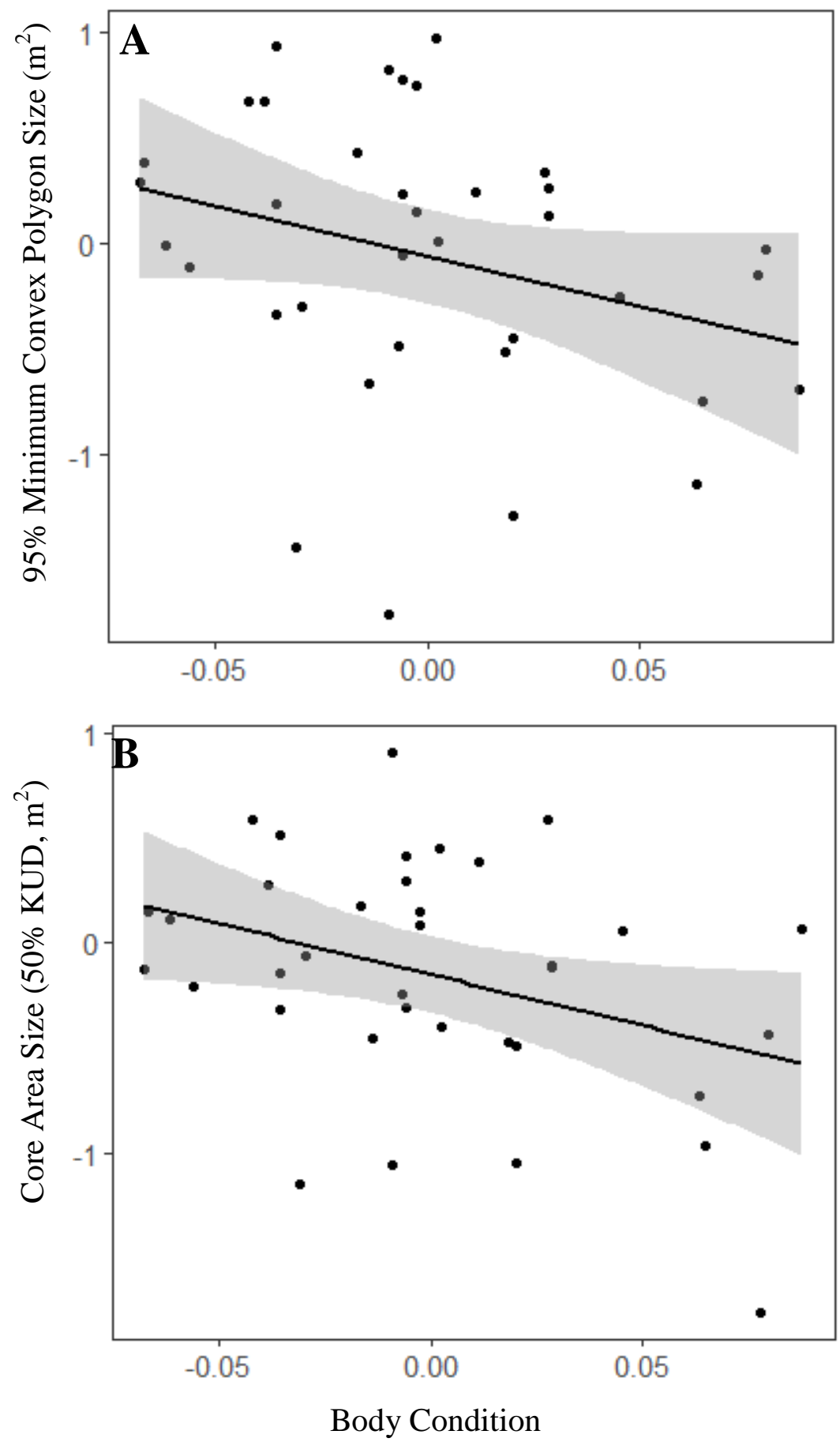

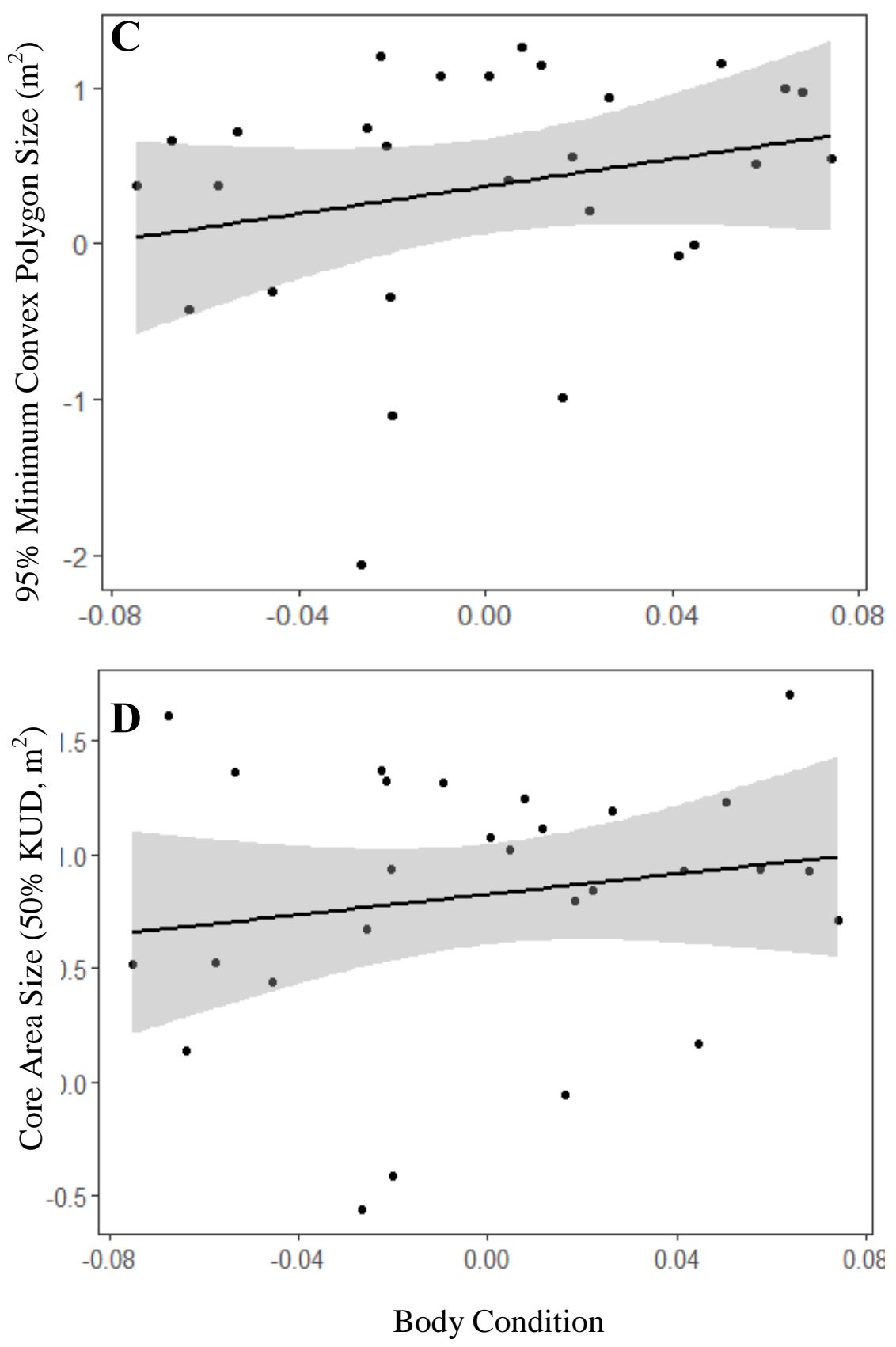


\title{
CHAPTER 4
}

\section{Evaluating the potential for testosterone to mediate aggressive behavior in wild female Anolis gundlachi lizards}

\author{
Ellee G. Cook, Matthew B. Lovern, Manuel Leal
}

\begin{abstract}
Aggressive behavior is an important component of social interactions and is widespread across taxonomic groups. Individuals use aggression in social contexts including courtship, resource defense, and parental care, and it is common for aggressive behavior to vary among conspecifics. As such, researchers have long sought to elucidate the mechanisms that mediate this variation. Here, we investigated the potential for the hormone testosterone to predict aggressive behavior in female Anolis gundlachi lizards. Testosterone has been repeatedly implicated in the control of aggressive behavior in males of a variety of taxa, including males of several Anolis species, but its heterologous function in mediating female aggressive behavior remains understudied. Working in a free-living population of A. gundlachi in Puerto Rico, we characterized the baseline concentrations of circulating testosterone in male and female A. gundlachi to establish the potential for variation in testosterone to explain sex-differences in behavior. We then staged territorial intrusions between females, recorded their aggressive responses, and measured testosterone concentrations following interactions to evaluate the potential for testosterone to explain individual differences in aggression among females. In the general population, we found that male $A$. gundlachi exhibit significantly higher testosterone than females (males: mean $=7.63 \pm 6.76 \mathrm{ng} / \mathrm{mL}$, females: mean $=0.476 \pm 0.808 \mathrm{ng} / \mathrm{mL}$ ). Females used in the staged intrusions exhibited a repertoire of aggressive behaviors comparable to males, and aggression scores and testosterone concentrations differed
\end{abstract}


among females. We observed the trend that female $A$. gundlachi facing intruders that were larger than themselves exhibited higher aggression scores than females facing intruders of equivalent or smaller sizes than themselves. However, testosterone did not differ significantly across our treatments and was not associated with differences in aggression score. This is contrary to results in similar studies of males in other Anolis species, in which testosterone and aggression have been associated. Our findings do not support a heterologous function of testosterone in mediating aggressive behavior in both sexes, suggesting that aggression in females is modulated by a different mechanism.

\section{Introduction}

Aggression is an important component of social interactions and can vary substantially both within and across species (Collias 1944, Kravitz and Huber 2003, Nelson 2005). It functions in contexts such as territoriality, courtship, and parental care, and thus has the potential to exert significant influence on fitness (e.g., Yasukawa and Searcy 1982, Wolff 1993, Desjardins et al. 2012). Within species, aggression often varies among members of different age classes or between the sexes (e.g., birds: Groves 1978, insects: Bertram and Rook 2012, mammals: Benus et al. 1991, reptiles: Baird et al. 1996), an observation that has inspired a large body of work investigating the mechanisms that mediate intraspecific variation (e.g., Simon et al. 2006, Soma et al. 2008).

Among the variety of mechanisms hypothesized to mediate aggression, and animal behavior in general, few have been as widely investigated as the influence of circulating hormones on patterns of behavior (Adkins-Regan 2005, Svare 2013). In particular, the role of testosterone in modulating behavior has been well studied in a 
diverse group of taxa (Leshner 1975, Adkins-Regan and Wade 2001, Nelson 2005) and has been associated with a variety of traits that influence fitness. For example, individual differences in testosterone are associated with variation in basal metabolic rate in house sparrows (Passer domesticus, Buchanan et al. 2001), can predict aggressive social rank in chacma baboons (Papio hamadryas, Bheener et al. 2006), and influence circadian patterns of behavior such as scent marking in Mongolian gerbils (Meriones unguiculatus, Probst et al. 1987). Testosterone profiles have been characterized for a diversity of species and have been correlated with differences in aggressive behavior both across and within species (e.g., Schlinger and Callard 1990, Negro et al. 2010, Rosvall 2013). For example, testosterone profiles vary substantially across bird species, such that baseline and seasonal differences in circulating testosterone vary in accordance with life history traits associated with aggression, such as mating system, territoriality, and population density (reviewed in Hau et al. 2008). Within species, there are often differences in aggressive behavior between the sexes and among individuals. For example, males often exhibit both more frequent aggression and higher concentrations of testosterone than females, suggesting a role for testosterone in mediating sex differences in aggressive behavior (e.g., Møller et al. 2005, Hews et al. 2012, but see Goymann et al. 2001). Although aggression has been associated with aggression in many cases, (e.g., Greenberg and Crews 1990, Wingfield et al. 1990, Muller and Wrangham 2004), there are also exceptions to this trend (e.g., Woodley and Moore 1999, Logan and Wingfield 1990). Thus, while testosterone and aggression are correlated in many cases, the heterogeneity of results also indicates that testosterone is only one player within the complex suite of traits that mediate aggression (reviewed in Olivera 2005, Rosvall 2013). 
In some species, males and females exhibit comparable repertoires of aggressive behavior (Clutton-Brock 2007, 2009). Although differences may exist in the frequency of behaviors or the contexts in which they are used, there are examples in which both sexes utilize similar behavioral patterns in pursuit of the same goal (e.g., display behaviors in lizards, Martins 1991, and singing behavior in birds, Langmore 1998). For instance, both males and females of many species exhibit territoriality and utilize aggressive behaviors to establish and maintain those territories (e.g., Levin and Wingfield 1992, Mahrt 1998, Wolff and Peterson 1998). Furthermore, intraspecific variation in aggression can also occur in both sexes. In the sage brush lizard (Sceloporus graciousus), both males and females exhibit repeatable individual variation in the use of push-up displays, a behavior that plays a role in territorial defense and resource competition (Martins 1991). In the Midas cichlid (Cichlasoma citrinellum), females become more aggressive than males in adulthood, but members of both sexes exhibit different and repeatable 'behavioral profiles' in response to staged agonistic interactions (Francis 1990). Such cases encourage pursuing opportunities to investigate whether the same behaviors are mediated by a shared mechanism across the sexes.

Here, we characterized the testosterone profiles of free-living male and female Anolis gundlachi lizards and evaluated the potential for testosterone to mediate aggression in female A. gundlachi. Several species in the genus Anolis have figured prominently in studies of animal aggression. Male Anolis lizards exhibit highly stereotyped aggressive behaviors as part of territorial defense, including species-specific patterns of dewlap (i.e., throat fan) extensions, push-up and head-bob displays, and ritualized fighting behaviors, and these were some of the first behaviors to be extensively 
characterized for members of this genus (e.g., Greenberg and Noble 1944, Echelle et al. 1971, Jenssen 1977, Carpenter 1978). Since then, a large body of work has investigated aggressive behavior and how it varies, both across and within different Anolis species. For example, phylogenetic studies have revealed that species that occur on different islands in the Greater Antilles but belong to the same ecomorph exhibit consistent patterns of territorial behavior (e.g., display rates, territory size), suggesting that the behavioral and morphological attributes of these ecomorphs in combination with microhabitat likely influenced the evolution of inter-specific differences in aggression among Anolis species (Losos 1990, Beuttell and Losos 1999, Johnson et al. 2010). Within species, many studies have described intra-specific variation in aggression and evaluated the mechanisms that mediate it. In particular, individual variation in body size and circulating hormones were some of the first traits hypothesized to mediate intraspecific variation in Anolis aggression, and have been the subjects of both observational and manipulative work over the last several decades (e.g., Mason and Adkins 1976, Tokarz 1985, Jenssen et al. 2005, Husak et al. 2007).

Although many studies have investigated the aggressive behavior of Anolis lizards, there are several important limitations to our current dataset. First, although Anolis is a genus highly rich in species, a significant portion of the work investigating mechanisms that mediate aggression has focused on a handful of species (e.g., $A$. carolinensis and A. sagrei). As a result, the overarching framework developed to understand the mechanistic control of territoriality and aggression in the genus stems heavily from data collected from these species (e.g., Evans 1936 \& 1938, Mason and Adkins 1976, Schoener and Schoener 1982, Greenberg and Crews 1990). Nonetheless, 
descriptive work conducted in the field with free-living lizards has yielded detailed accounts of aggressive behavior in other Anolis species, demonstrating that many patterns of territorial behavior are shared across the genus (e.g., Stamps 1973, Philibosian 1975, Johnson et al. 2010). Second, the influence of traits such as circulating hormones, which have been associated with aggressive behavior in laboratory and field investigations with well-studied Anolis species, has yet to be examined in the field or at all in many other species (Tokarz 1985, Wade 2005, Husak et al. 2007, but see Husak and Lovern 2014). Finally, even within well-studied species, much of the work investigating aggression in Anolis lizards has focused on male behavior with relatively little direct consideration of natural female behavior beyond their interactions with males and reproduction (e.g., Jones et al. 1983, Tokarz and Crews 1981). This is problematic, as territorial and other aggressive behaviors have been documented in females of several Anolis species (Andrews 1971, Stamps 1973, Jenssen and Nunez 1998, Nunez et al. 2007, Reedy 2017), and recent work with lizards and other animal groups suggest that female-female competition and intraspecific variation in female aggression, in particular, may exert stronger influence social dynamics than historically presumed (Clutton-Brock 2007, Stockely and Campbell 2013, Rosvall 2013).

Working in a free-living population of A. gundlachi in Puerto Rico, we measured concentrations of circulating testosterone in adult males and females in order to characterize baseline concentrations and to assess variation in testosterone within and across the sexes. Based on previous studies in other Anolis species, we hypothesized that females would exhibit lower testosterone concentrations than males (Lovern et al. 2001, Cox et al. 2015). Our previous work with A. gundlachi indicates that females exhibit 
aggressive behaviors associated with territoriality and that aggression varies between individuals (Cook et al. In Preparation). We hypothesized that circulating concentrations of testosterone would be positively associated with aggression in female A. gundlachi, as has been shown in male Anolis (Tokarz 1985, Husak and Lovern 2014). To test this hypothesis, we staged territorial intrusions among females, recorded their aggressive responses, and measured circulating concentrations of testosterone following interactions. Finally, we also measured circulating concentrations of corticosterone for all lizards in this study. Corticosterone is a glucocorticoid that is associated with mobilizing resources during stressful experiences including agonistic interactions and has thus also been associated with aggression in several taxa (reviewed in Sapolsky 2000, Summers and Winberg 2006). As such, we also assessed baseline concentrations of corticosterone in male and female A. gundlachi and considered the potential for an association between corticosterone and aggressive behavior in females, although our primary focus remained in evaluating the influence of testosterone.

\section{Materials and Methods}

\section{Study Location and Focal Species}

This work was conducted in the Luquillo Experimental forest near El Verde Field Station in Puerto Rico in July and August of 2017, which is in the midst of the breeding season of our focal species (Rand 1964). Anolis gundlachi occurs abundantly in this area and is considered a trunk-ground ectomorph. It is most frequently observed on the trunks of trees at approximately 1 meter above the ground but also ventures to the forest floor for foraging and social interactions (Rand 1964, Rodriguez-Robles et al. 2005). 
Female A. gundlachi exhibit territorial behavior that is comparable to the highly stereotyped territoriality observed in male A. gundlachi, and other Anolis species (Cook et al. In Preparation). Many individuals exhibit high site fidelity and can be found in the same area over a period of at least several weeks. Female territories are typically smaller than those defended by males and can vary considerably in size in shape. Nevertheless, females use very similar behavioral repertoire of those used by males, as females often behave aggressively toward conspecifics that come within a certain distance or crossed putative territory boundaries (Cook et al. In Preparation).

\section{Baseline Hormone Concentrations of General Population}

We sought to characterize baseline concentrations of testosterone and corticosterone, as well as any standing variation in the concentrations of these hormones, among the general population of adult male and female A. gundlachi. We captured adults by noose and collected a sample of whole blood from the suborbital sinus using a heparinized capillary tube. We only analyzed samples that were collected within an approximately five-minute window between initiating pursuit of the lizard and successful blood collection. This window was observed by setting a stop watch and implemented to standardize, if not also reduce, the potential effects of capture and handling on hormone profiles (methodology after Husak and Lovern 2014). Whole blood samples were stored on ice. Individuals were then stored in bags and transported to the field station, where we measured their mass and SVL and collected a drop of blood for a smear to be used in a different study. Plasma was separated by spinning in a centrifuge and pipetted into a new tube to be stored in at -20C. Plasma samples were later transported to the University of Missouri for storage, and ultimately to Oklahoma State University for hormone analyses 
(see methods below). All residents were returned to their site of capture within 24 hours. To avoid resampling, we only worked in a particular area for a few days. Each captured lizard was labeled using a marker which lasted for at least three days, and any individual that was already marked when captured was not resampled.

\section{Staged Territorial Intrusions}

To assess whether circulating concentrations of testosterone changed in the context of territorial interactions, we staged territorial intrusions among female $A$. gundlachi in the field. We used a paradigm based on a similar study conducted with male Anolis lizards (Husak and Lovern 2014), which also resembles methods used in studies of behavioral endocrinology in other groups of lizards (e.g., Smith and John-Adler 1999).

Intruder trials were staged by presenting a free-living female $A$. gundlachi (hereafter referred to as a resident female) with a conspecific female gently tethered to an apparatus made from a $10.2 \mathrm{~cm}$ X $15.2 \mathrm{~cm}$ plastic lid of a Critter Carrier cage glued to an approximately $20.3 \mathrm{~cm}$ X $20.3 \mathrm{~cm}$ piece of plastic sheeting (i.e., intruder female). Resident females were located by visually scanning an area of forest for female A. gundlachi perched singly on a tree, and behaving naturally. Based on our previous work, female $A$. gundlachi perching alone on trees are likely to be in their territories and are also therefore likely to behave aggressively toward conspecifics that venture close to these territories (Cook et al. In Preparation). Intruder females were captured approximately 12 hours prior to conducting each day's trails at a site of at least $100 \mathrm{~m}$ from the area where trials were to be conducted. Prior to trials, we measured the snout-vent length (SVL) of each intruder and gently tethered an intruder to the apparatus using dental floss such that the female could move and display but not escape. We attached a string (approximately $3 \mathrm{~m}$ 
in length) to the apparatus, which was used to retract the apparatus at the conclusion of trials. Each intruder was used for no more than two consecutive trials, and no intruders incurred injuries in the trials.

Once a resident female was located, an observer would note the time and approximate perching position of the resident female and slowly approach the tree to place the intruder apparatus within approximately $30 \mathrm{~cm}$ of the tree's base. The presence of a conspecific at this distance simulates a territorial intrusion, and is likely to elicit an aggressive response (Cook et al. In Preparation). After placing the intruder, the observer would slowly back away to a position of at least $3 \mathrm{~m}$ from the resident's tree, carrying with them the end of the string attached to the intruder apparatus. At this point, the observer would note the time and begin a 10-minute observation of the resident female, recording all the behaviors performed by the resident with a digital voice recorder. In particular, we noted any behaviors characteristic of Anolis territoriality (further details listed below, Table 1). We also noted any changes in the resident's position relative to the intruder, such as the distance or height from the intruder or the resident's head position (i.e., toward or away from the intruder). At the conclusion of the 10-minute observation, the observer would slowly pull the string attached to the intruder apparatus in order to pull the apparatus away from the tree and back to the observer, with the intent to minimize disturbance to the resident by a second approach to the tree. The observer then continued to follow the resident for a 20-minute period, after which the observer attempted to capture the resident by noose. If the resident was captured within approximately 5 minutes, we collected a blood sample using the same methods described for the general population. Samples were stored on ice until returning to the field station, 
where we separated plasma as described for baseline measurements (see sections above and below for descriptions of sampling and hormone analysis, respectively). Residents were then stored in bags and transported to the field station, where we measured their mass and snout-vent length (SVL). All residents were returned to their site of capture within 24 hours. We implemented the same strategies described for the generalpopulation study to avoid re-sampling in the staged intrusion study.

Some females exhibited highly aggressive behavior toward intruders. However, residents were not allowed to repeatedly attack the intruder; if escalated aggression occurred (e.g., lunging with the intent to bite), the observer could prematurely remove the intruder from the interaction by standing and retracting the string attached to the apparatus. In these cases, the observation period was cut short, but we proceeded with the same protocol after removal of the intruder.

We also conducted two control treatments following the same methodology described above but altering the apparatus presented to the residents. In one control treatment, we presented resident females with the apparatus without a conspecific tethered to it. This control was intended to assess the residents' potential behavioral and/or hormonal responses to the presence of the apparatus and is hereafter referred to as the "apparatus" treatment. In the second control treatment, we approached the residents' trees but did not place anything at the base. This treatment was intended to assess whether the residents' behavior and/or hormone profiles changed in response to the presence of the observer and is hereafter referred to as the "approach" treatment. Trials with the conspecific intruder present on the apparatus are referred to as the "conspecific" treatment. 


\section{Scoring Behavioral Observations}

In order to compare territorial behavior across individuals, we developed an index of aggressive behaviors to score our observations of females during the three treatments of the staged territorial intrusions. As female A. gundlachi exhibit a similar repertoire of behaviors as male Anolis lizards, we based this index on others used previously in studies of male aggression (e.g., Fleishman 1988, Husak and Lovern 2014). We considered the following behaviors to be associated with territory defense and awarded the respective value each time the behavior was observed: approach, display, posturing, and escalation (see Table 1 for descriptions of behaviors and associated weights for scoring). We calculated an overall aggression score for each female by summing the values awarded for all aggressive behaviors observed. For each individual that performed at least one aggressive behavior ( $\mathrm{n}=16$, behaviors described in Table 1), we denoted in Table 2 both the aggression score and behavior pattern through which the individual achieved that score.

\section{Calculating Body Condition}

To assess body condition, we collected the residual values of each individual's mass regressed on its SVL. Male and female body conditions were assessed separately, with respect to the substantial amount of sexual size dimorphism present between males and females of the A. gundlachi population we worked with (methods match those used in Cook et al. In Preparation).

\section{Hormone Assays}

Methods for hormone measurement were modeled after Husak and Lovern (2014). We measured plasma concentrations of testosterone and corticosterone using 
radioimmunoassay (RIA) following extraction and separation by column chromatography (Wingfield and Farner, 1975). All samples were run singly. We recorded the volume of plasma for each sample to the nearest microliter $(7.79 \pm 4.83 \mu \mathrm{l})$, and then combined plasma with $0.5 \mathrm{ml}$ of $d_{d d} \mathrm{H}_{2} \mathrm{O}$. Samples were equilibrated overnight at $4^{\circ} \mathrm{C}$ with -1000 cpm of ${ }^{3} \mathrm{H}$ testosterone (NET-370, $70 \mathrm{Ci} / \mathrm{mmol}$ ) and ${ }^{3} \mathrm{H}$ corticosterone (NET-399, 71 Cimmol) from PerkingElmer Life Sciences, Inc. (Boston, MA) for recovery determinations. We extracted each sample twice with $2 \mathrm{ml}$ diethyl ether dried under nitrogen gas in a $37^{\circ} \mathrm{C}$ water bath. Samples were then reconstituted in $0.5 \mathrm{ml}$ of $10 \%$ ethyl acetate in isooctane for use in chromatography. We made columns consisting of a diatomaceous earth:ethylene glycol:propylene upper phase (4:1:1 m:v:v) and a diatomaceous earth:ddH $\mathrm{d}_{2} \mathrm{O}$ lower phase. We used "Celpure" diatomaceous earth from Sigma-Aldrich (St. Louis, MO). After placing samples on columns, neutral lipids were removed with $1.5 \mathrm{ml}$ isooctane dihydrotestosterone was removed with $2 \mathrm{ml} 10 \%$ ethyl acetate in isooctane, and both were discarded. Testosterone was removed with $2 \mathrm{ml} 20 \%$ ethyl acetate in isooctane, corticosterone was removed with $2.5 \mathrm{~mL}$ of $52 \%$ ethyl acetate in isooctane, and both were collected into individual test tubes. Samples were dried under nitrogen gas in a $37^{\circ} \mathrm{C}$ water bath, resuspended in phosphate buffer, and refrigerated overnight at $4^{\circ} \mathrm{C}$. We performed competitive binding RIAs using titrated steroid tracer (see above), antisera from Wein Laboratories for testosterone (T-3003; Succasunna, NJ), Sigma-Aldrich for corticosterone (C8784), and steroid standards from Sigma-Aldrich. Standard curves ranged from 1.95 to $500 \mathrm{pg}$ for testosterone, and 3.91 to $1000 \mathrm{pg}$ for corticosterone. Samples were run singly, and adjusted for individual recovery and initial sample volume. Average testosterone recovery was $73 \%$, and corticosterone was 50\%. 
Average intra-assay coefficients of variation (CV) based on 4 aliquots from a standard pool for testosterone were $10.1 \%$, and $9.5 \%$ for corticosterone.

Although the assay was successful, a substantial portion of our samples contained testosterone at concentrations that were not detectable by this assay (35\%, 55 of 157).

Other studies of lizard endocrinology using the same radioimmunoassay technique have also observed non-detectable hormone concentrations - for example, $21 \%$ of the samples in a study of Texas horned lizards (Phrynosoma cornutum) presented with non-detectable concentrations of estradiol (Wack et al. 2008). We treated non-detectable samples in the same way the authors of that study did, and assigned these samples the minimum detectable dose $(0.1 \mathrm{pg} / \mathrm{mL})$, and then corrected for individual recovery and sample volume to establish a hormone concentration for these individuals (after Wack et al. 2008). In some of our analyses, we treated hormone concentration as a dichotomous variable by coding samples as "detectable" or "undetectable," with those treated with the correction just described considered in the undetectable group.

\section{Statistical Analyses}

All statistics were calculated using R (R Software version 3.5.2) in R Studio (RStudio, Inc. version 1.1.463). Because of the high occurrence of low values for both aggression scores and hormone concentrations, our data were not normally distributed. No transformation effectively fit these data to a normal distribution, and thus we used non-parametric tests to compare hormone concentrations across males and females in the general population, and of females in the three treatments of the staged intrusions. We used Mann-Whitney tests to compare baseline hormone concentrations between males and females. Kruskal-Wallis tests were used to compare hormone concentrations and 
aggression scores across the three treatments and baseline concentrations. To evaluate the potential influence of size asymmetry between residents and intruders on aggressive responses, we used Kruskal-Wallis tests to assess whether female residents that were larger than or equal in body length (SVL) to intruders exhibited differences in aggression score, testosterone, or corticosterone relative to females smaller than the intruder they faced. We used Kruskal-Wallis tests to compare hormone concentrations between females that performed at least one aggressive behavior as part of the staged intrusions and those that performed no behaviors. Unless otherwise specified, descriptive statistics are presented as mean \pm standard deviation.

We also evaluated whether undetectable concentrations of testosterone were equally likely to occur in males and females of the general population and across the three treatments of the staged intrusion study. The impetus for this was the possibility that the likelihood of finding undetectably low concentrations would be unequal across treatments or between males and females. If testosterone is naturally much lower in female A. gundlachi than in males, the likelihood of observing an undetectable value for testosterone may be higher for females. Similarly, if testosterone is associated with aggression in female A. gundlachi and the presence of a conspecific female elicits aggression, it may be more likely to find undetectably low concentrations in the controls of our staged intrusion study than in the treatment which presented the female with a conspecific. We tested the possibility that the likelihood of observing undetectable testosterone concentrations differs across our groups, and predicted that undetectable concentrations would be more common in 1) female A. gundlachi from the general population relative to males, and 2) females in the control treatments for the staged 
intrusions relative to females in the experimental treatment. To do so, we ran hurdle models with samples that were below the sensitivity of the assay assigned a value of zero (hurdle function in the brms package in R, Burkner 2017). The hurdle models use a twostep process, first fitting the probability of zero (i.e., undetectable concentrations) and non-zero values (i.e., detectable concentrations), and then fitting a gamma distribution to the zero and non-zero values. We fit four different candidate models for each data set (i.e., general population [two groups: males and females] and females from staged intrusions [three groups: approach, apparatus, and conspecific treatments]): 1) equal probability of the occurrence of undetectable concentrations in the different groups (e.g., either males and females or across the three staged intrusion treatments), fit to the same gamma distribution; 2) equal probability of the occurrence of undetectable concentrations in the different groups, fit to different gamma distributions for each group; 3) unequal probability of the occurrence of undetectable concentrations in the different groups, fit to same gamma distribution; and 4) unequal probability of the occurrence of undetectable concentrations in the different groups, fit to different gamma distributions for each group (Tables 3 and 4). We report the weights of the different models (i.e., the metric that indicates the support for each model), as well as the LOO ELPD of the models with respective standard error.

\section{Results}

\section{Baseline Hormone Concentrations in the General Population}

There is a weak but significant correlation between plasma volume and testosterone concentrations across all lizards measured in our study $(\mathrm{p}<0.001$, tau $=0.22$, Figure 1). In the general population (i.e., baseline concentrations), we measured 
testosterone and corticosterone concentrations for 28 female and 70 male A. gundlachi. Males were larger than females, with an average SVL of $63.3 \mathrm{~mm} \pm 4.35 \mathrm{~mm}$ and mass of $6.27 \mathrm{~g} \pm 1.33 \mathrm{~g}$, relative to females with an average SVL of $45.85 \mathrm{~mm} \pm 1.35 \mathrm{~mm}$ and mass of $2.41 \mathrm{~g} \pm 0.264 \mathrm{~g}$. On average, circulating testosterone was nearly sixteen times higher in males than in females (males: mean $=7.63 \pm 6.76 \mathrm{ng} / \mathrm{mL}$, females: mean $=$ $0.476 \pm 0.78 \mathrm{ng} / \mathrm{mL}, \mathrm{p}=<0.001$, Figure 2). There range of variation in testosterone was also much larger in males than in females (males: range $=0.0241 \mathrm{ng} / \mathrm{mL}-29.1 \mathrm{ng} / \mathrm{mL}$, female: range $=0.0153 \mathrm{ng} / \mathrm{mL}-2.85 \mathrm{ng} / \mathrm{mL}$, Figure 2). The number of undetectable concentrations of testosterone was higher for females than males in the general population, with more than half of the concentrations measured for females being undetectable $(67 \%$ for females $[n=19], 10 \%$ for males $[n=7))$.

For our zero-inflated gamma models for the general population (Table 3), the model with unequal probability of the occurrence of undetectable concentrations in the sexes fit to different gamma distributions for the sexes had the highest weight (model four: $94.4 \%$, LOO ELPD -256.1, SE = 13.6). The other three models had low to zero weights $($ model 1: weight $=0 \%$, LOO ELPD $=-281.0$, SE $=12.6 ;$ model 2: weight $=$ 5.6\%, LOO ELPD -271.5, SE = 12.7; model 4: weight $=0 \%$, LOO ELPD $=-256.1, \mathrm{SE}=$ 13.6) Our finding that model four had the most support suggests that there is a difference in the likelihood of observing undetectable concentrations across the sexes.

Finally, corticosterone also varied between and within the sexes (Figure 3). On average, corticosterone concentrations more than twice as high in females than in males (females: mean $=6.99 \pm 6.536 \mathrm{ng} / \mathrm{mL} ;$ males: mean $=3.06 \pm 2.85 \mathrm{ng} / \mathrm{mL} ; \mathrm{p}=<0.001$ ). Hormone Concentrations in Staged Intrusions 
We calculated aggression scores and measured circulating testosterone concentrations for 32 females with our staged territorial intrusion paradigm (conspecific $=16$, apparatus $=8$, approach $=8$ ). For two females (one each from the approach and apparatus treatments), we collected data on behavior but lost hormone samples as part of the radioimmunoassay. Thus, any comparisons considering aggression alone include all individuals whose behavior we recorded $($ conspecific $=16$, apparatus $=9$, approach $=9$ ), but comparisons incorporating hormone data exclude the behavior scores of those two lost samples.

The average SVL and mass of females used in this study was $45.2 \mathrm{~mm} \pm 1.96 \mathrm{~mm}$ and $2.16 \mathrm{~g} \pm 0.288 \mathrm{~g}$, respectively. We collected hormone and behavioral data for eight females tested in each of the two control treatments (i.e., approach and apparatus), and 16 were tested in the staged territorial intrusion interactions (i.e., conspecific treatment). Females exhibited different degrees of aggression, but the aggression scores did not differ significantly across the three treatments $(p=0.34$, Figure 4$)$. The highest scores were observed in the conspecific treatment $(\max =111$, mean $=16.94 \pm 27.65)$. However, females in the control treatments did exhibit a few signaling displays, which are considered aggressive but are weighted lower than the escalated aggression observed for some females facing a conspecific in our scoring technique (Approach: $\max =10$, mean $=$ $2.63 \pm 3.89$, Apparatus: $\max =11$, mean $=2.88 \pm 3.91)$. Aggression scores were not correlated with testosterone (Figure 6). Testosterone concentrations did not differ between females $(n=13)$ that performed no aggressive behavior and those $(n=19)$ that performed at least one aggressive behavior (Kruksal Wallis test, $\mathrm{n}=13, \mathrm{p}>0.8$ ). 
We also evaluated whether asymmetry in body length between residents and intruders was associated with differences in aggressive response among the females in the conspecific treatment. We found that aggression scores were marginally higher for resident females that faced a larger intruder $($ mean $=7.90 \pm 10.9$, range $=0-31)$ than for resident females that faced a same-size or smaller intruder $($ mean $=32.0 \pm 40.2$, range $=5$ $-111 ; \mathrm{p}=0.057$, Figure 5 ). Neither testosterone (equal or larger: mean $=0.767 \mathrm{ng} / \mathrm{mL} \pm$ $1.12 \mathrm{ng} / \mathrm{mL}$, range $=0.296 \mathrm{ng} / \mathrm{mL}-4.95 \mathrm{ng} / \mathrm{mL} ;$ smaller: mean $=10.0 \mathrm{ng} / \mathrm{mL} \pm 2.38$ $\mathrm{ng} / \mathrm{mL}$, range $=0.023 \mathrm{ng} / \mathrm{mL}-5.90 \mathrm{ng} / \mathrm{mL}$ ) nor corticosterone (equal or larger: mean $=$ $2.05 \mathrm{ng} / \mathrm{mL} \pm 1.88 \mathrm{ng} / \mathrm{mL}$, range $=0.113 \mathrm{ng} / \mathrm{mL}-4.95 \mathrm{ng} / \mathrm{mL} ;$ smaller: mean $=2.18$ $\mathrm{ng} / \mathrm{mL} \pm 0.308 \mathrm{ng} / \mathrm{mL}$, range $0.315 \mathrm{ng} / \mathrm{mL}-3.75 \mathrm{ng} / \mathrm{mL}$ ) differed significantly between these groups ( $\mathrm{p}$ values for both comparisons were > 0.4 ).

We expanded our comparison of testosterone and corticosterone concentrations to include not only females in the experimental treatments, but also those for which we measured only baseline concentrations. Corticosterone was significantly higher in baseline females than in females from any other treatment ( $p<0.001$, Figures 7 and 8 ). Neither testosterone nor body condition differed significantly between any of the four treatments ( $\mathrm{p}$ values for all comparisons were $>0.50$ ).

For the females in the three treatments of the staged intrusions trials (Table 4), only model one received support (equal probability of the occurrence of undetectable concentrations in the different groups fit to the same gamma distribution for both groups; weight $=100 \%$, LOO ELPD $-58.9, \mathrm{SE}=11.5)$. Models two, three, and four all had weights of $0 \%$ (model 2: $\mathrm{LOO}$ ELPD $=-60.0, \mathrm{SE}=11.8 ;$ model 3: $\mathrm{LOO}$ ELPD $=-60.6$, $\mathrm{SE}=11.7$; model $4: \mathrm{LOO}$ ELPD $=-62.1, \mathrm{SE}=12.2)$. Our finding that only model one 
received support suggests that there is an equal probability of observing undetectable concentrations in all three of our treatments.

\section{Discussion}

The influence of testosterone on aggression has been widely investigated in a variety of animals, including Anolis lizards. However, few studies have characterized the heterologous function of testosterone in mediating female behaviors. Furthermore, few studies have characterized the profiles of circulating testosterone for free-living males and females of the same species. Here, we investigated the potential for baseline concentrations of circulating testosterone to vary across male and female Anolis gundlachi, and tested the hypothesis that individual variation in female aggressive behavior is associated with differences in testosterone. Male A. gundlachi exhibit significantly higher baseline concentrations of circulating testosterone than females do (Figure 2). Testosterone concentrations varied among individuals in both males and females, establishing the potential for differences in circulating hormone concentrations to explain differences in behavior. However, differences in aggression between females during agonistic interactions were not explained by differences in testosterone (Table 2, Figure 6). This observation is contrary to results from studies in males of other Anolis species (e.g., Tokarz 1985, Husak and Lovern 2014) and suggests that testosterone does not have a heterologous function across both sexes as a modulator of aggressive behavior.

Our finding that male A. gundlachi generally exhibit higher concentrations of testosterone than females aligns with observations in other taxonomic groups (reviewed in Wingfield 1984, Goymann and Wingfield 2014). This pattern has also been observed in laboratory studies of males and females of other Anolis species, but there is limited 
data for both sexes for anoles in the wild (but see Tokarz et al. 1998, Jenssen et al. 2001). Field data collected from males of multiple Anolis species distributed across several islands in the Caribbean indicate that testosterone concentrations differ among species and ecomorphs (Husak and Lovern 2014). Further studies of wild anoles that include measurements of female hormone concentrations may help to establish whether the pattern we observed among wild A. gundlachi and other researchers have observed in the lab is common across the genus, or whether further differences exist among the sexes, and across species, ecomorphs, or geographical locations.

Territorial aggression is well characterized in male Anolis lizards, and our results demonstrate that female A. gundlachi exhibit aggressive behaviors similar to males when facing territorial intruders. Females in our staged intrusion study performed displays such as dewlap extensions and pushups, postural modifications such as dorsoventral flattening, and engaged in physical confrontations including lunging at intruders (Tables 1 and 2). Although we observed females approaching the base of the tree and a few bouts of display behaviors by some females in the treatments in which we only walked up to the tree (approach) or presented females with an empty apparatus (apparatus), we only observed escalation in the behavioral trajectory of females presented with a conspecific intruder (Table 2). We observed display behavior by four out of 18 females in the treatments that did not include a conspecific intruder (i.e., approach and apparatus treatments), but these females did not perform more than two bouts of display (Table 2). This is much lower than females that were presented with a conspecific, in which 11 out of 16 females performed displays and two exhibited escalated aggressive behaviors (Table 2). This suggests that the presence of a conspecific elicits more aggressive 
behaviors in female A. gundlachi. These results align with our previous work with $A$. gundlachi (Cook et al. In Preparation) and with recent work in female Anolis sagrei (Reedy et al. 2017), which demonstrates that both males and females exhibit similar repertoires of territorial behaviors in response to conspecific intruders, although at different frequencies and intensities.

We observed substantial differences in aggressive behavior among females during staged agonistic interactions. Some females quickly and repeatedly performed aggressive displays and attempted physical confrontations with the intruder, while others never displayed at or approached the intruder (Table 2). We hypothesized that such differences in aggression would be explained by one of two factors: 1) asymmetry in residentintruder body sizes, and 2) resident circulating testosterone. Females facing an intruder that was larger than themselves exhibited more aggression than those facing intruders that were the same length or smaller than themselves (Figure 5), suggesting that asymmetry in body size may influence aggressive behavior. However, our findings failed to support the hypothesis that differences in testosterone predict differences in aggression. Although corticosterone, testosterone and aggression all varied among females, hormone concentrations did not differ significantly across the three treatments, indicating that the presence of a conspecific alone did not elicit a change in hormone concentration in females (Figures 8 and 9). Furthermore, testosterone was unrelated to aggression scores (Figure 6). Interestingly, a female that exhibited the highest aggressive behavior score in our study (score $=111$ ) and several females that exhibited no aggressive behaviors (score $=0, \mathrm{n}=9$ ) all had undetectably low concentrations. Thus, our results suggest that testosterone does not explain variation in aggression in female A. gundlachi. 
The finding that females facing intruders that were larger than themselves behaved more aggressively than those facing intruders of equal size or smaller has also been observed in other animal groups, and several hypotheses have been proposed to explain this behavior (e.g., Morrell et al. 2005). For instance, the 'desperado effect' hypothesis posits that small individuals may be more motivated to engage in aggression because they are unlikely to be able to secure resources in the future and thus benefit from initiating an aggressive interaction immediately or sustaining high aggression during an encounter to improve their already limited chances of winning a resource contest (Grafen 1987). Aggressive interactions can be costly, both in terms of resource expenditure and risk of injury or death, and thus individuals should theoretically engage in aggression as little as possible (e.g., Marler and Moore 1989, Knell 2009). By engaging in agonistic interactions quickly and aggressively, small individuals may deter large individuals from engaging in the interaction in favor of a contest they might win more easily. Success in contests has been associated with contest initiation in other groups (e.g., Taylor et al. 2001, Morrell 2004). Female A. gundlachi that faced intruders larger than themselves may have engaged in escalataed aggression to improve their chances of contest success as part of a tactic like the desperado effect. Future work should explore how asymmetries in body size between residents and intruders influence the outcome of territorial interactions in females.

Many females in our study, both from the general population and the staged territorial intrusions, exhibited testosterone concentrations that were undetectable in our assay $-67 \%$ for the general population and $68 \%$ for the staged intrusions. Only $10 \%$ of males exhibited undetectable testosterone concentrations. Furthermore, males in the 
general population had testosterone concentrations that were sixteen times higher than females, on average. Taken together, these findings suggest that female A. gundlachi may generally have very low circulating concentrations of testosterone relative to males. Furthermore, the results of our hurdle models indicate that there was no difference in the likelihood of observing undetectable concentrations across our three treatments (i.e., approach, apparatus, and conspecific; Table 4). If testosterone and aggression were associated, we would expect to observe more undetectably low concentrations in the two controls relative to the females that faced an intruder, the treatment in which aggressive behavior is most likely to occur. The fact that we did not observe this pattern in our study lends further support to our conclusion that testosterone is not associated with aggression in A. gundlachi.

Studies of testosterone in other Anolis species also report low testosterone concentrations in females. For example, Jenssen et al. (2001) reported concentrations of $0.02 \pm 0.01 \mathrm{ng} / \mathrm{mL}$ in female A. carolinensis, and Cox et al. (2014) reported concentrations of $0.366 \pm 0.42 \mathrm{ng} / \mathrm{mL}$ in female A. sagrei. Both are lower than the average concentration we observed in female A. gundlachi from the general population $(0.44 \pm 0.78 \mathrm{ng} / \mathrm{mL})$. Thus, it may be that female Anolis lizards, in general, exhibit very low concentrations of circulating testosterone relative to males. When females are experimentally implanted with testosterone and achieve circulating concentrations that are similar to males, they exhibit behavior patterns that more closely resemble males, including substantially heightened aggression (Mason and Adkins 1976, Lovern et al. 2001). As such, testosterone does have the potential to induce male-like aggression in female anoles. However, our observation that females with very low testosterone exhibit 
aggressive behavior, including many with concentrations below the detection sensitivity of the radioimmunoassay technique used in this study and many others (e.g., Tokarz 1985, Jenssen et al. 2001, Lovern et al. 2001, Cox et al. 2014, Husak and Lovern 2014), suggests that circulating testosterone may not be a major driver of aggression in female A. gundlachi.

We also found no association between aggression and corticosterone in our study. Corticosterone has been associated with aggression in several different animal groups (reviewed in McEwen 2000, Nelson 2005). Because one of the most important functions of corticosterone is to mobilize energy reserves to fuel behavioral interactions, it can be an important player in agonistic interactions (reviewed in Sapolsky 2000). Studies of corticosterone species in several different groups suggest a relationship between the glucocorticoid and aggression (reviewed in Summers and Winberg 2006). However, our observation that corticosterone and aggression were not associated is also supported in the literature (e.g., Denardo and Licht 1993, Oyegbile and Marler 2006, Garamszegi et al. 2012). It has been hypothesized that there is a trade-off between the expression of testosterone and corticosterone, but we found no evidence of such a trade-off (Figure 9). This finding suggests that exposing A. gundlachi to the staged intrusion paradigm did not induce production of corticosterone to a concentration that might have masked the expression of testosterone. Taken together, our findings suggest that there is standing variation in both hormones and aggression in A. gundlachi, but that neither hormone measured in the present study is likely to be a major modulator of aggressive behaviors in female A. gundlachi. 
Efforts to include both males and females in endocrinology studies have revealed complexity in hormone-behavior relationships. For example, work with a songbird suggests that females faced with an intruder exhibited lower testosterone than control females, and female iguanas that engaged in aggressive interactions had lower testosterone than non-aggressive females (Elekonich and Wingfield 2000, Rubenstein and Wikelski 2005). Sex differences in hormone production, metabolism, and response initiated during development may translate to different associations between hormones and behavior in adults of the two sexes. The size differences between male and female $A$. gundlachi, for example, may result in substantial sex differences in the capacity of individuals to produce hormones, how quickly they move throughout the body, and the quantity required to elicit behavioral change (Simon 2002). As such, it will be important to consider how these potential differences may influence hormone-behavior relationships in males and females (Rosvall 2013).

While we find no evidence to support an association between plasma testosterone and/or corticosterone and aggression in A. gundlachi in our study, future work should consider the potential for different parts of the hormone production-expressionmetabolism pathways to influence behavior (Sih et al. 2004, McGuire and Bentley 2010, Svare 2013, Rosvall 2013, Celec et al. 2015). We analyzed concentrations present in plasma in this study and observed no association between aggression and plasma concentrations of either. Future work considering individual variation in production of hormones (Sih et al. 2004, McGuire et al. 2010, Svare 2013, Rosvall 2013, Celec et al. 2015) or response to them (Canoine et al. 2007, Rosvall et al. 2012), such as individual 
differences in receptor density, may help to elucidate the complex relationships between hormones, behavior, and fitness.

A growing body of literature suggests that female aggression is more than simply a byproduct of the evolution of aggression in males-aggressive interactions among females can have important implications for access to resources, the distribution of individuals across landscapes, and which individuals interact (reviewed in Stockley and Bro-Jorgensen 2011, Tobias et al. 2012, Clutton-Brock and Huchard 2013). The results of our study suggest that a similar suite of behaviors exhibited by male and female $A$. gundlachi may be differently influenced by a shared mechanism, or perhaps be mediated by different traits entirely. We encourage future studies to consider including both sexes when addressing the potential role of a given mechanism in modulating behaviors in order to develop more cohesive frameworks to understand those behaviors, and avoid the pitfalls of studies evaluating the mechanisms driving territoriality or aggression in just one sex.

\section{Acknowledgements}

We thank D. Lopez-Nieves, J. Pita-Aquino, and P. Pearson for their assistance in data collection. We thank A. Messerman, S. Michaels, and L. Storks for comments on an earlier version of the manuscript, and J. Burkhart and K. Middleton for their assistance with data analysis. We thank the Departmento de Recursos Naturales y Ambientales for permitting for this work, and El Verde Field Station for use of facilities. This work was conducted in compliance with protocols approved by the ACUC of the University of Missouri. This work was supported by funding from the University of Missouri, National Science Foundation, Animal Behavior Society, and Sigma-Xi Society for Research. 


\section{References}

Adkins-Regan, E. (2005). Hormones and animal social behavior. Princeton University Press.

Adkins-Regan, E., \& Wade, J. (2001). Masculinized sexual partner preference in female zebra finches with sex-reversed gonads. Hormones and Behavior, 39(1), 22-28.

Andrews, R. M. (1971). Structural habitat and time budget of a tropical Anolis lizard. Ecology, 52(2), 262-270.

Baird, T. A., Acree, M. A., \& Sloan, C. L. (1996). Age and gender-related differences in the social behavior and mating success of free-living collared lizards, Crotaphytus collaris. Copeia, 336-347.

Benus, R. F., Bohus, B., Koolhaas, J. M., \& Van Oortmerssen, G. A. (1991). Heritable variation for aggression as a reflection of individual coping strategies. Experientia, 47(10), 1008- 1019.

Bertram, S. M., \& Rook, V. (2012). Relationship between condition, aggression, signaling, courtship, and egg laying in the field cricket, Gryllus assimilis. Ethology, 118(4), 360-372.

Beehner, J. C., Bergman, T. J., Cheney, D. L., Seyfarth, R. M., \& Whitten, P. L. (2006). Testosterone predicts future dominance rank and mating activity among male chacma baboons. Behavioral Ecology and Sociobiology, 59(4), 469-479.

Beuttell, K., \& Losos, J. B. (1999). Ecological morphology of Caribbean anoles. Herpetological Monographs, 1-28.

Buchanan, K. L., Evans, M. R., Goldsmith, A. R., Bryant, D. M., \& Rowe, L. V. (2001). Testosterone influences basal metabolic rate in male house sparrows: a new cost of dominance signaling?. Proceedings of the Royal Society of London. Series B: Biological Sciences, 268(1474), 1337-1344.

Bürkner, P.C. (2017). brms: An R Package for Bayesian Multilevel Models Using Stan. Journal of Statistical Software, 80(1), 1-28.<doi:10.18637/jss.v080.i01>

Canoine, V., Fusani, L., Schlinger, B., \& Hau, M. (2007). Low sex steroids, high steroid receptors: increasing the sensitivity of the nonreproductive brain. Developmental Neurobiology, 67(1), 57-67.

Carpenter, C. C. (1978). Ritualistic social behavior in lizards. In: Behavior and Neurology of Lizards (Ed. by N. Greenberg \& P. D. MacLean), pp. 253-267. Maryland: National Institute of Mental Health. 
Celec, P., Ostatníková, D., \& Hodosy, J. (2015). On the effects of testosterone on brain behavioral functions. Frontiers in Neuroscience, 9, 12.

Collias, N. E. (1944). Aggressive behavior among vertebrate animals. Physiological Zoology, 17(1), 83-123.

Clutton-Brock, T. (2007). Sexual selection in males and females. Science, 318(5858), 1882-1885.

Clutton-Brock, T. (2009). Sexual selection in females. Animal Behaviour, 77(1), 3-11.

Clutton-Brock, T. H., \& Huchard, E. (2013). Social competition and selection in males and females. Philosophical Transactions of the Royal Society B: Biological Sciences, 368(1631), 20130074.

Cox, R. M., Lovern, M. B., \& Calsbeek, R. (2014). Experimentally decoupling reproductive investment from energy storage to test the functional basis of a life-history trade-off. Journal of Animal Ecology, 83(4), 888-898.

Cox, C. L., Hanninen, A. F., Reedy, A. M., \& Cox, R. M. (2015). Female anoles retain responsiveness to testosterone despite the evolution of androgen-mediated sexual dimorphism. Functional Ecology, 29(6), 758-767.

Denardo, D. F., \& Licht, P. (1993). Effects of corticosterone on social behavior of male lizards. Hormones and Behavior, 27(2), 184-199.

Desjardins, J. K., Hofmann, H. A., \& Fernald, R. D. (2012). Social context influences aggressive and courtship behavior in a cichlid fish. PLoS One, 7(7), e32781.

Echelle, A. A., Echelle, A. F., \& Fitch, H. S. (1971). A comparative analysis of aggressive display in nine species of Costa Rican Anolis. Herpetologica, 271288.

Elekonich, M. M., \& Wingfield, J. C. (2000). Seasonality and hormonal control of territorial aggression in female song sparrows (Passeriformes: Emberizidae: Melospiza melodia). Ethology, 106(6), 493-510.

Evans, L. T. (1936). Territorial behavior of normal and castrated females of Anolis carolinensis. The Pedagogical Seminary and Journal of Genetic Psychology, 49(1), 49-60.

Evans, L. T. (1938). Cuban field studies on territoriality of the lizard Anolis sagrei. Journal of Comparative Psychology, 25(1), 97.

Fleishman, L. J. (1988). The social behavior of Anolis auratus, a grass anole from Panama. Journal of Herpetology, 13-23. 
Francis, R. C. (1990). Temperament in a fish: a longitudinal study of the development of individual differences in aggression and social rank in the Midas cichlid. Ethology, 86(4), 311-325.

Garamszegi, L. Z., Markó, G., \& Herczeg, G. (2012). A meta-analysis of correlated behaviours with implications for behavioural syndromes: mean effect size, publication bias, phylogenetic effects and the role of mediator variables. Evolutionary Ecology, 26(5), 1213-1235.

Goymann, W., East, M. L., \& Hofer, H. (2001). Androgens and the role of female "hyperaggressiveness" in spotted hyenas (Crocuta crocuta). Hormones and Behavior, 39(1), 83-92.

Goymann, W., \& Wingfield, J. C. (2014). Male-to-female testosterone ratios, dimorphism, and life history - what does it really tell us?. Behavioral Ecology, 25(4), 685-699.

Grafen, A. (1987). The logic of divisively asymmetric contests: respect for ownership and the desperado effect. Animal Behaviour, 35(2), 462-467.

Greenberg, N., \& Crews, D. (1990). Endocrine and behavioral responses to aggression and social dominance in the green anole lizard, Anolis carolinensis. General and Comparative Endocrinology, 77(2), 246-255.

Greenberg, B., \& Noble, G. K. (1944). Social behavior of the American chameleon (Anolis carolinensis voigt). Physiological Zoology, 17(4), 392-439.

Groves, S. (1978). Age-related differences in Ruddy Turnstone foraging and aggressive behavior. The Auk, 95(1), 95-103.

Hau, M., Gill, S. A., \& Goymann, W. (2008). Tropical field endocrinology: ecology and evolution of testosterone concentrations in male birds. General and Comparative Endocrinology, 157(3), 241-248.

Hews, D. K., Hara, E., \& Anderson, M. C. (2012). Sex and species differences in plasma testosterone and in counts of androgen receptor-positive cells in key brain regions of Sceloporus lizard species that differ in aggression. General and Comparative Endocrinology, 176(3), 493-499.

Husak, J. F., Irschick, D. J., Meyers, J. J., Lailvaux, S. P., \& Moore, I. T. (2007). Hormones, sexual signals, and performance of green anole lizards (Anolis carolinensis). Hormones and Behavior, 52(3), 360-367. 
Husak, J. F., \& Lovern, M. B. (2014). Variation in steroid hormone levels among Caribbean Anolis lizards: Endocrine system convergence?. Hormones and behavior, 65(4), 408-415.

Jenssen, T. A. (1977). Evolution of anoline lizard display behavior. American Zoologist, 17(1), 203-215.

Jenssen, T. A., \& Nunez, S. C. (1998). Spatial and breeding relationships of the lizard, Anolis carolinensis: evidence of intrasexual selection. Behaviour, 981-1003.

Jenssen, T. A., Lovern, M. B., \& Congdon, J. D. (2001). Field-testing the protandrybased mating system for the lizard, Anolis carolinesis: does the model organism have the right model?. Behavioral Ecology and Sociobiology, 50(2), 162172.

Jenssen, T. A., Decourcy, K. R., \& Congdon, J. D. (2005). Assessment in contests of male lizards (Anolis carolinensis): how should smaller males respond when size matters?. Animal Behaviour, 69(6), 1325-1336.

Johnson, M. A., Revell, L. J., \& Losos, J. B. (2010). Behavioral convergence and adaptive radiation: effects of habitat use on territorial behavior in Anolis lizards. Evolution: International Journal of Organic Evolution, 64(4), 1151-1159.

Jones, R. E., Guillette Jr, L. J., Summers, C. H., Tokarz, R. R., \& Crews, D. (1983). The relationship among ovarian condition, steroid hormones, and estrous behavior in Anolis carolinensis. Journal of Experimental Zoology, 227(1), 145-154.

Knell, R. J. (2009). Population density and the evolution of male aggression. Journal of Zoology, 278(2), 83-90.

Kravitz, E. A., \& Huber, R. (2003). Aggression in invertebrates. Current Opinion in Neurobiology, 13(6), 736-743.

Langmore, N. E. (1998). Functions of duet and solo songs of female birds. Trends in Ecology \& Evolution, 13(4), 136-140.

Leshner, A. I. (1975). A model of hormones and agonistic behavior. Physiology \& Behavior, 15(2), 225-235.

Levin, R. N., \& Wingfield, J. C. (1992). The hormonal control of territorial aggression in tropical birds. Ornis Scandinavica, 284-291.

Logan, C. A., \& Wingfield, J. C. (1990). Autumnal territorial aggression is independent of plasma testosterone in mockingbirds. Hormones and Behavior, 24(4), 568581. 
Losos, J. B. (1990). Ecomorphology, performance capability, and scaling of West Indian Anolis lizards: an evolutionary analysis. Ecological Monographs, 60(3), 369388.

Lovern, M. B., McNabb, F. A., \& Jenssen, T. A. (2001). Developmental effects of testosterone on behavior in male and female green anoles (Anolis carolinensis). Hormones and Behavior, 39(2), 131-143.

Mahrt, L. A. (1998). Territorial establishment and maintenance by female tree lizards, Urosaurus ornatus. Journal of Herpetology, 176-182.

Marler, C. A., \& Moore, M. C. (1989). Time and energy costs of aggression in testosterone-implanted free-living male mountain spiny lizards (Sceloporus jarrovi). Physiological Zoology, 62(6), 1334-1350.

Martins, E. P. (1991). Individual and sex differences in the use of the push-up display by the sagebrush lizard, Sceloporus graciosus. Animal Behaviour, 41(3), 403-416.

Mason, P., \& Adkins, E. K. (1976). Hormones and social behavior in the lizard, Anolis carolinensis. Hormones and behavior, 7(1), 75-86.

McEwen, B. S. (2000). The neurobiology of stress: from serendipity to clinical relevance. Brain Research, 886(1-2), 172-189.

McGuire, N. L., \& Bentley, G. E. (2010). A functional neuropeptide system in vertebrate gonads: gonadotropin-inhibitory hormone and its receptor in testes of fieldcaught house sparrow (Passer domesticus). General and Comparative Endocrinology, 166(3), 565-572.

Møller, A. P., Garamszegi, L. Z., Gil, D., Hurtrez-Boussès, S., \& Eens, M. (2005). Correlated evolution of male and female testosterone profiles in birds and its consequences. Behavioral Ecology and Sociobiology, 58(6), 534-544.

Morrell, L. J. (2004). Ownership conflicts and their resolution (Doctoral dissertation, University of Glasgow).

Morrell, L. J., Lindström, J., \& Ruxton, G. D. (2005). Why are small males aggressive?. Proceedings of the Royal Society B: Biological Sciences, 272(1569), 12351241.

Muller, M. N., \& Wrangham, R. W. (2004). Dominance, aggression and testosterone in wild chimpanzees: a test of the 'challenge hypothesis'. Animal Behaviour, 67(1), 113-123.

Negro, S. S., Caudron, A. K., Dubois, M., Delahaut, P., \& Gemmell, N. J. (2010). Correlation between male social status, testosterone levels, and parasitism in a dimorphic polygynous mammal. PLoS One, 5(9), e12507. 
Nelson, R. J. (Ed.). (2005). Biology of aggression. Oxford University Press.

Nunez, S. C., Jenssen, T. A., \& Ersland, K. (1997). Female activity profile of a polygynous lizard (Anolis carolinensis): evidence of intersexual asymmetry. Behaviour, 134(3-4), 205-223.

Oliveira, R. F. (2005). Hormones, social context and animal communication. In P. K. McGregor, Animal Communication Networks, 481-520. Cambridge University Press, London.

Oyegbile, T. O., \& Marler, C. A. (2006). Weak winner effect in a less aggressive mammal: correlations with corticosterone but not testosterone. Physiology \& behavior, 89(2), 171-179.

Philibosian, R. (1975). Territorial behavior and population regulation in the lizards, Anolis acutus and A. cristatellus. Copeia, 428-444.

Probst, B., Eisermann, K., \& Stöhr, W. (1987). Diurnal patterns of scent-marking, serum testosterone concentration and heart rate in male Mongolian gerbils. Physiology \& Behavior, 41(6), 543-547.

R Core Team (2018). R: A language and environment for statistical computing. $R$ Foundation for Statistical Computing, Vienna, Austria. URL https://www.Rproject.org/.

Rand, A. S. (1964). Ecological distribution in anoline lizards of Puerto Rico. Ecology, $45(4), 745-752$.

Reedy, A. M., Pope, B. D., Kiriazis, N. M., Giordano, C. L., Sams, C. L., Warner, D. A., $\&$ Cox, R. M. (2017). Female anoles display less but attack more quickly than males in response to territorial intrusions. Behavioral Ecology, 28(5), 13231328.

Rodríguez-Robles, J. A., Leal, M., \& Losos, J. B. (2005). Habitat selection by the Puerto Rican yellow-chinned anole, Anolis gundlachi. Canadian journal of zoology, 83(7), 983-988.

Rosvall, K. A. (2013). Proximate perspectives on the evolution of female aggression: good for the gander, good for the goose?. Philosophical Transactions of the Royal Society B: Biological Sciences, 368(1631), 20130083.

Rosvall, K. A., Bergeon Burns, C. M., Barske, J., Goodson, J. L., Schlinger, B. A., Sengelaub, D. R., \& Ketterson, E. D. (2012). Neural sensitivity to sex steroids predicts individual differences in aggression: implications for behavioural 
evolution. Proceedings of the Royal Society B: Biological Sciences, 279(1742), 3547-3555.

RStudio Team (2016). RStudio: Integrated Development for R. RStudio, Inc., Boston, MA. URL http://www.rstudio.com/.

Rubenstein, D. R., \& Wikelski, M. (2005). Steroid hormones and aggression in female Galapagos marine iguanas. Hormones and Behavior, 48(3), 329-341.

Sapolsky, R. M. (2000). Stress hormones: good and bad. Neurobiology of disease, 7(5), $540-542$

Schlinger, B. A., \& Callard, G. V. (1990). Aromatization mediates aggressive behavior in quail. General and Comparative Endocrinology, 79(1), 39-53.

Schoener, T. W., \& Schoener, A. (1982). Intraspecific variation in home-range size in some Anolis lizards. Ecology, 63(3), 809-823.

Sih, A., Bell, A., \& Johnson, J. C. (2004). Behavioral syndromes: an ecological and evolutionary overview. Trends in Ecology \& Evolution, 19(7), 372-378.

Simon, N. G., Mo, Q., Hu, S., Garippa, C., \& Lu, S. F. (2006). Hormonal pathways regulating intermale and interfemale aggression. International Review of Neurobiology, 73, 99-123.

Smith, L. C., \& John-Alder, H. B. (1999). Seasonal specificity of hormonal, behavioral, and coloration responses to within-and between-sex encounters in male lizards (Sceloporus undulatus). Hormones and Behavior, 36(1), 39-52.

Soma, K. K., Scotti, M. A. L., Newman, A. E., Charlier, T. D., \& Demas, G. E. (2008). Novel mechanisms for neuroendocrine regulation of aggression. Frontiers in Neuroendocrinology, 29(4), 476-489.

Stamps, J. A. (1973). Displays and social organization in female Anolis aeneus. Copeia, 264-272.

Stockley, P., \& Bro-Jørgensen, J. (2011). Female competition and its evolutionary consequences in mammals. Biological Reviews, 86(2), 341-366.

Stockley, P., \& Campbell, A. (2013). Female competition and aggression: interdisciplinary perspectives. Philosophical Transactions of the Royal Society B: Biology Sciences , 368 (1631): 20130073

Summers, C. H., \& Winberg, S. (2006). Interactions between the neural regulation of stress and aggression. Journal of Experimental Biology, 209(23), 4581-4589. 
Svare, B. B. (2013). Hormones and aggressive behavior. Springer Science \& Business Media.

Taylor, P. W., Hasson, O., \& Clark, D. L. (2001). Initiation and resolution of jumping spider contests: roles for size, proximity, and early detection of rivals. Behavioral Ecology and Sociobiology, 50(5), 403-413.

Tobias, J. A., Montgomerie, R., \& Lyon, B. E. (2012). The evolution of female ornaments and weaponry: social selection, sexual selection and ecological competition. Philosophical Transactions of the Royal Society B: Biological Sciences, 367(1600), 2274-2293.

Tokarz, R. R. (1985). Body size as a factor determining dominance in staged agonistic encounters between male brown anoles (Anolis sagrei). Animal Behaviour, 33(3), 746-753.

Tokarz, R. R., \& Crews, D. (1981). Effects of prostaglandins on sexual receptivity in the female lizard, Anolis carolinensis. Endocrinology, 109(2), 451-457.

Tokarz, R. R., McMann, S., Seitz, L., \& John-Alder, H. (1998). Plasma corticosterone and testosterone levels during the annual reproductive cycle of male brown anoles (Anolis sagrei). Physiological Zoology, 71(2), 139-146.

Wack, C. L., Fox, S. F., Hellgren, E. C., \& Lovern, M. B. (2008). Effects of sex, age, and season on plasma steroids in free-ranging Texas horned lizards (Phrynosoma cornutum). General and Comparative Endocrinology, 155(3), 589-596.

Wade, J. (2005). Current research on the behavioral neuroendocrinology of reptiles. Hormones and Behavior, 48(4), 451-460.

Wingfield, J. C., \& Farner, D. S. (1978). The annual cycle of plasma irLH and steroid hormones in feral populations of the white-crowned sparrow, Zonotrichia leucophrys gambelii. Biology of reproduction, 19(5), 1046-1056.

Wingfield, J. C. (1984). Environmental and endocrine control of reproduction in the song sparrow, Melospiza melodia: II. Agonistic interactions as environmental information stimulating secretion of testosterone. General and Comparative Endocrinology, 56(3), 417-424.

Wingfield, J. C., \& Farner, D. S. (1975). The determination of five steroids in avian plasma by radioimmunoassay and competitive protein-binding. Steroids, 26(3), 311-327.

Wingfield, J. C., Hegner, R. E., Dufty Jr, A. M., \& Ball, G. F. (1990). The" challenge hypothesis": theoretical implications for patterns of testosterone secretion, 
mating systems, and breeding strategies. The American Naturalist, 136(6), 829846.

Wolff, J. O. (1993). Why are female small mammals territorial?. Oikos, 364-370.

Wolff, J. O., \& Peterson, J. A. (1998). An offspring-defense hypothesis for territoriality in female mammals. Ethology Ecology \& Evolution, 10(3), 227-239.

Woodley, S. K., \& Moore, M. C. (1999). Female territorial aggression and steroid hormones in mountain spiny lizards. Animal Behaviour, 57(5), 1083-1089.

Yasukawa, K., \& Searcy, W. A. (1982). Aggression in female red-winged blackbirds: a strategy to ensure male parental investment. Behavioral Ecology and Sociobiology, 11(1), 13-17. 
Table 1: Descriptions of the behaviors associated with territoriality in female Anolis gundlachi, based on accounts of territorial behavior in male Anolis lizards (e.g.,

Flieshman 1988, Husak and Lovern 2014). Also included are the variable names assigned to each behavior (for use in table 2), and the scores assigned to each. Weights associated with behaviors are based on observations of natural behavior of female A. gundlachi, and reflect the likelihood that individuals, in their natural habitat and social interactions, progress between performing increasingly aggressive behaviors (Cook et al. In Preparation).

\begin{tabular}{|l|c|c|l|}
\hline Behavior & $\begin{array}{c}\text { Representative } \\
\text { Variable }\end{array}$ & Weight & Description \\
\hline Approach & $\mathrm{W}$ & 1 & $\begin{array}{l}\text { Movement to a distance within } \\
\text { approximately 2 feet of the base of } \\
\text { tree (approach only treatment), empty } \\
\text { apparatus, or conspecific on apparatus }\end{array}$ \\
\hline Display & $\mathrm{X}$ & 5 & $\begin{array}{l}\text { Performance of dewlap extensions, } \\
\text { pushups, and/or head-bobs }\end{array}$ \\
\hline $\begin{array}{l}\text { Escalated } \\
\text { Aggression }\end{array}$ & $\mathrm{Y}$ & 15 & $\begin{array}{l}\text { Performance of posturing, opening of } \\
\text { mouth, extension of tongue, and/or } \\
\text { darkening of coloration }\end{array}$ \\
\hline Lunge & $\mathrm{Z}$ & 30 & $\begin{array}{l}\text { Lunging movement toward base of } \\
\text { tree, apparatus, or conspecific (based } \\
\text { on treatment), with obvious intent to } \\
\text { strike }\end{array}$ \\
\hline
\end{tabular}


Table 2: We observed the behavior of 34 females in the staged intrusion study -9 females in the treatment in which we only walked up to the resident's tree (approach), 9 females in the treatment in which we presented the resident with an empty apparatus (apparatus), and 16 females in the treatment in which a conspecific was attached to the apparatus (conspecific). In total, nineteen females performed aggressive behaviors in the three treatments of the staged intrusions. Females exhibited different combinations of behaviors: $\mathrm{W}=$ approach within two feet of base of tree, apparatus, or conspecific; $\mathrm{X}=$ display (e.g., dewlap extension and pushups), Y = escalated aggression (posturing, opening of mouth), $\mathrm{Z}=$ lunge. Scores are calculated by awarding the following weights to each behavior: $\mathrm{W}=1, \mathrm{X}=5, \mathrm{Y}=15, \mathrm{Z}=30$ (see Table 1 for descriptions of behaviors and weights). These behavioral scores were awarded based on assessment of behavioral observations of free-living females in their natural habitat and social context, and the calculated likelihood of exhibiting progressively more aggressive behaviors. The remaining 15 individuals performed no behaviors represented on this scale during focal observations.

\begin{tabular}{|c|c|c|c|c|}
\hline Lizard ID & Treatment & Score & $\begin{array}{l}\text { Bouts of } \\
\text { Behavior }\end{array}$ & $\begin{array}{c}\text { Behaviors } \\
\text { Performed }\end{array}$ \\
\hline GU011 & Conspecific & 31 & 7 & $W+6 X$ \\
\hline GU012 & Conspecific & 111 & 7 & $W+X+3 Y+Z$ \\
\hline GU013 & Conspecific & 10 & 5 & $5 X$ \\
\hline GU014 & Conspecific & 11 & 3 & $W+2 X$ \\
\hline GU017 & Conspecific & 5 & 1 & $X$ \\
\hline GU018 & Conspecific & 20 & 4 & $4 X$ \\
\hline GU022 & Conspecific & 26 & 6 & $W+5 X$ \\
\hline GU023 & Conspecific & 5 & 1 & $\mathrm{X}$ \\
\hline GU027 & Conspecific & 36 & 8 & $W+7 X$ \\
\hline GU029 & Conspecific & 10 & 2 & $2 X$ \\
\hline GU034 & Conspecific & 6 & 2 & $W+X$ \\
\hline GU038 & Apparatus & 1 & 1 & $\mathrm{~W}$ \\
\hline GU039 & Apparatus & 1 & 1 & $\mathrm{~W}$ \\
\hline GU040 & Apparatus & 11 & 3 & $W+2 X$ \\
\hline
\end{tabular}




\begin{tabular}{|l|l|c|c|c|}
\hline GU041 & Apparatus & 5 & 1 & X \\
\hline GU046 & Apparatus & 5 & 1 & X \\
\hline GU048 & Approach & 6 & 2 & W + X \\
\hline GU051 & Approach & 10 & 2 & $2 \mathrm{X}$ \\
\hline GU057 & Approach & 5 & 1 & X \\
\hline
\end{tabular}


Table 3: Model comparison of four hurdle models predicting the probability of observing testosterone concentrations below the sensitivity of the assay among males and females in the general population. Samples that were below the sensitivity of the assay were assigned a value of zero. The hurdle models first fit the probability of observing zero and non-zero concentrations, and then fits the non-zero observations to a gamma distribution. We fit four different candidate models for the two groups (i.e., males and females) of the general population: 1) equal probability of the occurrence of undetectable concentrations in the different groups (e.g., males and females) fit to the same gamma distribution; 2) equal probability of the occurrence of undetectable concentrations in the different groups, fit to different gamma distributions for each group; 3) unequal probability of the occurrence of undetectable concentrations in the different groups, fit to same gamma distribution; and 4) unequal probability of the occurrence of undetectable concentrations in the different groups, fit to different gamma distributions for each group. We report the weights of the different models, as well as the LOO ELPD of the models with respective standard error.

\begin{tabular}{|l|l|l|}
\hline Model: Parameters & LOO ELPD (Standard & Model Weight \\
\hline Model 1: $\mathrm{P}[0]_{\text {shared }} \Gamma_{\text {shared }}$ & $-281.0(12.6)$ & $0 \%$ \\
\hline Model 2: $\mathrm{P}[0]_{\text {shared }} \Gamma_{\text {sex }}$ & $-271.5(12.7)$ & $5.6 \%$ \\
\hline Model 3: $\mathrm{P}[0]_{\text {sex }} \Gamma_{\text {shared }}$ & $-265.6(14.2)$ & $0 \%$ \\
\hline Model 4: $\mathrm{P}[0]_{\text {sex }} \Gamma_{\text {sex }}$ & $-256.1(13.6)$ & $94.4 \%$ \\
\hline
\end{tabular}


Table 4: Comparison of four hurdle models as in Table 3. We fit four different candidate models for the three treatment groups (i.e., approach, apparatus, and conspecific) of the staged intrusion study: 1) equal probability of the occurrence of undetectable concentrations in the different groups (i.e., approach, apparatus, and conspecific), fit to the same gamma distribution; 2) equal probability of the occurrence of undetectable concentrations in the different groups, fit to different gamma distributions for each group; 3) unequal probability of the occurrence of undetectable concentrations in the different groups, fit to same gamma distribution; and 4) unequal probability of the occurrence of undetectable concentrations in the different groups, fit to different gamma distributions for each group. We report the weights of the different models, as well as the LOO ELPD of the models with respective standard error.

\begin{tabular}{|l|l|l|}
\hline Model: Parameters & LOO ELPD (Standard Error) & Model Weight \\
\hline Model 1: $\mathrm{P}[0]_{\text {shared }} \Gamma_{\text {shared }}$ & $-58.9(11.5)$ & $100 \%$ \\
\hline Model 2: $\mathrm{P}[0]_{\text {shared }} \Gamma_{\text {treatment }}$ & $-60.0(11.8)$ & $0 \%$ \\
\hline Model 3: $\mathrm{P}[0]_{\text {treatment }} \Gamma_{\text {shared }}$ & $-60.6(11.7)$ & $0 \%$ \\
\hline Model 4: $\mathrm{P}[0]_{\text {treatment }} \Gamma_{\text {treatment }}$ & $-62.1(12.2)$ & $0 \%$ \\
\hline
\end{tabular}


Figure 1: Concentrations of circulating corticosterone and testosterone $(\mathrm{ng} / \mathrm{mL})$ relative to volume of plasma $(\mathrm{uL})$ used for hormone analysis for each individual in the study $(\mathrm{n}=$ 121). Lines represent linear regressions, and shaded regions represent standard error.

Corticosterone concentrations are represented with black circles, and testosterone concentrations are represented by grey triangles.

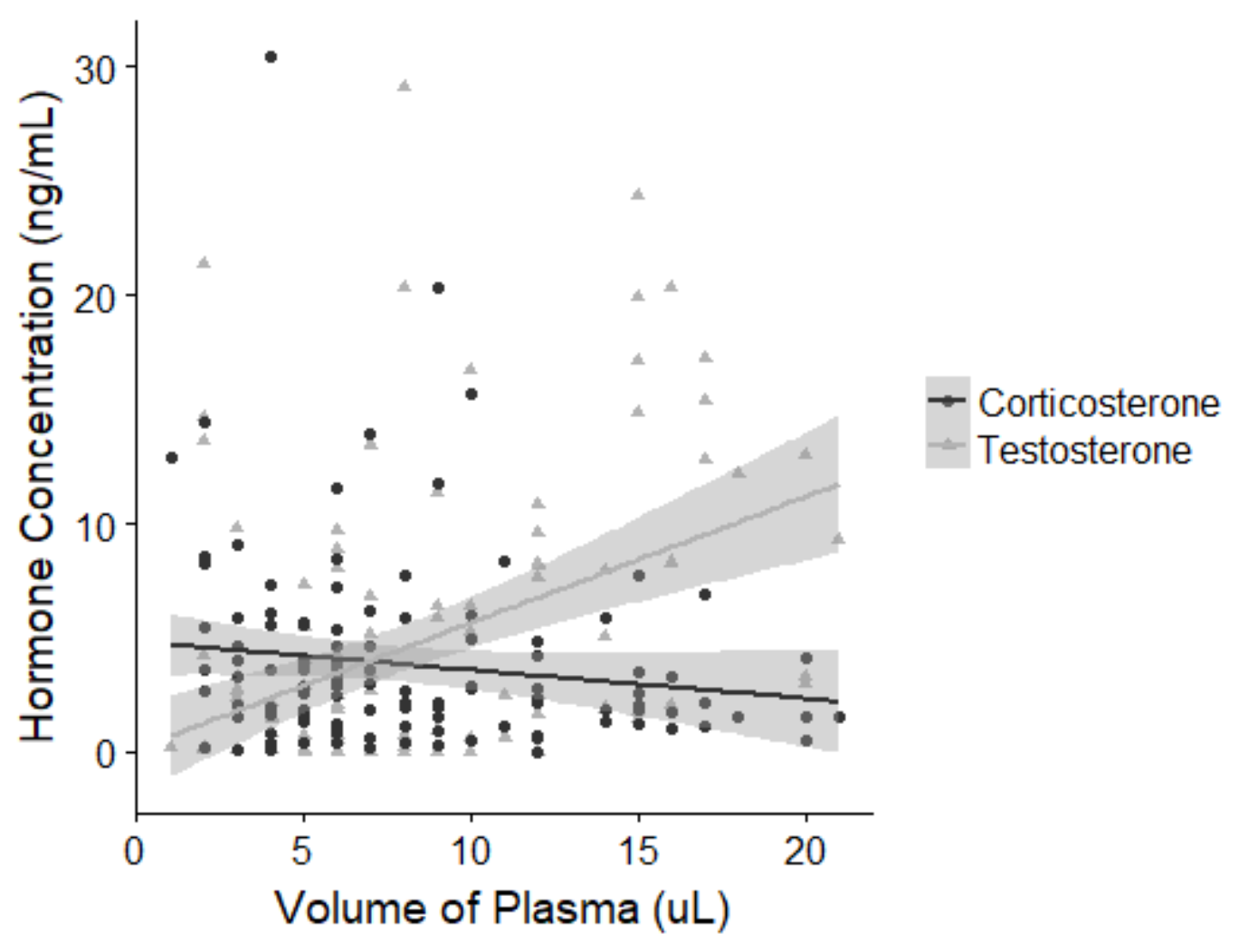


Figure 2: Baseline concentrations of circulating testosterone of males $(n=63)$ and females $(n=26)$ sampled from the general population of Anolis gundlachi at our study site. Median testosterone concentrations for males was $6.35 \mathrm{ng} / \mathrm{mL}$, and the median concentration for females was $0.055 \mathrm{ng} / \mathrm{mL}$. The box indicates the upper and lower $25 \%$ quartile range, the center lines indicate the median, and bars indicate the maximum and minimum values excluding outliers.

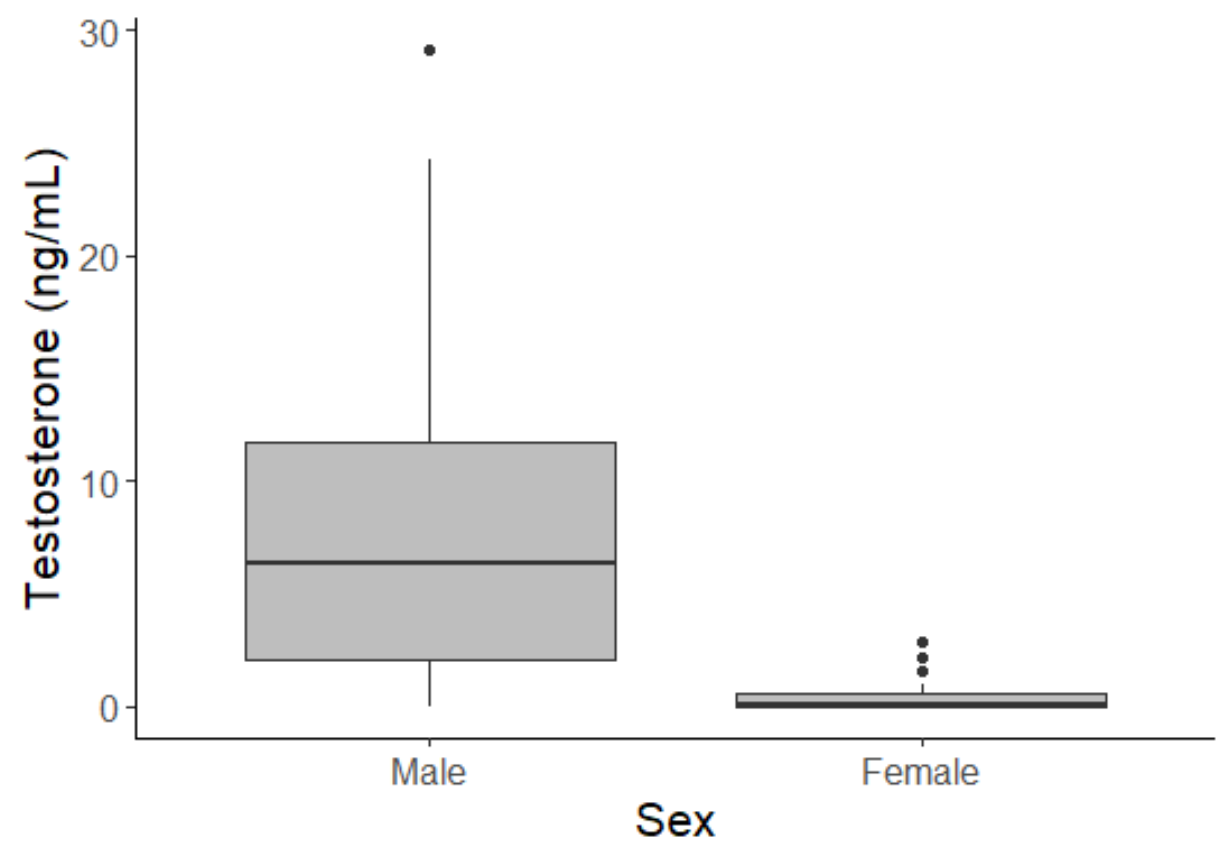


Figure 3: Baseline concentrations of circulating corticosterone of males $(n=63)$ and females $(n=26)$ sampled from the general population of Anolis gundlachi at our study site. Median corticosterone concentrations for males was $2.13 \mathrm{ng} / \mathrm{mL}$, and the median concentration for females was $5.52 \mathrm{ng} / \mathrm{mL}$. The box indicates the upper and lower $25 \%$ quartile range, the center lines indicate the median, and bars indicate the maximum and minimum values excluding outliers.

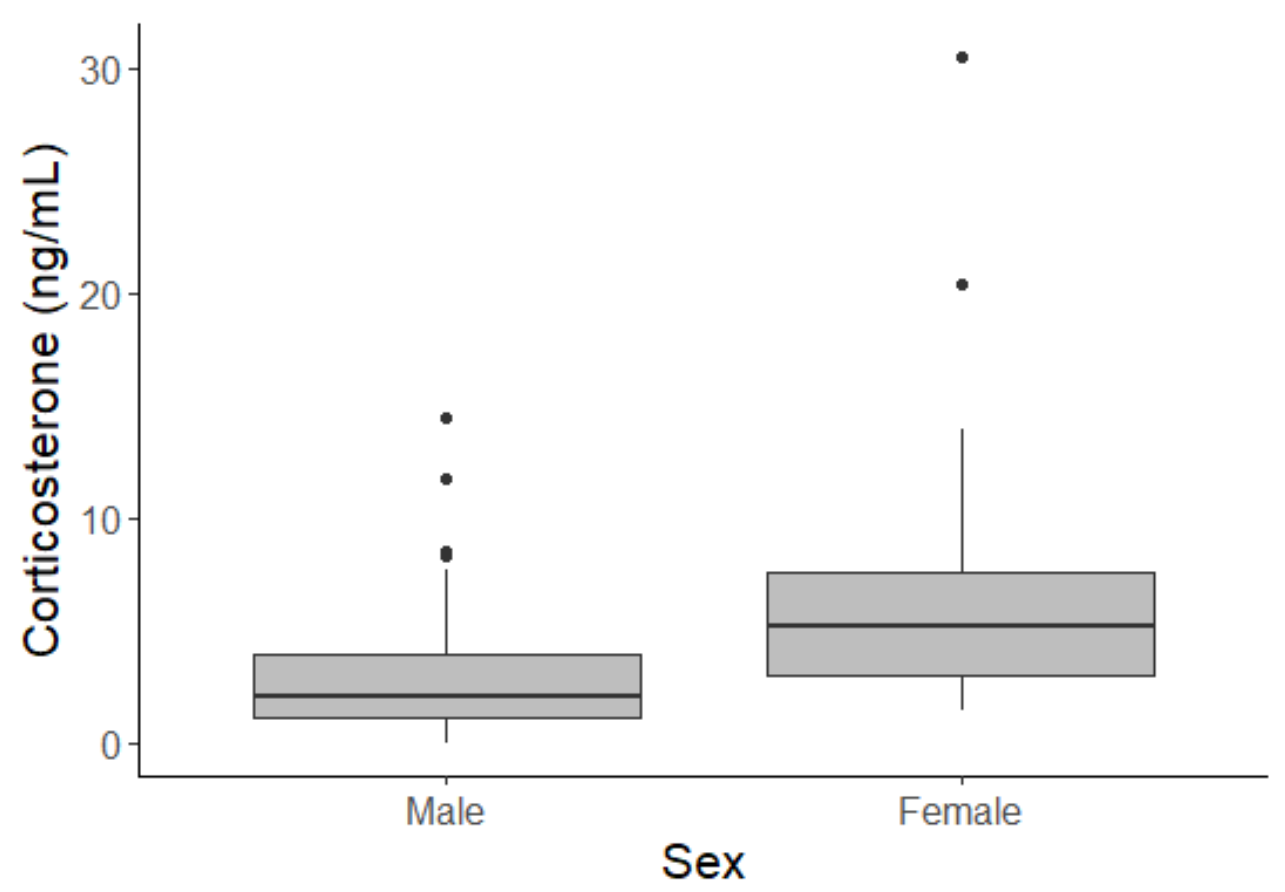


Figure 4: Aggression scores of females that behaved in the three treatments of the staged intrusion study (approach $n=9$, apparatus $=9$, conspecific $=16$ ). These sample sizes include two individuals (one each from the approach and apparatus treatments) for which we measured aggressive responses, but lost hormone samples as part of the assay. Thus, those females are included here but excluded from the analyses integrating aggression and hormone concentrations. Median aggression scores for each of the three treatments are as follows: approach $=0$, apparatus $=1$, conspecific $=1.85$. The box indicates the upper and lower $25 \%$ quartile range, the center lines indicate the median, and bars indicate the maximum and minimum values excluding outliers.

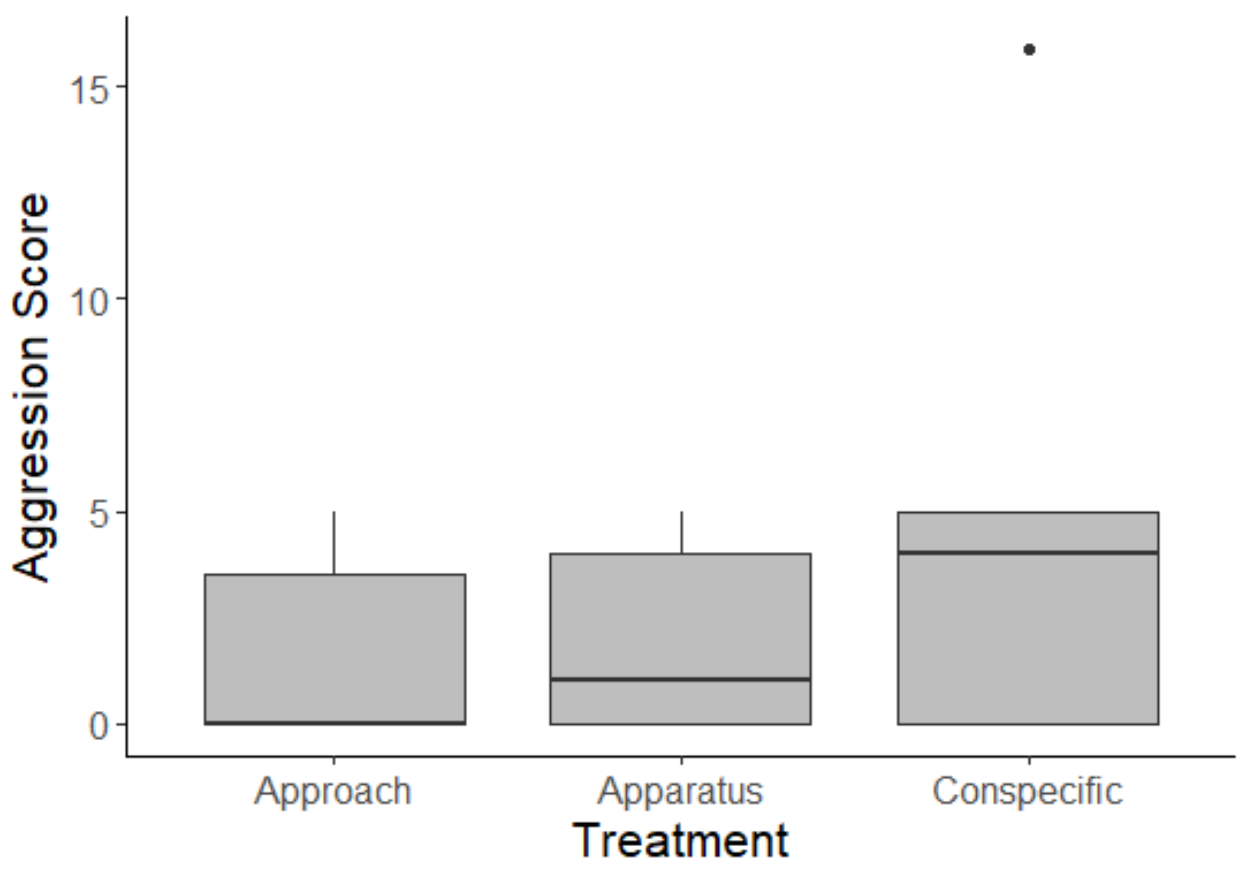


Figure 5: A comparison of the aggression scores of females in the treatment of the staged intrusion study that presented residents with conspecific intruders. Females were separated into two categories. The first box represents females that faced intruders that they were either larger than or of the same size as (median aggression score $=2.5$ ), denoted by Equal or Larger to reflect body size ratios equal to or larger than 1 between the two females (resident SVL/intruder SVL). The second box represents residents that were smaller than the intruder presented to them (median aggression score $=15$ ), denoted by Lower to reflect body size ratios less than 1 . The box indicates the upper and lower $25 \%$ quartile range, the center lines indicate the median, and bars indicate the maximum and minimum values excluding outliers.

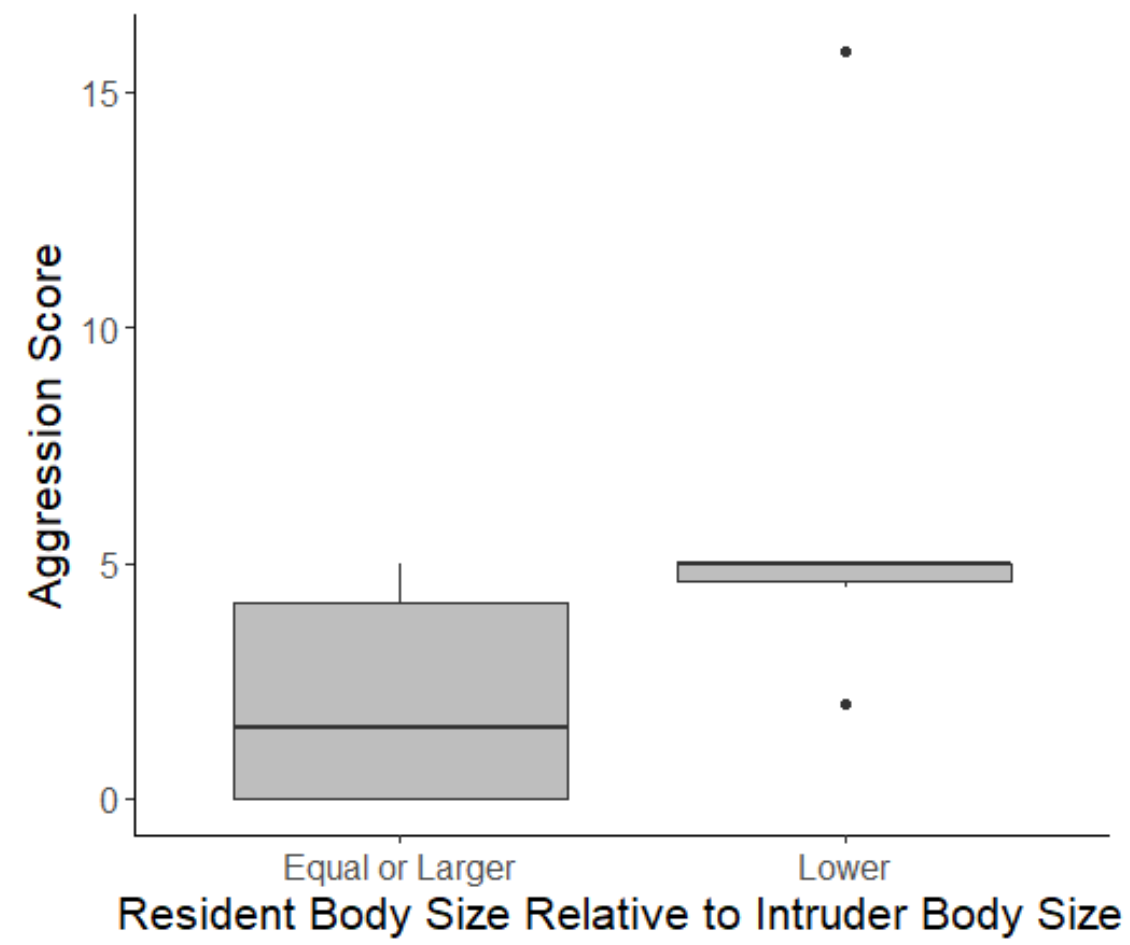


Figure 6: Aggression scores and testosterone concentrations (ng/mL) of females in the staged intrusion study. Circles indicate females in the approach treatment, triangles the empty apparatus treatment, and the squares the treatment with a conspecific intruder.

Points have been jittered by a factor of 0.7 in order to make each data point visible in the plot.

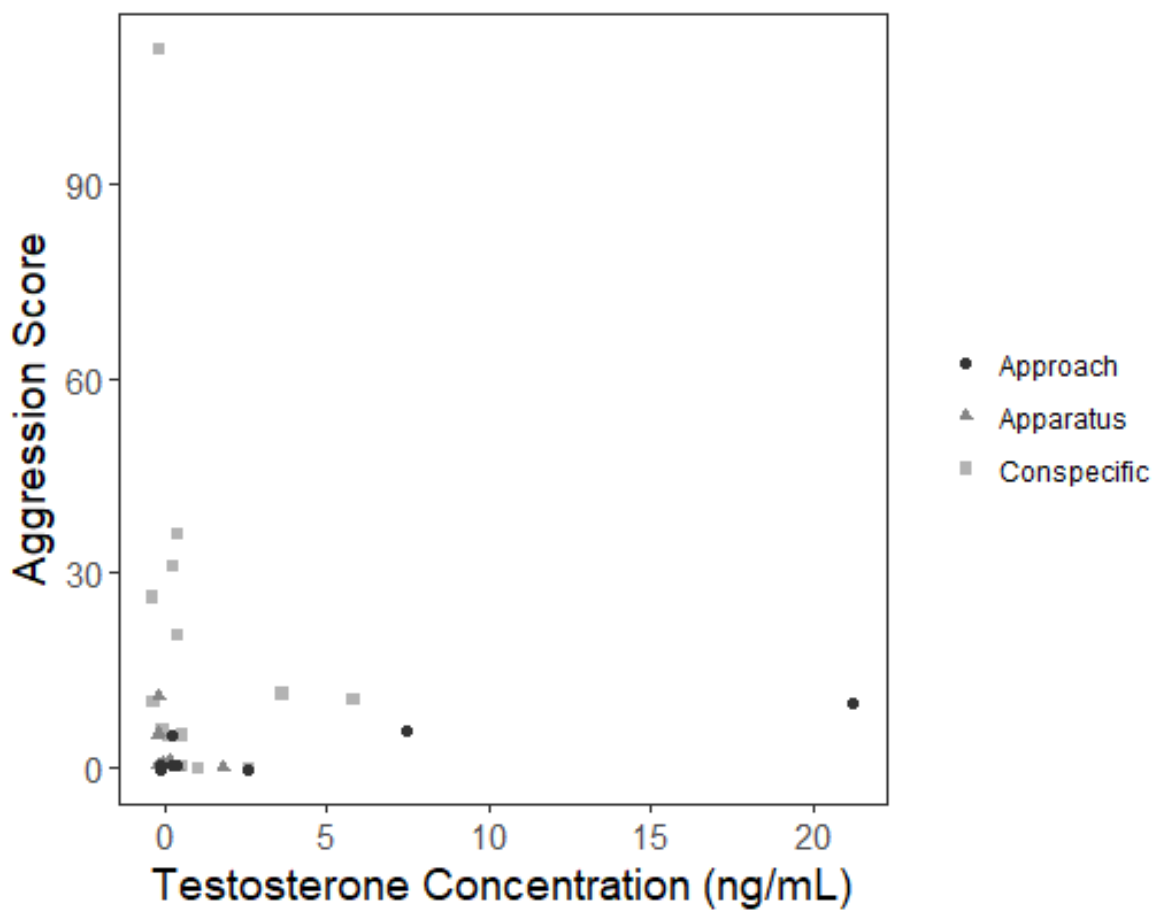


Figure 7: A comparison of corticosterone concentrations (ng/mL) across all females in our study, including females from both the general population (Baseline, $\mathrm{n}=26$ ) and all three treatments of the staged intrusion study $(n=32)$. Median concentrations are as follows: baseline $=5.51$, approach $=4.44$, apparatus 1.58 , and conspecific $=2.02$. The box indicates the upper and lower $25 \%$ quartile range, the center lines indicate the median, and bars indicate the maximum and minimum values excluding outliers.

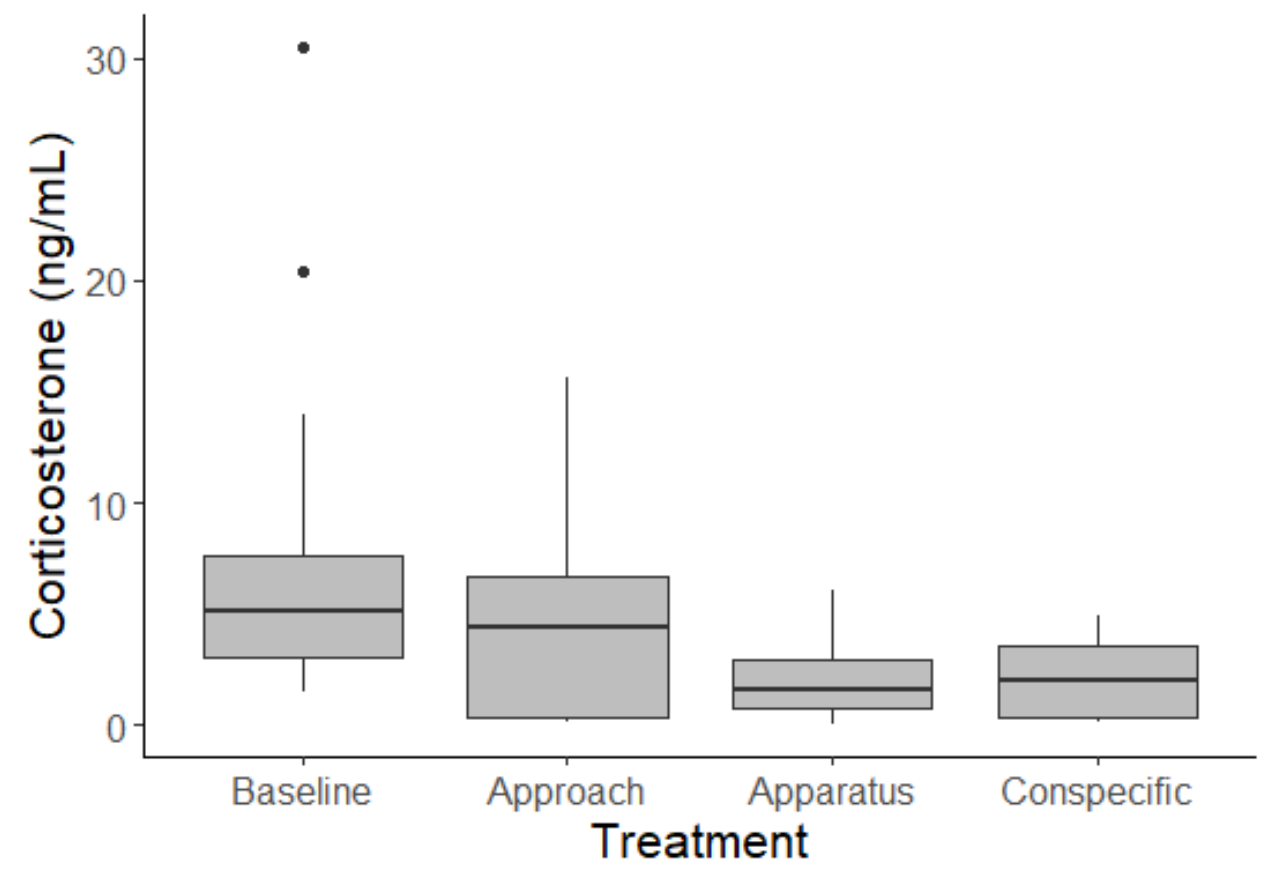


Figure 8: A comparison of testosterone concentrations (ng/mL) across all females in our study, including females from both the general population (Baseline, $\mathrm{n}=26$ ) and all three treatments of the staged intrusion study $(n=32)$. Median concentrations are as follows: baseline $=0.055$, approach $=0.33$, apparatus 0.053, and conspecific $=0.105$. The box indicates the upper and lower $25 \%$ quartile range, the center lines indicate the median, and bars indicate the maximum and minimum values excluding outliers.

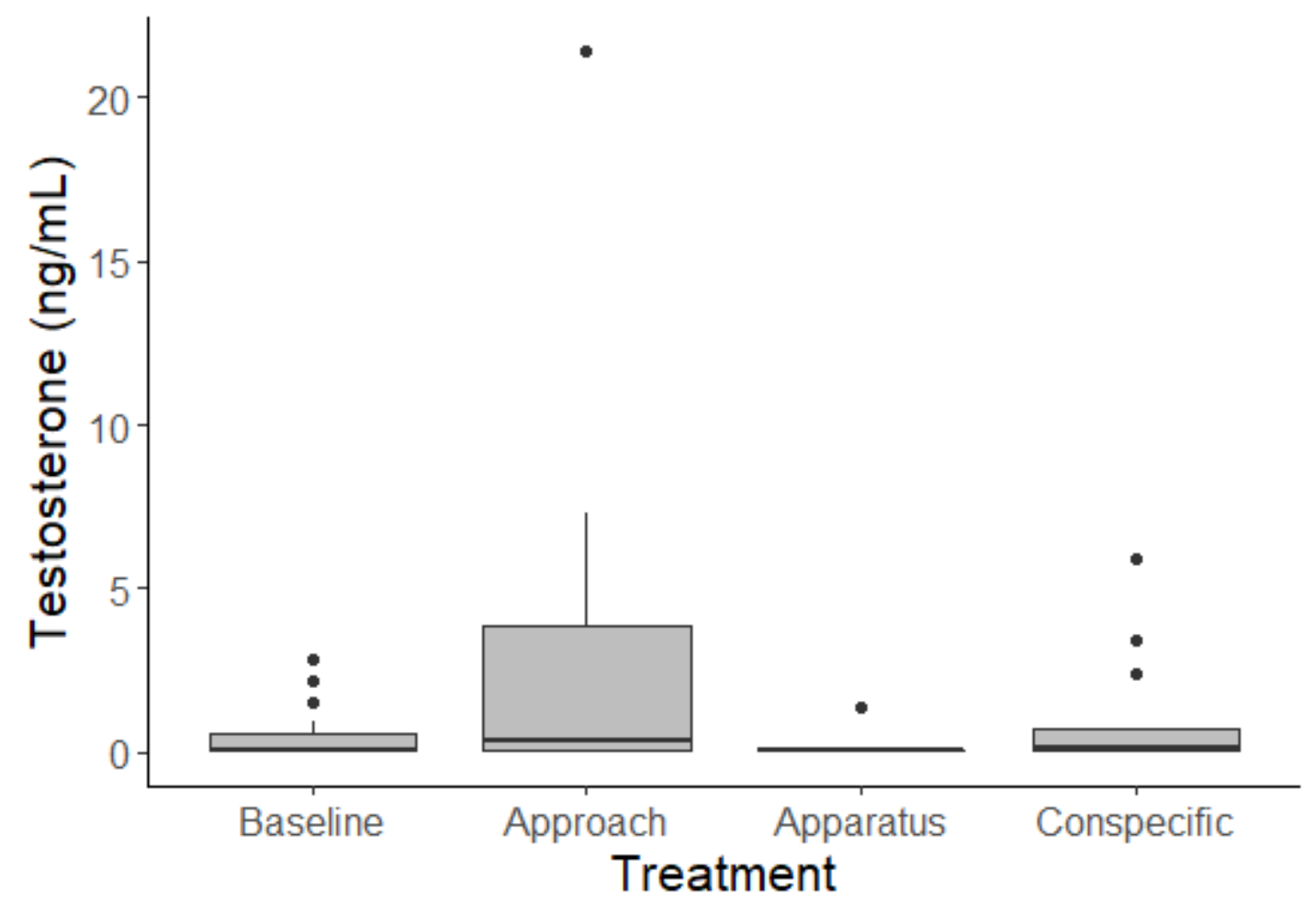


Figure 9: A comparison of testosterone and corticosterone concentrations of all females in our study, including females from both the general population (Baseline, $\mathrm{n}=26$, denoted by closed circles) and those from all three treatments of the staged intrusion study (Treatment, $\mathrm{n}=32$, denoted by closed triangles).

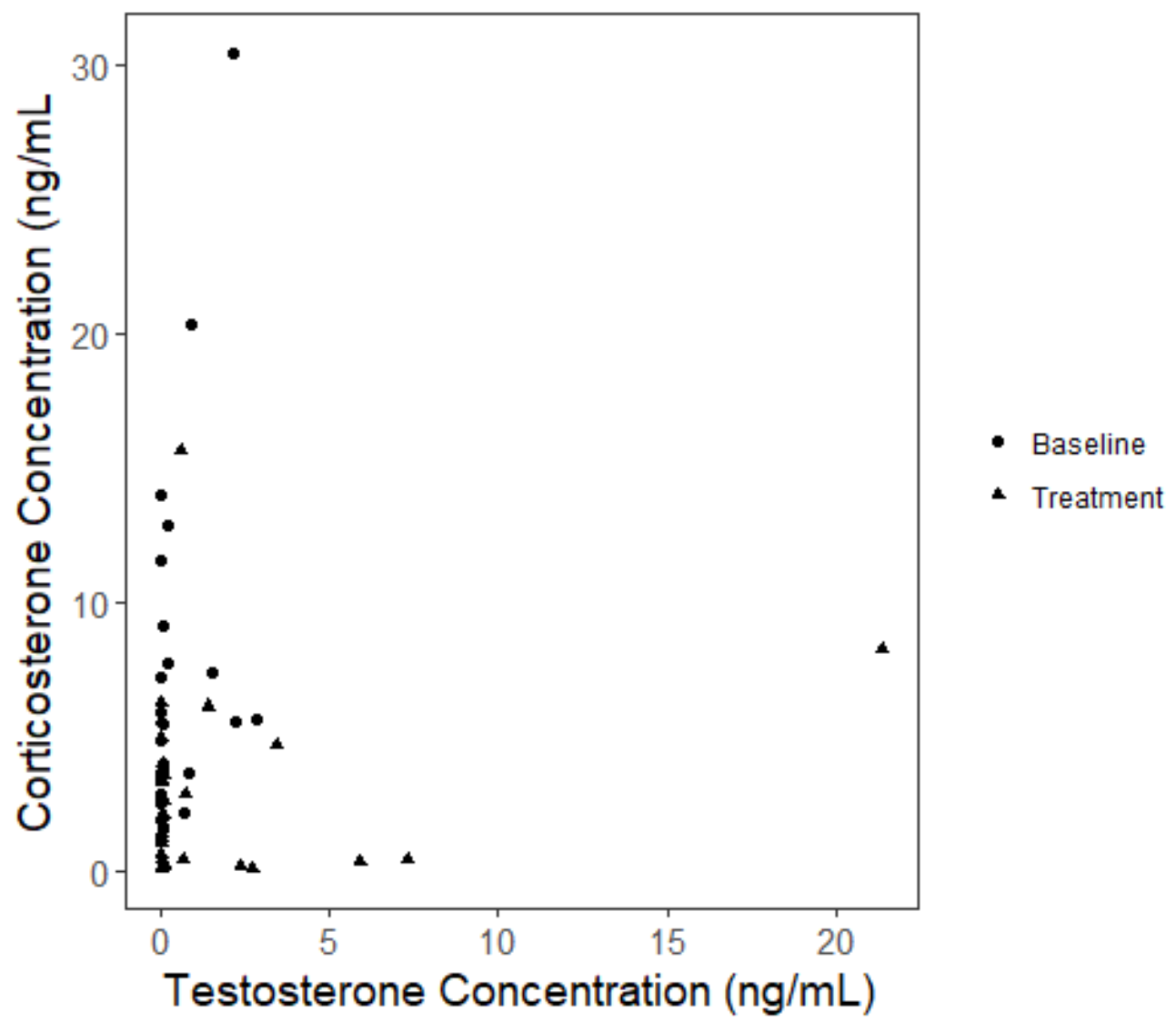




\title{
CHAPTER 5
}

\section{Testosterone and Parasite Load: An investing ation of the immunocompetence hypothesis in wild Anolis gundlachi lizards}

\author{
Ellee G. Cook and Manuel Leal
}

\begin{abstract}
Parasites are a ubiquitous threat to organisms, and animals must constantly mount defenses against them and the negative effects they cause in order to survive and reproduce. However, organisms must also balance the energy costs of mounting immune response with the other tasks associated with growth, social behavior, and reproduction. Testosterone, which is a hormone critical in regulating development and behavior, is negatively associated with immune response, and as a result, individuals must strike a balance between maintaining circulating testosterone and an appropriately functioning immune system. Here, we evaluated whether circulating testosterone concentrations were negatively associated with parasite load in free-living Anolis gundlachi lizards to assess the potential for a trade-off between testosterone and immune function. We measured testosterone concentrations and assessed infection by the malarial parasite Plasmodium using microscopy in adult male and female A. gundlachi in Puerto Rico. We observed relatively low levels of infection (10 individuals, $8 \%$ of our study population) and found that the likelihood of infection with Plasmodium was not positively associated with testosterone. We also characterized the corticosterone profiles of these individuals, and similarly found no association between corticosterone and the probability of infection with Plasmodium. Thus, we did not find support for the hypothesis that a trade-off exists between testosterone and parasite load in this species.
\end{abstract}

\section{Introduction}


Organisms must constantly cope with trade-offs. Both intrinsic processes such as growth, reproduction, and immune function, and extrinsic processes such as social interactions, predator avoidance, and foraging, are critical, energetically costly, and rely on similar pools of resources (e.g., Festa-Bianchet 1989, Yearsley et al. 2004, Sah et al. 2017). In addition to resource balance, individuals must also modulate the expression of traits that draw upon resources and elicit both positive and negative outcomes for the individual. One physiological trade-off that has received widespread attention across animals is the negative association between the androgen testosterone and immune function (reviewed in Lochmiller and Deerenberg 2000, Wingfield et al. 2001, Segner et al. 2017).

Testosterone modulates a variety of physiological and behavioral processes. For example, seasonal changes in testosterone can drive changes in reproductive organs and social behavior during the breeding season (e.g., Crews et al. 1996, Frisch 2004, Soma 2006). Thus, testosterone plays a critical role in processes that can directly impact individual fitness. In several species, for example, individuals with high testosterone also exhibit high amounts of aggressive behavior in contexts such as mate guarding and territoriality relative to individuals with lower testosterone (reviewed in Book et al. 2001), and as result, can experience increased mating success relative to conspecifics with lower aggression (e.g., Potter 1976, Hohmann and Fruth 2003, Reaney and Backwell 2007). Although such observations demonstrate that having relatively high testosterone may result in substantial benefits, individuals do not maintain high concentrations for long. One hypothesis to explain this widespread phenomenon is that individuals must balance positive and negative effects of testosterone and that a trade-off 
exists between testosterone production and immune function (Roberts et al. 2004, Nunn et al. 2008, Tobler et al. 2010).

Many potential costs of testosterone have been explored, especially within birds (e.g., Wingfield et al. 2001, Soma 2006). Although it may have direct physiological costs, many of the negative implications of circulating testosterone are the product of its influence on behavior (Marler and Moore 1988, Saino and Moller 1995, Wingfield et al. 2001). Seasonal changes in testosterone coincide with changes to behaviors such as courtship and territoriality, which are energetically costly. Individuals with elevated testosterone may engage more frequently or effectively in these activities but also incur related costs, such as increased risk of injury, depleting fat stores, and changes to parental care behavior (e.g., Marler and Moore 1989, Haller et al. 1996, Nicieza and Metcalfe 1999). Furthermore, elevated testosterone concentrations have been associated with decreased immune function. Testosterone is hypothesized to influence immunity via two mechanisms - direct immunosuppressive effects of the hormone and indirect impacts on resource allocation because of behavioral and energetic changes induced by testosterone (reviewed in Boonekamp et al. 2008). Some evidence suggests that testosterone itself is immunosuppressive, but there is more support for the latter mechanism, that the negative association is due to a diversion of resources from immune function to behaviors and processes induced by testosterone (reviewed in Roberts et al. 2004). Regardless of the mechanism, interference with immunity is perilous - failure to respond to a pathogen or parasite quickly and effectively results in illness and ultimately death. Mounting an immune response is costly: as immunity is upregulated following an infection, metabolic rates increase, food intake decreases, and fat stores are depleted (e.g., Zuk and Stoehr 
2002, Martin et al. 2003, Sandland and Minchella 2003). Thus, if an individual is maintaining a high level of testosterone and performing the associated behaviors, it may suffer costs to immunity, and thus be at greater risk of infection.

One potential consequence of this trade-off is parasite load. Individuals with high testosterone that are engaging in more extensive social interactions may come into contact with more parasites through increased activity rates or may be more susceptible to infection due to injury than less aggressive individuals (e.g., Marler and Moore 1989, Denardo and Sinervo 1994, Oppliger et al. 2004). Once infected, individuals with high testosterone and thus compromised immunity may mount less effective acute responses, cope less effectively with chronic infection, and succumb to infection than individuals with lower testosterone and potentially less compromised immune responses. In light of both phenomena, we might expect to see higher rates of infection and more virulent infections in individuals with elevated testosterone. However, evidence suggests that there can be a wide range of responses. Elevated testosterone has been associated with increased parasite load in the Algerian Psammodromus lizard (Psammordromus algirus, Salvador et al. 1996) and the meerkat (Suricata suricatta, Smyth et al. 2016), but no association between testosterone and parasite load in red-winged blackbirds (Agelaius phoeniceus, Weatherhead et al. 1993), white-plumed honeyeaters (Lichenostornus penicillatus, Buttemer and Astheimer 2000), or sand lizards (Lacerta agilis, Olsson et al. 2000).

Here, we investigated whether individual differences in circulating testosterone concentrations were associated with differences in the likelihood of infection by a parasite in Anolis gundlachi lizards. Lizards including members of the genus Anolis are 
the natural hosts of a variety of different Plasmodium species (Staats and Schall 1996, Schall et al. 2000). Anolis gundlachi are susceptible to infection by two species, $P$. floridense and $P$. aszurophilium, and infection rates vary across years, with reported values often around 30\% (Schall and Vogt 1993, Perkins 2000, Schall and Pearson2000). Plasmodium is known to be virulent in lizards. Among Sceloporus occidentalis lizards, infected individuals mobilize premature red blood cells, which carry less oxygen and such mobilization may have implications for behavior, such as long-term movement (Schall 1983). Infected males also had smaller testes and infected females laid smaller clutches, suggesting that the parasite may reduce reproductive success (Schall 1983). Similar results are also observed in Agama agama (1982). In contrast, there is little evidence of direct negative effects of Plasmodium infection on host health in Anolis. For example, A. gundlachi infected with malaria did not exhibit reduced body condition relative to uninfected conspecifics (Schall and Pearson. 2000). However, Plasmodium has been associated with differences in interspecific competition between $A$. wattsi and $A$. gingivinus, such that $A$. wattsi only occurs in areas in which $A$. gingivinus, the superior competitor of the pair, is infected with P. azurophilium (Schall 1992). Thus, Plasmodium may elicit effects that cause competitive ability to suffer but have yet to be identified.

We tested the hypothesis the likelihood of Plasmodium infection is positively associated with testosterone, such that individuals with high testosterone concentrations would have a higher likelihood of infection than individuals with lower testosterone. Previously (Chapter 4), we characterized the testosterone profiles of the male and female A. gundlachi evaluated in this study. We observed that males exhibit significantly higher testosterone concentrations than females, and that there is individual variation in 
testosterone in both males and females (Cook et al. In Preparation). In combination with the previous work characterizing Plasmodium infections in A. gundlachi over the last twenty years, the availability of these hormone data makes this an excellent species in which to evaluate the relationship between individual variation in testosterone and risk of infection by Plasmodium. Finally, we also characterized the corticosterone profiles of these individuals to assess whether infection with Plasmodium was associated with circulating concentrations of this glucocorticoid. Like testosterone, elevated corticosterone has also been negatively associated with immune function in several groups, likely through its involvement with stress and mobilizing resources during stressful interactions (e.g., Berger et al. 2005, Martin II et al. 2005, Graham et al. 2012). Thus, we also evaluated the potential for an association between corticosterone and parasite infection in A. gundlachi, although our primary focus remained in investigating the potential association between parasite infection and testosterone.

\section{Materials and Methods}

Anolis gundlachi is endemic to wet shaded forests in Puerto Rico and is classified within the trunk-ground ecomorph. Thus, individuals are most often found on the lower trunks of trees but will travel to the ground to forage and to interact with other lizards (Rand 1964, Rodriguez-Robles et al. 2005).

This work was conducted in the Luquillo Experimental Forest near El Verde Field Station in Rio Grande, Puerto Rico, where A. gundlachi are abundant. Samples were collected between June and August 2017 during the breeding season of A. gundlachi (Gorman and Licht 1974). We measured parasite load and circulating testosterone concentrations from individuals used as part of two studies, the data from which are the 
subject of Cook et al. (In Preparation). First, we sampled adult males and females from the general population of A. gundlachi in the area to characterize testosterone profiles of males and females and to demonstrate potential variation between the sexes or across individuals. Second, we sampled adult females as part of a study of territorial behavior in which we used staged agonistic encounters between females to elicit potential aggression by female A. gundlachi. The sample sizes from the projects just described are as follows: males from the general population $(n=63)$, females from the general population $(n=26)$, and females from the staged intrusion study $(\mathrm{n}=32)$. It should be noted that we did not find an association between aggressive behavior and circulating testosterone in the staged intrusion study, and given the lack of an effect of experimental manipulation on testosterone concentrations, it seemed appropriate to include these samples in our study of potential association between testosterone and parasite load.

We measured testosterone and corticosterone concentrations were measured in plasma. We collected samples from the sub-orbital sinus after catching the individual by hand or noose. To standardize the influence of capture and handling on testosterone concentrations, we only used samples from lizards that we successfully captured and collected blood from within 5 minutes of initiating a capture. We kept samples kept on ice, and at the field station we centrifuged samples to separate plasma. We then froze plasma smaples, and ultimately transported them to Oklahoma State University for hormone analyses in November 2017. We measured the weight (g) and snout-vent length (SVL, mm) of each individual we sampled. We then collected blood smears by cutting off the last digit of one toe to produce a drop of blood to smear on the slide. Individuals were returned to the site of capture within 24 hours of collection. 
Slides with blood smears were fixed in methanol, and then transported to the University of Missouri, where they were stained with Giemsa (Baker) at a pH between 7.0-7.2 for 50 minutes in December 2018. Parasite counts were obtained by scanning approximately 1000 erythrocytes (mean $=1014 \pm 20$ erythrocytes) at $1000 \mathrm{X}$ magnification and visually identifying parasites in the cells (Figure 1). Data were coded to reflect presence or absence of parasites.

Methods for hormone measurement were modeled after Husak and Lovern (2014). We measured plasma concentrations of testosterone using radioimmunoassay (RIA) following extraction and separation by column chromatography (Wingfield and Farner 1975). All samples were run singly. We recorded the volume of plasma for each sample to the nearest microliter $(7.79 \pm 4.83 \mu \mathrm{l})$, and then combined plasma with $0.5 \mathrm{ml}$ of $\mathrm{ddH}_{2} \mathrm{O}$. Samples were equilibrated overnight at $4^{\circ} \mathrm{C}$ with $-1000 \mathrm{cpm}$ of ${ }^{3} \mathrm{H}$ testosterone (NET-370, $70 \mathrm{Ci} / \mathrm{mmol}$ ) or ${ }^{3} \mathrm{H}$ corticosterone (NET-399, $71 \mathrm{Cimmol}$ ) from PerkingElmer Life Sciences, Inc. (Boston, MA) for recovery determinations. We extracted each sample twice with $2 \mathrm{ml}$ diethyl ether dried under nitrogen gas in a $37^{\circ} \mathrm{C}$ water bath. Samples were then reconstituted in $0.5 \mathrm{ml}$ of $10 \%$ ethyl acetate in isooctane for use in chromatography. We made columns consisting of a diatomaceous earth:ethylene glycol:propylene upper phase (4:1:1 m:v:v) and a diatomaceous earth: $\mathrm{ddH}_{2} \mathrm{O}$ lower phase. We used "Celpure" diatomaceous earth from Sigma-Aldrich (St. Louis, MO). After placing samples on columns, neutral lipids were removed with 1.5 $\mathrm{ml}$ isooctanem dihydrotestosterone was removed with $2 \mathrm{ml} 10 \%$ ethyl acetate in isooctane, and both were discarded. Testosterone was removed with $2 \mathrm{ml} 20 \%$ ethyl acetate in isooctane and collected into individual test tubes. Samples were dried under 
nitrogen gas in a $37^{\circ} \mathrm{C}$ water bath, resuspended in phosphate buffer, and refrigerated overnight at $4^{\circ} \mathrm{C}$. We performed competitive binding RIAs using titrated steroid tracer (see above), antisera from Wein Laboratories for testosterone (T-3003; Succasunna, NJ), and steroid standards from Sigma-Aldrich. Standard curves ranged from 1.95 to $500 \mathrm{pg}$. Samples were run singly, and adjusted for individual recovery and initial sample volume. Average testosterone recovery was $73 \%$, and corticosterone was 50\%. Average intraassay coefficients of variation (CV) based on 4 aliquots from a standard pool for testosterone were $10.1 \%$, and $9.5 \%$ for corticosterone.

We performed logistic regressions to determine if plasma concentration of testosterone or corticosterone were significant predictor of the probability of hosting a parasite. All statistics were calculated using R (R Software version 3.5.2) in R Studio (RStudio, Inc. version 1.1.463). Plots were made using the package ggplot2 (Wickham 2016).

\section{Results}

We measured concentrations of both hormones and inspected blood smears for 121 A. gundlachi, including 58 females and 63 males. As in other studies of A. gundlachi, males in our study were generally larger than females (male: mean mass $=6.27 \pm 1.33 \mathrm{~g}$, mean SVL $=63.51 \pm 4.35 \mathrm{~mm}$; female: mean mass $=2.28 \pm 0.302 \mathrm{~g}$, mean SVL $=45.5-$ $1.73 \mathrm{~mm}$, both $\mathrm{p}<0.0001)$. We observed much lower infection rates in our sample than we predicted based on previous work with $A$. gundlachi in the same geographic area (Schall and Vogt 1993, Schall and Pearson 2000). Parasites were observed in the erythrocytes of 10 individuals in this sample (8\%), and the number of parasites observed across the 1000 erythrocytes inspected for each individual varied slightly (mean $=1.8 \pm$ 
1.1 parasites). We observed parasites in four females and six males. Males had higher testosterone concentration than females (male: mean $=7.63 \pm 6.76 \mathrm{ng} / \mathrm{mL}$; female: mean $=1.04 \pm 3.06 \mathrm{ng} / \mathrm{mL} ; \mathrm{p}<0.0001)$. Testosterone also varied among members of the same sex $($ male range $=0.0241-29.1 \mathrm{ng} / \mathrm{mL}$; female range $=0.0154-21.4 \mathrm{ng} / \mathrm{mL}) . \mathrm{We}$ observed a non-significant trend for females to have higher corticosterone than males $($ female mean $=4.38 \pm 5.36 \mathrm{ng} / \mathrm{mL} ;$ male mean $=3.06 \pm 2.85 ; \mathrm{p}=0.08)$. Like testosterone, corticosterone also varied among members of the same sex (female range $=$ $0.0668-30.44 \mathrm{ng} / \mathrm{mL}$; male range $=0.0313-14.5 \mathrm{ng} / \mathrm{mL})$. Neither hormone was a significant predictor of the probability of hosting a parasite in either males or females (all $\mathrm{p}>0.1$, Figures 2 and 3).

\section{Discussion}

The challenge hypothesis posits that organisms must simultaneously cope with both the positive and negative effects of the hormone testosterone, a balance that results in a trade-off between maintaining high concentrations of the hormone that mediate sexually selected traits and behaviors and immune function (e.g., Kilpimaa et al. 2004, Boonekamp et al. 2008). Whether testosterone itself is immunosuppressive or immunity is compromised due to the effects of testosterone on behavior, high testosterone has been associated with decreased immunity (reviewed in Roberts et al. 2004). Thus, individuals

with high circulating testosterone are hypothesized to be more susceptible to pathogens or parasites than individuals with lower concentrations. We tested this hypothesis with Anolis gundlachi lizards and evaluated whether the likelihood of being infected with malaria parasites (Plasmodium sp.) was correlated with testosterone concentrations. 
We observed malaria infections in $8 \%$ of our population (10 individuals of 121). This infection rate was lower than what we expected based on previous work (Schall and Vogt 1993, Perkins 2000, Schall and Pearson 2000) but aligns with results collected by other researchers in the same area and year (D. Clark, personal communication). Testosterone varied among A. gundlachi, and males generally exhibit higher testosterone concentrations than females. However, the likelihood of infection with Plasmodium was not significantly associated with testosterone concentration (Figure 2).

Although the potential trade-off between maintaining testosterone and immunity has been explored in several different animal groups in the last few decades, the results are mixed. Some studies find a negative association between the two, observations that led to the development of the challenge hypothesis and related work (e.g., Wingfield et al. 1990, Muller and Wrangham 2003, Desjardins et al. 2005). However, other studies find limited or no correlations between the two (reviewed in Oliveira 2005, Muehlenbein and Bribiescas 2005). This pattern is true of literature investigating testosterone and immunity in lizards, with some observations that elevated testosterone is associated with increased parasite load or compromised immune function (e.g., Olsson et al. 2000, Cox et al. 2007, Schroderus et al. 2010). Other studies have found that testosterone and immunity are not associated in lizards (e.g., Huyghe et al. 2009), and still others observe that testosterone is negatively associated with immune response but not directly associated with parasite load (Oppliger et al. 2004). The diversity of results observed in lizards and other animal groups demonstrates that the interactions between testosterone and immune function are complex, and that it is not uncommon for the two to be uncoupled as we observed in our study. We also found no association between parasite 
infection and corticosterone (Figure 3), another hormone frequently associated with immune function (e.g., Martin II et al. 2005, Graham et al. 2012). Together, these results suggest that neither hormone is associated with the likelihood of being infected with Plasmodium in A. gundlachi.

One possible hypothesis to explain our finding that testosterone did not predict probability of hosting Plasmodium is that A. gundlachi have sustained Plasmodium infections for so long that the virulence of infection has decreased over time (Otero et al. 2019). If the parasite exerts minimal negative effects on the host, A. gundlachi may not need to mount a substantial immune response to combat infection (Ewald 1995), which in turn may negate the potential trade-off between maintaining testosterone concentrations and immune response. Thus far, evidence suggests that Plasmodium does not substantially impact A. gundlachi. Several studies of Plasmodium dynamics in A. gundlachi revealed no effect of parasitism by Plasmodium on body condition (Schall and Pearson 2000, Schall et al. 2000, Otero et al. 2019), a metric frequently used as an indicator of host health (e.g., Jakob et al. 1996, Irvine et al. 2006).

Several avenues for future research on Plasmodium parasitism in Anolis lizards exist. First, it is possible that other aspects of host physiology, morphology, or behavior may be negatively associated with Plasmodium infection. Future work investigating additional axes of host health and fitness may reveal a negative impact of Plasmodium infection, and is worth pursuing in order to more completely understand the dynamics and effects of Plasmodium infection in A. gundlachi. Second, several different species of Anolis lizards are known to be parasitized by Plasmodium (e.g., Telford Jr. 1974, Staats and Schall 1996). A large portion of work investigating Plasmodium and its potential 
impacts on host health and fitness in anoles has focused on a few species, including $A$. gundlachi and A. sagrei, in particular (e.g., Schall and Pearson. 2000, Perkins et al. 2007, Bonneaud et al. 2017). Further studies of additional Anolis species will help us to understand whether the patterns observed in A. gundlachi are also informative in other species. To our knowledge, this is the first published study of a potential association between testosterone and Plasmodium in an Anolis lizard, and it will be interesting to determine whether there is also no association in other species. To this end, it will also be important to investigate this association during times in which parasite prevalence is higher, given that our infection rates are substantially lower than those observed in previous work. Third, investigations with species invading new habitats may provide interesting opportunities to evaluate the hypothesis that virulence of Plasmodium has decreased over time during the long-term association between Plasmodium and Anolis hosts (e.g., Meshaka Jr. 1993, Kolbe et al. 2008). The community of Anolis species both native and exotic to Florida that has appeared over the last few decades, for example, may be experiencing new infections or infection by novel species of Plasmodium parasites, and may thus be interesting cases in which to investigate the virulence hypothesis.

\section{Acknowledgements}

We thank D. Lopez-Nieves, J. Pita-Aquino, and P. Pearson for their assistance in the field, and M. Acevedo and D. Clark for their supplies and assistance with the parasitology methods we used. We thank the Departmento de Recursos Naturales y Ambientales for permitting for this work, and El Verde Field Station for use of facilities. This work was conducted in compliance with protocols approved by the ACUC of the 
University of Missouri. This work was supported by funding from the University of Missouri, National Science Foundation, Animal Behavior Society, and Sigma-Xi Society for Research. 


\section{References}

Berger, S., Martin II, L. B., Wikelski, M., Romero, L. M., Kalko, E. K., Vitousek, M. N., \& Rödl, T. (2005). Corticosterone suppresses immune activity in territorial Galapagos marine iguanas during reproduction. Hormones and Behavior, 47(4), 419-429.

Bonneaud, C., Sepil, I., Wilfert, L., \& Calsbeek, R. (2017). Plasmodium infections in natural populations of Anolis sagrei reflect tolerance rather than susceptibility. Integrative and Comparative Biology, 57(2), 352-361.

Book, A. S., Starzyk, K. B., \& Quinsey, V. L. (2001). The relationship between testosterone and aggression: a meta-analysis. Aggression and Violent Behavior, $6(6), 579-599$.

Boonekamp, J. J., Ros, A. H., \& Verhulst, S. (2008). Immune activation suppresses plasma testosterone level: a meta-analysis. Biology letters, 4(6), 741-744.

Buttemer, W. A., \& Astheimer, L. B. (2000). Testosterone does not affect basal metabolic rate or blood parasite load in captive male white-plumed honeyeaters Lichenostomus penicillatus. Journal of Avian Biology, 31(4), 479-488.

Crews, D., Coomber, P., Baldwin, R., Azad, N., \& Gonzalez-Lima, F. (1996). Brain organization in a reptile lacking sex chromosomes: effects of gonadectomy and exogenous testosterone. Hormones and Behavior, 30(4), 474-486.

DeNardo, D. F., \& Sinervo, B. (1994). Effects of steroid hormone interaction on activity and home-range size of male lizards. Hormones and Behavior, 28(3), 273-287.

Desjardins, J. K., Hofmann, H. A., \& Fernald, R. D. (2012). Social context influences aggressive and courtship behavior in a cichlid fish. PLoS One, 7(7), e32781.

Ewald, P. W. (1995). The evolution of virulence: a unifying link between parasitology and ecology. The Journal of Parasitology, 81(5), 659-669.

Festa-Bianchet, M. (1989). Individual differences, parasites, and the costs of reproduction for bighorn ewes (Ovis canadensis). The Journal of Animal Ecology, 785-795.

Frisch, A. (2004). Sex-change and gonadal steroids in sequentially-hermaphroditic teleost fish. Reviews in Fish Biology and Fisheries, 14(4), 481-499.

Gorman, G. C., \& Licht, P. (1974). Seasonality in ovarian cycles among tropical Anolis lizards. Ecology, 55(2), 360-369. 
Graham, S. P., Kelehear, C., Brown, G. P., \& Shine, R. (2012). Corticosterone-immune interactions during captive stress in invading Australian cane toads (Rhinella marina). Hormones and Behavior, 62(2), 146-153.

Haller, J., Miklósi, Á., Csányi, V., \& Makara, G. B. (1996). Behavioral tactics control the energy costs of aggression: the example of Macropodus opercularis. Aggressive Behavior: Official Journal of the International Society for Research on Aggression, 22(6), 437-446.

Hohmann, G., \& Fruth, B. (2003). Intra-and inter-sexual aggression by bonobos in the context of mating. Behaviour, 140(11), 1389-1414.

Husak, J. F., \& Lovern, M. B. (2014). Variation in steroid hormone levels among Caribbean Anolis lizards: Endocrine system convergence?. Hormones and behavior, 65(4), 408-415.

Huyghe, K., Husak, J. F., Herrel, A., Tadić, Z., Moore, I. T., Van Damme, R., \& Vanhooydonck, B. (2009). Relationships between hormones, physiological performance and immunocompetence in a color-polymorphic lizard species, Podarcis melisellensis. Hormones and behavior, 55(4), 488-494.

Irvine, R. J., Corbishley, H., Pilkington, J. G., \& Albon, S. D. (2006). Low-level parasitic worm burdens may reduce body condition in free-ranging red deer (Cervus elaphus). Parasitology, 133(4), 465-475.

Jakob, E. M., Marshall, S. D., \& Uetz, G. W. (1996). Estimating fitness: a comparison of body condition indices. Oikos, 77(1), 61-67.

Kilpimaa, J., Alatalo, R. V., \& Siitari, H. (2004). Trade--offs between sexual advertisement and immune function in the pied flycatcher (Ficedula hypoleuca). Proceedings of the Royal Society of London. Series B: Biological Sciences, 271(1536), 245-250.

Kolbe, J. J., Larson, A., Losos, J. B., \& de Queiroz, K. (2008). Admixture determines genetic diversity and population differentiation in the biological invasion of a lizard species. Biology Letters, 4(4), 434-437.

Lochmiller, R. L., \& Deerenberg, C. (2000). Trade-offs in evolutionary immunology: just what is the cost of immunity?. Oikos, 88(1), 87-98.

Marler, C. A., \& Moore, M. C. (1988). Evolutionary costs of aggression revealed by testosterone manipulations in free-living male lizards. Behavioral Ecology and Sociobiology, 23(1), 21-26. 
Marler, C. A., \& Moore, M. C. (1989). Time and energy costs of aggression in testosterone-implanted free-living male mountain spiny lizards (Sceloporus jarrovi). Physiological Zoology, 62(6), 1334-1350.

Martin II, L. B., Scheuerlein, A., \& Wikelski, M. (2003). Immune activity elevates energy expenditure of house sparrows: a link between direct and indirect costs? Proceedings of the Royal Society of London. Series B: Biological Sciences, 270(1511), 153-158.

Martin II, L. B., Gilliam, J., Han, P., Lee, K., \& Wikelski, M. (2005). Corticosterone suppresses cutaneous immune function in temperate but not tropical house sparrows, Passer domesticus. General and comparative endocrinology, 140(2), 126-135.

Meshaka Jr, W. E. (1993). Hurricane Andrew and the colonization of five invading species in south Florida. Florida Scientist, 193-201.

Muehlenbein, M. P., \& Bribiescas, R. G. (2005). Testosterone-mediated immune functions and male life histories. American Journal of Human Biology: The Official Journal of the Human Biology Association, 17(5), 527-558.

Nicieza, A. G., \& Metcalfe, N. B. (1999). Costs of rapid growth: the risk of aggression is higher for fast-growing salmon. Functional Ecology, 13(6), 793-800.

Nunn, C. L., Lindenfors, P., Pursall, E. R., \& Rolff, J. (2008). On sexual dimorphism in immune function. Philosophical Transactions of the Royal Society B: Biological Sciences, 364(1513), 61-69.

Oliveira, R. F. (2005). Hormones, social context and animal communication. In P. K. McGregor, Animal Communication Networks, 481-520. Cambridge University Press, London.

Olsson, M., Wapstra, E., Madsen, T., \& Silverin, B. (2000). Testosterone, ticks and travels: a test of the immunocompetence-handicap hypothesis in free-ranging male sand lizards. Proceedings of the Royal Society of London. Series B: Biological Sciences, 267(1459), 2339-2343.

Oppliger, A., Giorgi, M. S., Conelli, A., Nembrini, M., \& John-Alder, H. B. (2004). Effect of testosterone on immunocompetence, parasite load, and metabolism in the common wall lizard (Podarcis muralis). Canadian Journal of Zoology, 82(11), 1713-1719.

Otero, L., Schall, J. J., Cruz, V., Aaltonen, K., \& Acevedo, M. A. (2019). The drivers and consequences of unstable Plasmodium dynamics: A long-term study of three malaria parasite species infecting a tropical lizard. Parasitology, 146(4), 453461. 
Perkins, S. L. (2000). Species concepts and malaria parasites: detecting a cryptic species of Plasmodium. Proceedings of the Royal Society of London. Series B: Biological Sciences, 267(1459), 2345-2350.

Perkins, S. L., Rothschild, A., \& Waltari, E. (2007). Infections of the malaria parasite, Plasmodium floridense, in the invasive lizard, Anolis sagrei, in Florida. Journal of Herpetology, 41(4), 750-755.

Potter, D. A., Wrensch, D. L., \& Johnston, D. E. (1976). Aggression and mating success in male spider mites. Science, 193(4248), 160-161.

Rand, A. S. (1964). Ecological distribution in anoline lizards of Puerto Rico. Ecology, 45(4), 745-752.

Reaney, L. T., \& Backwell, P. R. (2007). Risk-taking behavior predicts aggression and mating success in a fiddler crab. Behavioral Ecology, 18(3), 521-525.

Roberts, M. L., Buchanan, K. L., \& Evans, M. R. (2004). Testing the immunocompetence handicap hypothesis: a review of the evidence. Animal Behaviour, 68(2), 227239.

Rodríguez-Robles, J. A., Leal, M., \& Losos, J. B. (2005). Habitat selection by the Puerto Rican yellow-chinned anole, Anolis gundlachi. Canadian Journal of Zoology, 83(7), 983-988.

Sah, P., Leu, S. T., Cross, P. C., Hudson, P. J., \& Bansal, S. (2017). Unraveling the disease consequences and mechanisms of modular structure in animal social networks. Proceedings of the National Academy of Sciences, 114(16), 41654170 .

Saino, N., \& Møller, A. P. (1995). Testosterone-induced depression of male parental behavior in the barn swallow: female compensation and effects on seasonal fitness. Behavioral Ecology and Sociobiology, 36(3), 151-157.

Salvador, A., Veiga, J. P., Martin, J., Lopez, P., Abelenda, M., \& Puertac, M. (1996). The cost of producing a sexual signal: testosterone increases the susceptibility of male lizards to ectoparasitic infestation. Behavioral Ecology, 7(2), 145-150.

Smyth, K. N., Greene, L. K., Clutton-Brock, T., \& Drea, C. M. (2016). Androgens predict parasitism in female meerkats: a new perspective on a classic tradeoff. Biology Letters, 12(10), 20160660.

Sandland, G. J., \& Minchella, D. J. (2003). Costs of immune defense: an enigma wrapped in an environmental cloak?. Trends in parasitology, 19(12), 571-574. 
Schall, J. J. (1982). Lizards infected with malaria: physiological and behavioral consequences. Science, 217(4564), 1057-1059.

Schall, J. J. (1983). Lizard malaria: parasite host ecology. In R. B. Huey, E. R. Pianka, and T. W. Schoener (Eds.) Lizard ecology: studies of a model organism. 84100, Harvard University Press, Cambridge, Massachusetts.

Schall, J. J. (1992). Parasite-mediated competition in Anolis lizards. Oecologia, 92(1), 58-64.

Schall, J. J., \& Vogt, S. P. (1993). Distribution of malaria in Anolis lizards of the Luquillo Forest, Puerto Rico: implications for host community ecology. Biotropica, 229235.

Schall, J. J., Pearson, A. R. (2000). Body condition of a Puerto Rican anole, Anolis gundlachi: Effect of a malaria parasite and weather variation. Journal of Herpetology, 34(3), 489-491.

Schall, J., Pearson, A. R., \& Perkins, S. L. (2000). Prevalence of malaria parasites (Plasmodium floridense and Plasmodium azurophilum) infecting a Puerto Rican lizard (Anolis gundlachi): a nine-year study. Journal of Parasitology, 86(3), 511-516.

Schroderus, E., Jokinen, I., Koivula, M., Koskela, E., Mappes, T., Mills, S. C., ... \& Poikonen, T. (2010). Intra-and intersexual trade-offs between testosterone and immune system: implications for sexual and sexually antagonistic selection. The American Naturalist, 176(4), E90-E97.

Segner, H., Verburg-van Kemenade, B. L., \& Chadzinska, M. (2017). The immunomodulatory role of the hypothalamus-pituitary-gonad axis: proximate mechanism for reproduction-immune trade offs?. Developmental \& Comparative Immunology, 66, 43-60.

Soma, K. K. (2006). Testosterone and aggression: Berthold, birds and beyond. Journal of Neuroendocrinology, 18(7), 543-551.

Staats, C. M., \& Schall, J. J. (1996). Malarial parasites (Plasmodium) of Anolis lizards: biogeography in the Lesser Antilles. Biotropica, 388-393.

Telford Jr, S. R. (1974). The malarial parasites of Anolis species (Sauria: Iguanidae) in Panama. International Journal for Parasitology, 4(1), 91-102.

Tobler, M., Hasselquist, D., Smith, H. G., \& Sandell, M. I. (2010). Short-and long-term consequences of prenatal testosterone for immune function: an experimental study in the zebra finch. Behavioral ecology and sociobiology, 64(5), 717-727. 
Weatherhead, P. J., Metz, K. J., Bennett, G. F., \& Irwin, R. E. (1993). Parasite faunas, testosterone and secondary sexual traits in male red-winged blackbirds.

Behavioral Ecology and Sociobiology, 33(1), 13-23.

Wickham, H. (2009). ggplot2: Elegant Graphics for Data Analysis. Springer-Verlag, New York.

Wingfield, J. C., \& Farner, D. S. (1975). The determination of five steroids in avian plasma by radioimmunoassay and competitive protein-binding. Steroids, 26(3), 311-327.

Wingfield, J. C., Hegner, R. E., Dufty Jr, A. M., \& Ball, G. F. (1990). The" challenge hypothesis": theoretical implications for patterns of testosterone secretion, mating systems, and breeding strategies. The American Naturalist, 136(6), 829846.

Wingfield, J. C., Lynn, S. E., \& Soma, K. K. (2001). Avoiding the 'costs' of testosterone: ecological bases of hormone-behavior interactions. Brain, behavior and evolution, 57(5), 239-251.

Yearsley, J. M., Kyriazakis, I., \& Gordon, I. J. (2004). Delayed costs of growth and compensatory growth rates. Functional Ecology, 18(4), 563-570.

Zuk, M., \& Stoehr, A. M. (2002). Immune defense and host life history. The American Naturalist, 160(S4), S9-S22. 
Figure 1: Anolis gundlachi erythrocytes stained with Giemsa and viewed at $1000 \mathrm{X}$ magnification. The white arrows point to two uninfected erythrocytes, and the black arrow points to an erythrocyte infected with a Plasmodium parasite.

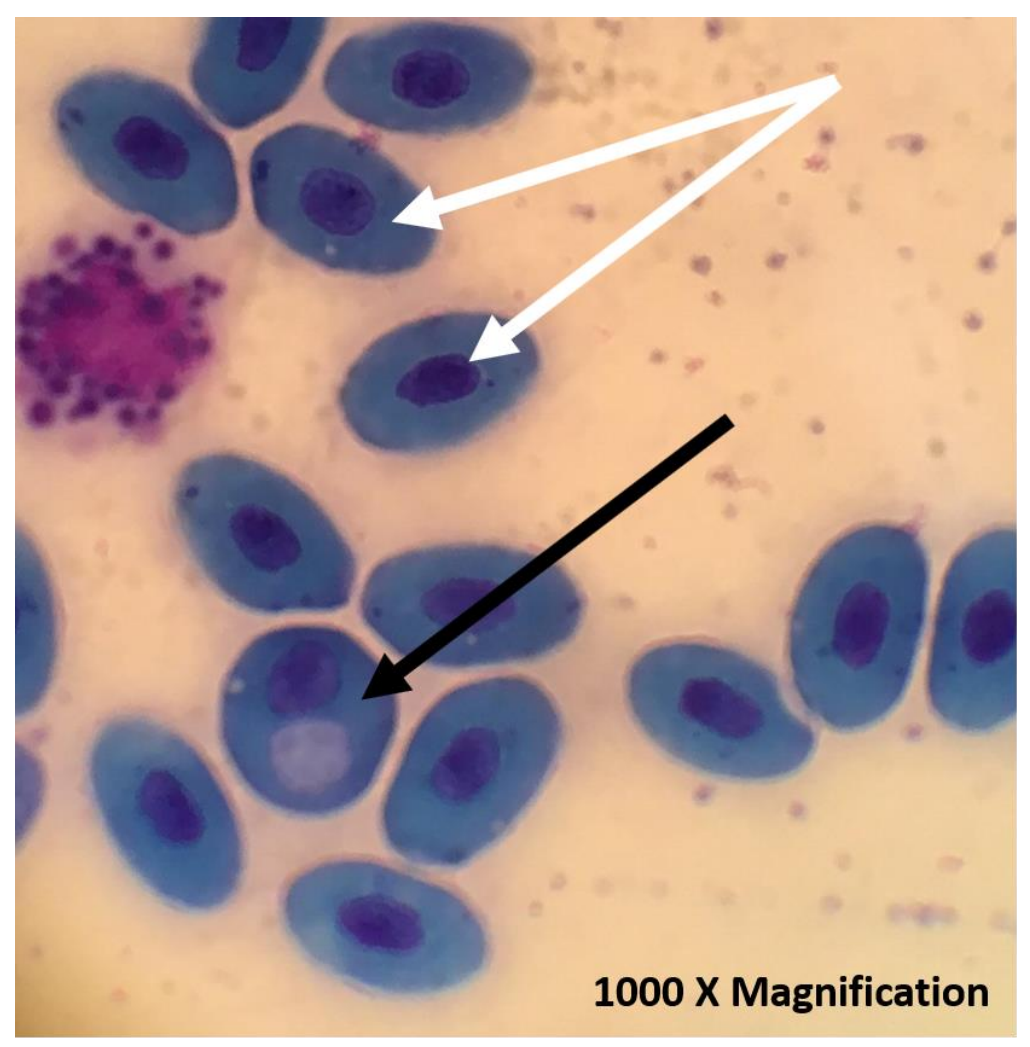


Figure 2: Logistic regression was used to estimate whether testosterone concentration was a significant predictor of the likelihood of hosting Plasmodium parasites. We identified Plasmodium infections in ten A. gundlachi in our sample: 4 females (2A) and 6 males (2B). (Figure appears on following page) 

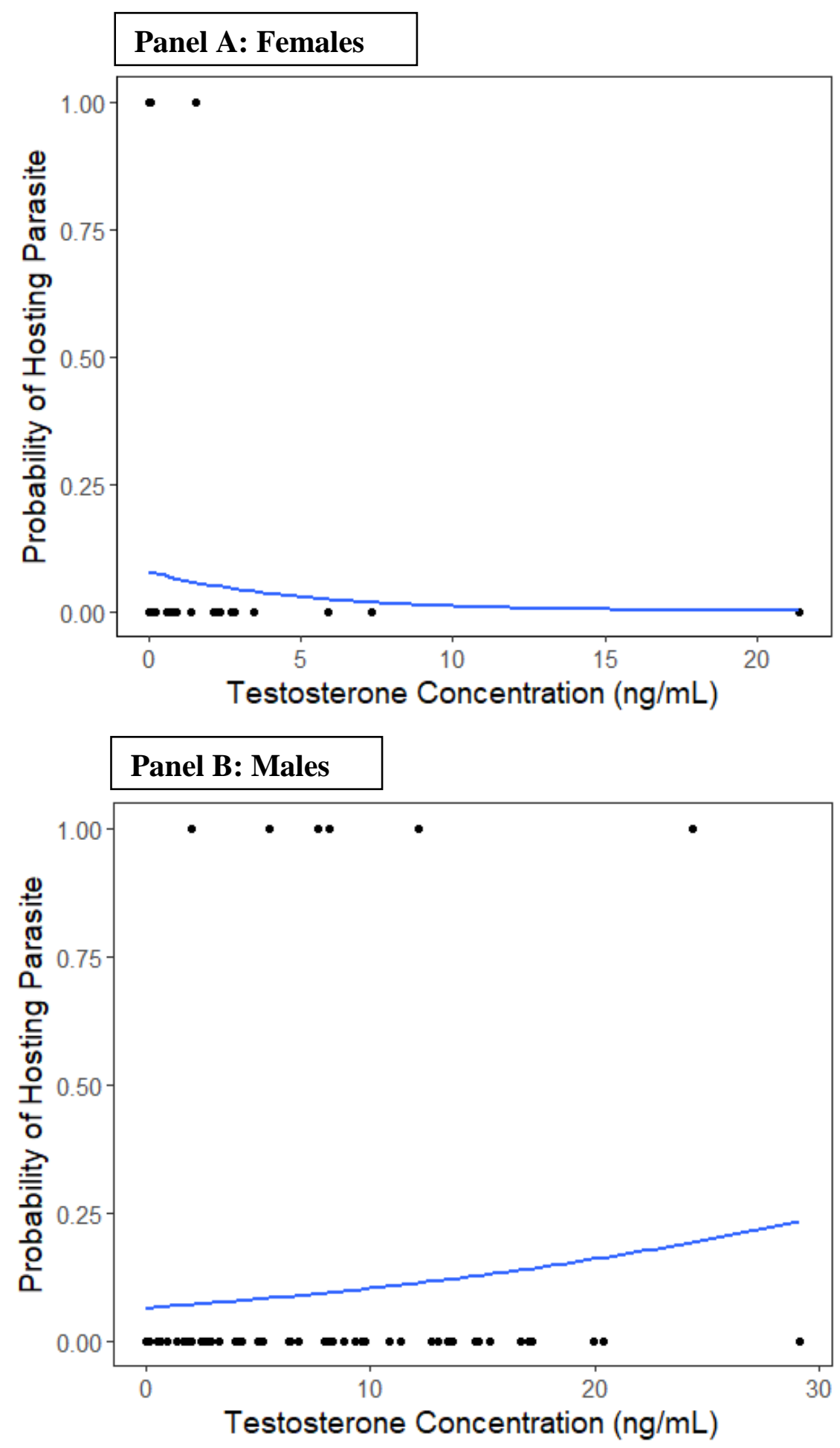
Figure 3: Logistic regression was used to estimate whether corticosterone concentration was a significant predictor of the likelihood of hosting Plasmodium parasites. We identified Plasmodium infections in ten A. gundlachi in our sample: 4 females (2A) and 6 males (2B). (Figure appears on following page) 

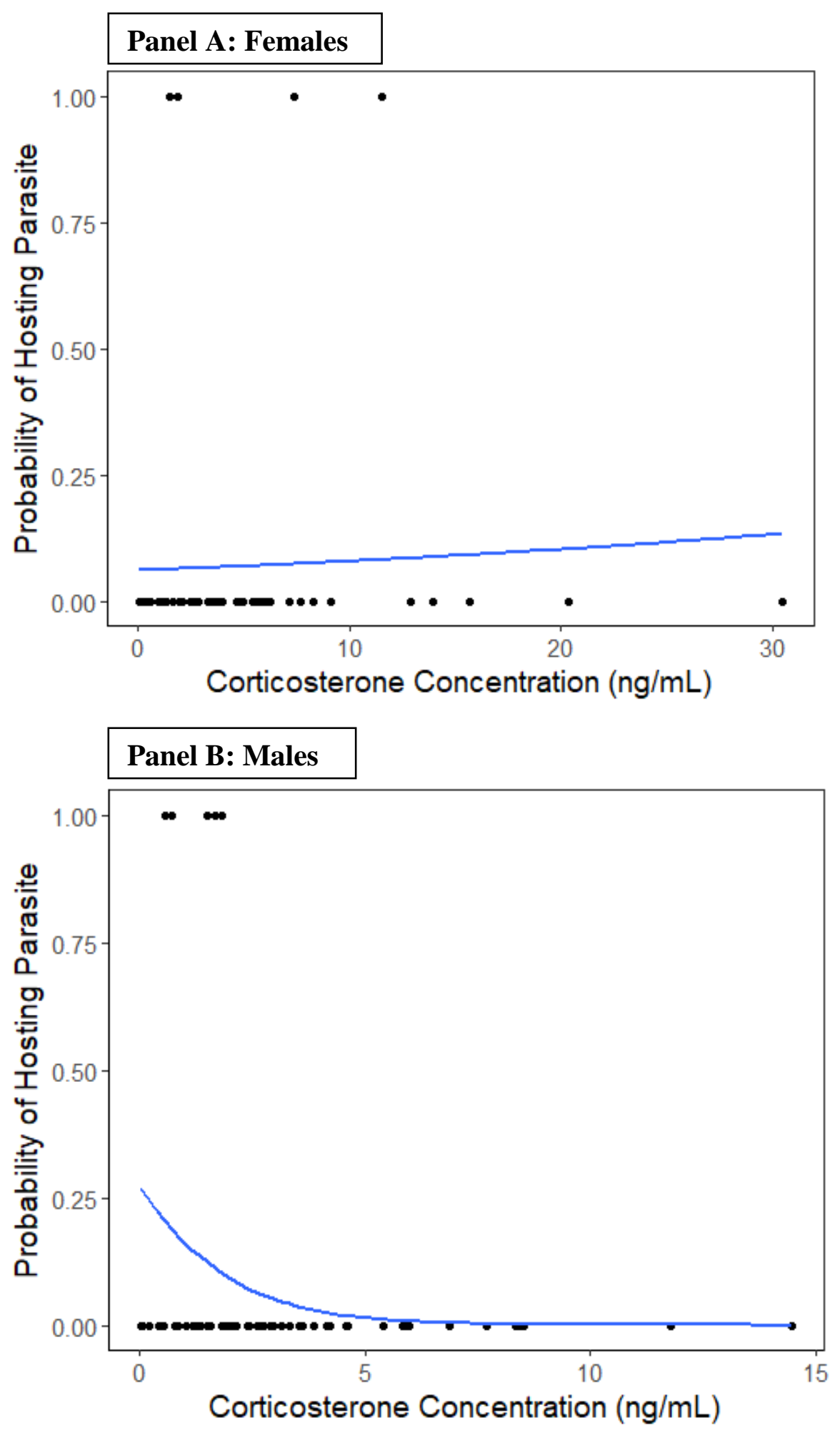


\section{CHAPTER 6}

\section{Conclusions, Summary of Results, and Future Directions}

\section{Conclusions}

Taken together, our findings demonstrate that female Anolis gundlachi exhibit territoriality. We find that females occupy exclusive space and that they use a repertoire of displays and other aggressive behaviors similar to males in order to deter conspecifics from accessing those areas. Thus, female A. gundlachi are exhibiting the pattern of territorial behavior previously described for males of most Anolis species and females of several other species, demonstrating that territorial behavior may be prevalent across the genus in both sexes. However, our results also suggest that the mechanistic control of female territoriality, and in particular variation in territorial behavior among females, may be different than what is observed in males. Specifically, neither body condition nor circulating androgen concentrations were associated with variation in territory size or aggression, while both have been implicated in regulating male behavior.

Historically, it has been presumed that male Anolis lizards establish territories around females and that males gain exclusive access to those females by doing so. As a result, relatively little work has considered the socio-spatial dynamics among females within those male territories beyond their interactions with males and reproduction. Our finding that females maintain spatial dynamics of their own through the use of aggressive behavior contradicts the long-standing presumption that females are relatively passive players within the context of male space use. Furthermore, if females establish territories earlier than males and then males establish territories around them, females may actually directly influence male space use in this capacity. These observations contribute to a 
growing body of animal behavior research investigating the evolution, function, and regulation of aggressive behaviors like territoriality in females, which posits that female aggression serves important functions in females and is not simply a byproduct of the evolution of aggression in males. Finally, they provide further impetus for directly testing hypotheses to explain variation in aggressive behavior in both males and females, rather than presuming that findings in one sex will predict patterns in the other sex.

\section{Summary of Results and Future Directions}

CHAPTER 2: Territoriality: a survey of the progression from observation to manipulation to understand the evolution, function, and regulation of territorial behavior

- Territoriality has been widely studied across animal groups and has important implications for individual fitness.

- Despite extensive study, direct studies of female territoriality remain limited in many taxa, compromising our ability to evaluate if hypotheses proposed for males also explain territorial behaviors observed in females.

- Anolis have a rich history of territorial research and represent an excellent group in which to pursue future studies of female territoriality that will help to inform our understanding of the function, evolution, and regulation of territoriality in lizards and more generally across animals.

CHAPTER 3: Similar behavior, shared mechanism? Evaluating the influence of body condition on territorial behavior in female Anolis gundlachi lizards

- Female Anolis gundlachi exhibit patterns of space use and aggression that are consistent with the territoriality described for male A. gundlachi and other male and female Anolis species. 
- Territory size varied among females, but this variation was not explained by differences in female body condition. This observation contradicts findings in males of other Anolis species, in which metrics of male body size have been positively associated with territory size.

- The results from this study demonstrate that female A. gundlachi exhibit territorial behavior but that different traits mediate variation in territory size in males and females of this species.

- Future work should evaluate the attributes of territories that determine territory quality for female A. gundlachi. Researchers of space use have often assumed that large territories provide more resources and are therefore the most desirable. However, more detailed study of how and why females establish territories may demonstrate that this is not the case for female A. gundlachi and open lines of inquiry to identify both the territory attributes that females seek, and the traits that make particular females better able to secure those territories.

CHAPTER 4: Evaluating the potential for testosterone to mediate aggressive behavior in wild female Anolis gundlachi lizards

- On average, male A. gundlachi exhibit significantly higher concentrations of testosterone than females, but concentrations are variable among individuals in both sexes. Female A. gundlachi exhibit both higher average concentrations of corticosterone and a larger range of variation in corticosterone concentrations than males do. 
- Female A. gundlachi behave aggressively toward a conspecific that is placed in close proximity to their territory, but aggression varies substantially among females.

- Variation in aggressive behavior was not associated with either corticosterone or testosterone concentrations. Unlike was has been shown in male Anolis, neither of these hormones appears to explain differences in aggressive behavior in females A. gundlachi.

- Future studies that incorporate direct manipulations of hormone concentrations in females may reveal the thresholds at which concentrations of testosterone or corticosterone influence behavior. In combination with the field data we have collected, researchers will be able to assess whether the concentrations achieved in response to those manipulations represent biologically relevant changes and further clarify the potential for shifts in these hormones to impact behavior in nature.

CHAPTER 5: Testosterone and Parasite Load: An investigation of the immunocompetence hypothesis in wild Anolis gundlachi lizards

- Eight percent of Anolis gundlachi sampled in this study were parasitized by a malarial parasite (Plasmodium sp.), which is a lower rate of infection than has been previously reported for the area where we worked.

- The likelihood of being infected with Plasmodium was not postively associated with either testosterone or corticosterone concentrations in males or females.

- We find no evidence to support the immunocompetence hypothesis in this species, which posits that increased concentrations of testosterone and 
corticosterone negatively influence immune function and are therefore associated with increased parasite load.

- Future studies at times when parasite prevalence aligns more closely with previous work will be needed to establish whether our findings are generalizable in this population. In addition, work with Anolis populations that have become parasitized by Plasmodium more recently than A. gundlachi may reveal that we observed no association due to a long coevolution of this host-parasite system, and lead to new inquiries as to resistance to the negative effects of Plasmodium infection may have evolved. 


\section{Vita}

Ellee Cook was born and raised in Santa Fe, New Mexico. There, she attended Santa Fe Preparatory School, and became fascinated with biology. She went on to attend Trinity University in San Antonio, Texas, where she earned a Bachelors of Science in Biology with Honors in 2013. At Trinity, she also conducted three years of independent research in the laboratory of Dr. Michele Johnson. This experience motivated her to continue research and puruse a doctoral degree in biology, and Ellee began her graduate study in the laboratory of Dr. Manuel Leal at Duke University in August of 2013. While there, she was a teaching assistant for courses in urban ecology and evolutionbegan conducting field work in Puerto Rico. In August of 2014, the Leal Laboratory moved to the University of Missouri, and Ellee moved to Columbia, Missouri, to continue her doctoral work with Dr. Leal. Throughout her time at Mizzou, she served as a teaching assistant for courses in general biology and ecology, and pursued coursework in leadership in higher education. Ultimately, she discovered a passion for education, and will begin a science teaching position at her own former high school, Santa Fe Preparatory School, in August of 2019. Ellee is eager to return to the mountains, green chile, and her family as she pursues her passion for science education in the Land of Enchantment. 